\title{
The role of community mobilization in the promotion of maternal health of women living with HIV in Zambia
}

Citation for published version (APA):

Muzyamba, C. (2018). The role of community mobilization in the promotion of maternal health of women living with HIV in Zambia. [Doctoral Thesis, Maastricht University]. Maastricht University. https://doi.org/10.26481/dis.20180625cm

Document status and date:

Published: 01/01/2018

DOI:

$10.26481 /$ dis. $20180625 \mathrm{~cm}$

Document Version:

Publisher's PDF, also known as Version of record

\section{Please check the document version of this publication:}

- A submitted manuscript is the version of the article upon submission and before peer-review. There can be important differences between the submitted version and the official published version of record.

People interested in the research are advised to contact the author for the final version of the publication, or visit the DOI to the publisher's website.

- The final author version and the galley proof are versions of the publication after peer review.

- The final published version features the final layout of the paper including the volume, issue and page numbers.

Link to publication

\footnotetext{
General rights rights.

- You may freely distribute the URL identifying the publication in the public portal. please follow below link for the End User Agreement:

www.umlib.nl/taverne-license

Take down policy

If you believe that this document breaches copyright please contact us at:

repository@maastrichtuniversity.nl

providing details and we will investigate your claim.
}

Copyright and moral rights for the publications made accessible in the public portal are retained by the authors and/or other copyright owners and it is a condition of accessing publications that users recognise and abide by the legal requirements associated with these

- Users may download and print one copy of any publication from the public portal for the purpose of private study or research.

- You may not further distribute the material or use it for any profit-making activity or commercial gain

If the publication is distributed under the terms of Article $25 \mathrm{fa}$ of the Dutch Copyright Act, indicated by the "Taverne" license above, 


\section{The role of community mobilization in the promotion of maternal health of women living with HIV in Zambia}




\section{The role of community mobilization in the promotion of maternal health of women living with HIV in Zambia}

\section{Dissertation}

to obtain the degree of Doctor at Maastricht University, on the authority of the Rector Magnificus, Prof. dr. Rianne M. Letschert in accordance with the decision of the board of the Deans, to be defended in public on Monday $25^{\text {th }}$ of June , 2018, at $16.00 \mathrm{hrs}$.

by

Choolwe Muzyamba 


\section{Promoter:}

Prof. dr. Wim Groot

\section{Co-promoters:}

Dr. Milena Pavlova

Dr. Sonila M. Tomini

\section{Assessment Committee:}

Prof.dr. J.S.M Kruimeich, Maastricht University (Chair)

Prof.dr. F. Gassmann, Maastricht University

Prof.dr. S. Ramani, Maastricht University

Prof.dr. R. Reis, University of Amsterdam 


\section{Acknowledgement of funding}

The research presented in this dissertation is made possible through the funding of the United Nations University Maastricht Economic and Social Research Institute on Innovation and Technology (UNU-MERIT)/Maastricht Graduate School of Governance (MGSoG). All views presented in this dissertation are solely that of the author, and do not reflect in any way views of the above mentioned institution. 


\section{Contents}

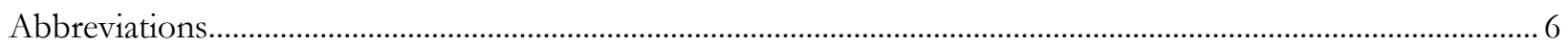

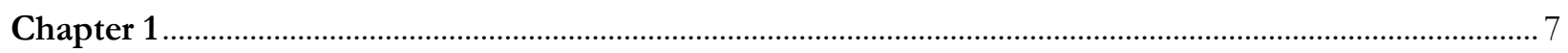

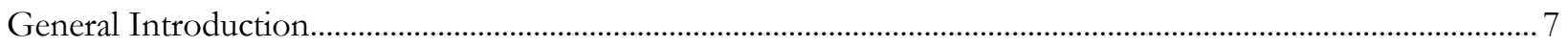

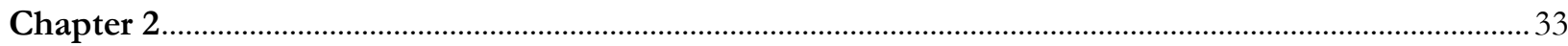

The role of community mobilization in maternal care provision of women living with HIV in Sub-Saharan

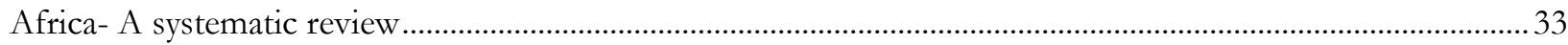

Chapter 3

Community mobilization and maternal care of women living with HIV in poor settings: The case of Mfuwe,

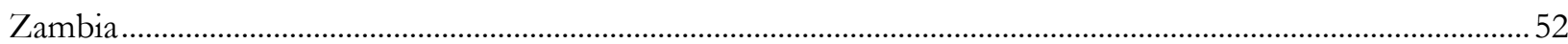

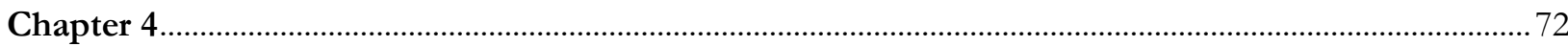

The relevance of TBAs to women living with HIV in resource poor settings: The case of Mfuwe, Zambia ... 72

Chapter 5 .

Skilled birth attendants or TBAs? Factors associated with choice of antenatal, delivery and postnatal services

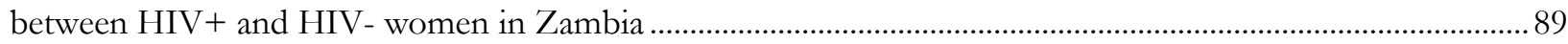

Chapter 6 . 105

Professional care or TBAs? The impact of choice of care by mothers on under-five mortality of their children

Chapter 7

General discussion

Bibliography

Appendix

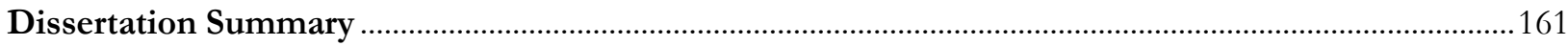

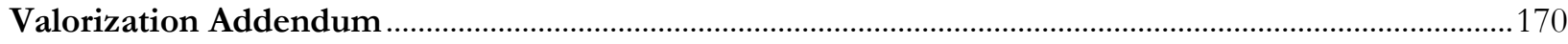

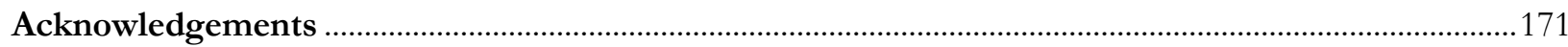




\author{
Abbreviations \\ AIDS: Acquired Immune Deficiency Syndrome \\ ART: Antiretroviral Treatment \\ CIDRZ: Centre for Infectious Disease Research in Zambia \\ DHS: Demographic Health Survey \\ FGD: Focus Group Discussion \\ HIV: Human Immunodeficiency Virus \\ PMTCT: Prevention of Mother to Child Transmission \\ PPAZ: Planned Parenthood Association of Zambia \\ SSA: Sub-Saharan Africa \\ TBA: Traditional Birth Attendants \\ WHO: World Health Organization \\ UN: United Nations \\ ZDHS: Zambia Demographic Health Survey
}


Chapter 1

General Introduction 


\subsection{Scope of the dissertation}

This dissertation investigates the role of community mobilization in promoting maternal health in women living with HIV in Zambia. Community mobilization in maternal health is defined as any maternal health promotion strategy which makes use of a) indigenous resources such as Traditional Birth Attendants (TBAs), b) peer support, and c) community involvement in designing and implementation of maternal health initiatives. The dissertation starts by broadly investigating all the three principles of community mobilization and later narrows down to indigenous resources and in particular, TBAs which seems to be the most pronounced form of community mobilization in the context of Zambia (Cheelo, et al., 2016).

A research topic of this nature is increasingly important in an era where both maternal health and HIV/AIDS have been defined as key global health concerns in the Sustainable Development Goals (SDGs) (UN, 2015; UNICEF, 2014). An intersection of pregnancy-related complications and HIV/AIDS increases the risk of morbidity and mortality by as much as four times during pregnancy. This is known as "intersecting-vulnerabilities" (Kendall, et al., 2014). Scholars have been divided on how to best respond to this predicament (Campbell \& Cornish, 2010). Mainstream researchers for example argue for the exclusive use of evidence-based strategies which are mostly premised on the idea of "what works"; these are tried and tested methods with common consent of their efficacy. These solutions normally constitute 'modern' strategies such as reliance on skilled care, good quality infrastructure, adequate supply of health workers, increased supply of medical equipment and drugs (Vallely, et al., 2005). Where they have been applied, a combination of these strategies has proved to be effective in reducing maternal morbidity and mortality (Hanson, 2013); and likewise, in low income countries where they have not been fully applied, maternal morbidity and mortality are still high, representing what most scholars call a "vicious cycle of morbidity and mortality" (Hanson, 2013; Torpey, et al., 2010). Mainstream strategies have been particularly useful for women living with HIV (who are more vulnerable) (Calvert \& Ronsmans, 2013). It is for this reason that these strategies have been popularized and subsequently universalized (Vallely, et al., 2005; Harrison, 2011).

Recently however, mainstream solutions have attracted sharp criticism and have been accused of being out of touch with local realities in Sub-Saharan Africa (SSA) (Campbell \& Cornish, 2010; Campbell \& Jovchelovitch, 2000; Easterly, 2014; Muzyamba, et al., 2015). The critique suggests that when applied in the African context, these interventions have three weaknesses: 
a) they are 'attractive' but impractical: Research has continuously shown that while mainstream strategies are useful in reducing maternal mortality and morbidity, the fact however is that in most low-income societies, little is done to implement these ideal solutions in sustainable ways (Rifkin \& Pridmore, 2001; Lippman, et al., 2013; Abdool-Karim, et al., 2010). This is partly because most of these strategies are costly ventures, thus the majority of the resource-poor governments have been unable to implement them (Bolu, et al., 2007; Crowe, et al., 2012).

b) They may sometimes conflict local realities: Some scholars have shown how universally acclaimed strategies such as the Human Rights approach, and the outlawing of TBAs have failed to resonate with local realities in SSA and thus have been met with resistance (Muzyamba, et al., 2015). A growing body of research suggests that in the context of SSA, handling of maternal health challenges requires careful dialogue with vulnerable groups and greater flexibility for context-specific implementation rather than a one-size-fits-all conceptualization and implementation of strategies (Campbell \& Cornish, 2012; Cornish, et al., 2014; Muzyamba, et al., 2015; Balogun \& Odeyemi, 2010; Kendall \& Danel, 2004; Campbell, et al., 2013).

c) They delegitimize and ignore benefits of local strategies (Abdool-Karim, et al., 2010; Marston, et al., 2013; Ana, 2011): The inherent assumption that indigenous knowledge is ignorance within the mainstream approach is seen to be counterproductive. As Campbell (2014) has shown, mainstream interventions are usually premised on the faulty assumption that indigenous strategies in SSA are always mundane and unrewarding, an act which is self-defeating. This assumption is contrary to the evidence emanating from different parts of SSA, in which it has been proved that local communities usually possess unrecognized useful strategies of coping amidst weak health institutions (MacQueen, et al., 2001; Campbell \& Mzaidume, 2002 ; Ana, 2011). These local strategies can in most cases be used to complement the weak health institutions that exist (Nahar, et al., 2012; Ackerman \& Kiragu, 2012). However, given the dominance of the mainstream strategies, these local strategies have been obscured (Rifkin \& Pridmore, 2001).This has led to expensive yet unrealistic quests to establish strategies synonymous to those in the west, and in the process losing all potential benefits inherent in local strategies (Tripathy, et al., 2011; Lippmann, et al., 2012).

Given the foregoing, questions of what interventions are contextually-feasible and effective have gained dominance in the recent past (Kendall, et al., 2014). Considering the fact that in most lowincome countries, health systems are crippled by lack of resources, adequate trained personnel, medical equipment and drugs, distantly-located health centers and poor infrastructure etc., questions 
are increasingly being asked as to how local strategies can complement mainstream (evidence-based) strategies. It is for this reason that community mobilization is increasingly being suggested as a useful complement to mainstream solutions.

\subsection{What is community mobilization?}

The looseness of the concept of community mobilization defies the possibility of constructing a universally-accepted definition. Therefore, the concept of community mobilization is not consistently defined and operationalized in the existing literature (Cornish, et al., 2014; Altman, et al., 2015). There exist several different definitions of community mobilization (Campbell, 2014; Cornish, et al., 2014). The major reason for the diversity in the community mobilization definitions is because the concept is influenced by different theories (Altman, et al., 2015; Campbell, 2014). The second challenge in defining community mobilization is its fragility and fluidity to fit a single definition applicable across time and space (Campbell, 2014). Different communities contain different unique health-relevant resources, thus summarizing all of them in one definition becomes difficult (Campbell \& Jovchelovitch, 2000). This challenge is usually worsened by the fact that there exist different understandings of what is meant by the term "community". The idea of "community" itself is viewed differently across countries. Added to this, depending on the type of health issue being pursued, constitutes of mobilization may be different too (Altman, et al., 2015; Campbell, 2014). Before providing a relevant definition of community mobilization, it is important to explain what is meant by "community" and "mobilization". This is followed by an exploration of theoretical roots of community mobilization, after which a summary of existing definitions of community mobilization is presented. After this thorough exploration, a synthesized definition of community mobilization is provided.

What is a community?

In general, there seems to be two main usage of the term "community" (MacQueen, et al., 2001). Firstly, the term community is used to epitomize a geographical area or physical territory where individuals live, work or socialize (Bartle, 2007). In this sense, a community constitutes a collectivity of individuals who share a common territorial area as their base of operation for daily activities and socialization (Bartle, 2007). This socialization within a given territory results from, and is constantly re-enforced by a sense of belonging created by daily interaction (MacQueen, et al., 2001). This type 
of community is usually distinguished by the existence of geographical connectedness, organized interaction, cultural similarity, common values and beliefs, and a sense of belonging (Altman, et al., 2015; Bartle, 2007). Secondly, community can refer to the quality or character of human interaction in which people are bound not by geographical disposition, but by common identity irrespective of geography (Bartle, 2007; MacQueen, et al., 2001). For example, gay people living in different parts of the world can consider themselves as a community based on their identity as gay people. In this dissertation however, we adopt the former definition in which community constitutes collectivity of individuals who share a common geographical area as their base of operation for daily activities and socialization.

What is mobilization?

The term "mobilization" is a product of two sociological theories: the "Social Movement theory" and "Participation theory" (Morris \& Herring, 1984; Rifkin, 1996). Under the social movement theory, the term mobilization is seen as a voluntary effort by marginalized individuals to act collectively to influence change with the ultimate goal of benefiting the entire community (Morris \& Herring, 1984). From a participation perspective, mobilization is seen as a process by which people collectively and collaboratively take action with members outside or within their community to change a social phenomenon affecting their community (Rifkin, 1996). Under the participation perspective, it does not matter whether the community collective action is internally or externally triggered. What matters most is that individuals as beneficiaries have a reasonable opportunity to use their local competences and knowledge, and to participate in the design, implementation and evaluation of a given health initiative (Altman, et al., 2015). Given the fact that the two perspectives are not necessarily mutually exclusive, rather they are mutually re-enforcing, we take them both into account in adopting a definition for mobilization. Therefore, we view mobilization as the act of capitalizing on community agency and capabilities be they internally or externally-precipitated while at the same time involving and collaborating with members of the community in actions that bring about desired change in a given community (Morris \& Herring, 1984; Rifkin, 1996).

Theoretical roots of community mobilization

Although the concept of community mobilization has been a popular theme especially in development and political discourse for over 50 years, it however only become a central theme in health policy following the Alma Ata declaration of 1978 which stressed the importance of involving 
beneficiaries in designing and implementing health programs (Rifkin, 1996). Attention to community was a key principle in the Alma-Ata Declaration of 1978. For example, the fourth article of the declaration states that, "people have the right and duty to participate individually and collectively in the planning and implementation of their health care", and the involvement of community is further emphasized in article seven of the declaration which states that primary health care "requires and promotes maximum community and individual self-reliance and participation in the planning, organization, operation and control of primary health care" (WHO, 1978). Although the Alma Ata declaration legitimized calls for community mobilization in primary health care; the concept of community mobilization itself was influenced by a diverse set of social theories (Rifkin, 1996). In particular, the concept of community mobilization draws its influence from Coleman's (1988), Bourdieu's (1986) and Putnam's (2000) theory of social capital, Foucault's (1977) theory of governmentality, Moscovici's (1993) theory of Cognitive Polyphasia and Freire's theory of "conscientization".

From a social capital perspective; the influence of social capital on the definition of community mobilization is seen from a community's collective action to deal with local challenges in locallyfeasible ways. This collective action usually results from building strategies that strengthen trust and cooperation between and among individuals within a community (Bourdieu, 1986; Putnam, 2000; Campbell \& Cornish, 2012).

Freire's perspective however holds that community mobilization results from a process of dialogue and critical thinking. Freire (1973) while working with communities stricken with social inequality, poverty and oppression argued that in order for marginalized people to experience positive social change, there is a need for them to engage in dialogue, which gives rise to critical thinking (Freire, 1973; Campbell \& Cornish, 2012). The resulting critical thinking enables marginalized people to critically assess and be aware of their social conditions; a state he called "conscientização" (conscientization in English) (Freire, 1970). Conscientization allowed marginalized people to develop a sense of solidarity, allowing them to collectively take action to change their situation. Freire (1973) in this sense argued against a top-down approach by positing that social change is only a product of a linear process that involves dialogue, critical thinking, "conscientização" and collective action respectfully (Altman, et al., 2015; Campbell \& Jovchelovitch, 2000; Freire, 1970). 
The other influential theory in the development of the concept of community mobilization is the theory of governmentality outlined by Foucault (1977) who argues against Freire's version of social change. While Freire (1973) sees social change as a linear process involving a three-staged process (dialogue, conscientization, and collective action) and also as a binary where there exists the oppressor and oppressed, Foucault argued against this by postulating that community mobilization stems not from a linear process or a binary condition, but rather that community mobilization is a result of intricate power relations within communities; a process which is usually complex, contradictory and 'microcapillary" (Foucault, 1977). Foucault gives importance to the notion of "agency", which is embedded in a complex pattern of power-relations within communities (Campbell, 2014). He argues that community mobilization is a product of a complex interaction of complex power struggles within the community resulting in context-specific and unique results. Therefore, in order to understand the complex community mobilization process, focusing on community members' intricate power relations and struggles is key (Foucault, 1977; Campbell, 2014). Moscovici's (1993) theory of "Cognitive Polyphasia" also serves as another influential theory in the development of the concept of community mobilization. Moscovici begins by asking why despite overwhelming evidence to the contrary, does scientific knowledge continue to distort and sometimes replace local/lay knowledge. Moscovici holds that rather than replacing local/lay knowledge with scientific knowledge, there is much to benefit by the democratic co-existence of both forms of knowledge (Jovchelovitch, 2012; Moscovici, 1993). Thus, different systems of knowledge in practice should not displace each other but rather 'live' side by side in an effort to fulfil different functions and address different social needs of a community. This theory thus challenges the traditional tendency to undermine local knowledge. The hidden assumption that "scientific" knowledge is best and local knowledge is "ignorance" is what Moscovici cites as one of the reasons for failed health promotion programs (Jovchelovitch, 2000). Thus, Moscovici intimates that community mobilization is a result of the coexistence of "scientific" knowledge and local knowledge.

Existing definitions of community mobilization

Although several scholars agree that community mobilization is critical in maternal health promotion, very few however agree on its definition. This is partly because of the diversity in theoretical roots in the development of the concept of community mobilization as explored above (Campbell, 2014). In general, the theoretical roots of community mobilization suggest that this 
concept is premised on the principles of equity, empowerment, inclusion in decision-making, social justice, attention to community, respect for diversity and collaboration (Altman, et al., 2015; Campbell, 2014; Cornish, et al., 2014; Howard-Grabman, et al., 2007). These principles work as core-values in different definitions of community mobilization. Different scholars attach different levels of importance to different principles in their definitions. This can be observed in the most dominant definitions summarized in the table 1.1.

Table 1.1: Summary of existing definitions of community mobilization

\begin{tabular}{|c|c|c|}
\hline Citation & Definition & Central theme \\
\hline $\begin{array}{l}\text { (Campbell } \\
\text { \& Cornish, } \\
2010)\end{array}$ & $\begin{array}{l}\text { "A process of creating and harnessing the agency of the marginalized } \\
\text { groups most vulnerable to HIV/AIDS, enabling them to build a } \\
\text { collective, community response, through their full participation in the } \\
\text { design, implementation and leadership of health programmes and by } \\
\text { forging supportive partnerships with significant groups both inside and } \\
\text { outside of the community" }\end{array}$ & $\begin{array}{l}\text {-Community participation } \\
\text {-Collaboration between community and } \\
\text { professionals } \\
\text {-Financial support } \\
\text {-Indigenous actors }\end{array}$ \\
\hline $\begin{array}{l}\text { (Cornish, } \\
\text { et al., 2014) }\end{array}$ & $\begin{array}{l}\text { "a component of externally-triggered HIV interventions, that allow } \\
\text { indigenous community work together with experts" }\end{array}$ & $\begin{array}{l}\text { - Collaboration between community and } \\
\text { professionals }\end{array}$ \\
\hline $\begin{array}{l}\text { (Tripathy, } \\
\text { et al., 2011) }\end{array}$ & $\begin{array}{l}\text { "A participatory approach, which involves building on local competences } \\
\text { and strategies by ensuring that community members take part in decision- } \\
\text { making and bring local knowledge, experiences and problems to the } \\
\text { fore." }\end{array}$ & $\begin{array}{l}\text {-Use of local knowledge } \\
\text {-Support to others } \\
\text {-Use of indigenous resources } \\
\text {-Traditional doctors }\end{array}$ \\
\hline $\begin{array}{l}\text { (Howard- } \\
\text { Grabman, } \\
\text { et al., 2007) }\end{array}$ & $\begin{array}{l}\text { A capacity building process through which community members, groups } \\
\text { and organizations plan, implement and evaluate on a participatory and } \\
\text { sustained basis to improve their health or other conditions either on their } \\
\text { own initiative or stimulated by others }\end{array}$ & $\begin{array}{l}\text {-Local initiatives } \\
\text {-Capacity building } \\
\text {-Community participatory } \\
\text {-Community support }\end{array}$ \\
\hline $\begin{array}{l}\text { (Rifkin \& } \\
\text { Pridmore, } \\
\text { 2001) }\end{array}$ & $\begin{array}{l}\text { "Community mobilization constitutes active involvement of the } \\
\text { community in information sharing , consultation, collaboration and } \\
\text { empowerment strategies aimed at bringing change in communities" }\end{array}$ & $\begin{array}{l}\text {-Use of indigenous strategies } \\
\text {-Collaboration } \\
\text {-Support to peers }\end{array}$ \\
\hline $\begin{array}{l}\text { (McKenzie, } \\
\text { et al., 2013) }\end{array}$ & $\begin{array}{l}\text { "Community mobilization is seen as health promotion intervention which } \\
\text { helps communities to identify and undertake appropriate actions in } \\
\text { relation to shared problems. }\end{array}$ & $\begin{array}{l}\text {-Health promotion intervention } \\
\text {-Cooperation for collective action } \\
\text {-Involvement of community }\end{array}$ \\
\hline $\begin{array}{l}\text { (Watson- } \\
\text { Thompson, } \\
\text { et al., 2008) }\end{array}$ & $\begin{array}{l}\text { "Community mobilization is seen as a process where people come } \\
\text { together to take action on an issue by relaying on enhanced social } \\
\text { connectedness and efficacy or the ability to have influence and control } \\
\text { over their situation" }\end{array}$ & $\begin{array}{l}\text {-Peer support } \\
\text {-Community cooperation } \\
\text {-local professionals } \\
\text {-Community advocacy }\end{array}$ \\
\hline $\begin{array}{l}\text { (Kim-Ju, et } \\
\text { al., 2008) }\end{array}$ & $\begin{array}{l}\text { "Community mobilization is defined as individuals taking action } \\
\text { organized around specific community issues. It involves community } \\
\text { empowerment, community participation, capacity-building, community } \\
\text { coalitions, community organization and development" }\end{array}$ & $\begin{array}{l}\text {-Community involvement - } \\
\text {-Capacity-building } \\
\text {-Community coalitions } \\
\text {-Use of community resources }\end{array}$ \\
\hline $\begin{array}{l}\text { (Nahar, et } \\
\text { al., 2012) }\end{array}$ & $\begin{array}{l}\text { "Low-cost, participatory, community-based approaches involving } \\
\text { women's groups aimed at effectively improving home delivery practices } \\
\text { and birth outcomes in a range of settings" }\end{array}$ & $\begin{array}{l}\text {-Participatory low cost } \\
\text {-Community based strategies } \\
\text {-Use of community resources }\end{array}$ \\
\hline $\begin{array}{l}\text { (Rosato, et } \\
\text { al., 2006) }\end{array}$ & $\begin{array}{l}\text { "A health promotion strategy best seen as a continuum of process which } \\
\text { include, Community informed of decisions made, Community } \\
\text { consultation about decisions tokenistically to gain buy in, Community's } \\
\text { views taken into account, Joint decision-making, and Community driven } \\
\text { decision-making" }\end{array}$ & $\begin{array}{l}\text {-Tokenistic } \\
\text {-Cooperation } \\
\text {-Community consultation } \\
\text {-Joint effort } \\
\text {-Support }\end{array}$ \\
\hline $\begin{array}{l}\text { (Mercy- } \\
\text { Corps, } \\
2009)\end{array}$ & $\begin{array}{l}\text { "Community mobilization is the process of engaging communities to } \\
\text { identify community priorities, resources, needs and solutions in such a } \\
\text { way as to promote representative participation, good governance, } \\
\text { accountability and peaceful change" }\end{array}$ & $\begin{array}{l}\text {-Community engagement } \\
\text {-Use of Community resources } \\
\text {-Community priorities } \\
\text {-Community strategies }\end{array}$ \\
\hline $\begin{array}{l}\text { (Lippman, } \\
\text { et al., 2013) }\end{array}$ & $\begin{array}{l}\text { "Actions that engage and galvanize community members to take action } \\
\text { towards achieving a common goal" }\end{array}$ & $\begin{array}{l}\text {-Engaging community members } \\
\text {-Galvanizing community members }\end{array}$ \\
\hline
\end{tabular}


Operationalization of community mobilization

Having taken into account the various theoretical roots and the diverse definitions explored above, it follows that there is no 'one-size-fits-all' definition of community mobilization. We also establish that before defining and operationalizing the concept of community mobilization, one needs to take into account what kind of "community" and "health concern" is being investigated (Altman, et al., 2015). It is important to define and operationalize community mobilization in a manner that allows for efficient measurement (Cornish, et al., 2014). It is also clear however that any definition of this concept should reflect the common principles identified above such as: community participation, community-based strategies, local experts, local professionals, traditional doctors, community empowerment, use of community competence, use of indigenous resources, collaboration with community, community cooperation, use of peer-support etc. It is also important to note that most of these aspects are related to each other or simply synonyms of each other. Thus from the foregoing exploration, it is necessary to group the related aspects of the concept into distinct broad categories. Therefore the first step in defining and operationalizing the concept of community mobilization is to identify the related aspects of the concept and group them into distinct categories.

As a starting point, it was clear that community mobilization endeavors to capture utilization of locally-available resources. This can be seen from its emphasis on 'local experts', 'local professional' 'traditional doctor' etc. All these aspects epitomize reliance on indigenous resources. Thus "use of indigenous resources" becomes our first category. Secondly, from the above exploration, we observe that several aspects of community mobilization emphasize provision of different forms of support by one community member to another. This form of support is normally based on trusts and conviviality between peers in the community (Campbell \& Cornish, 2010). This support can be in the form of financial, psychological, logistical support etc. To capture all these forms of support between peers, we establish the second category known as "Peer support". Finally, community mobilization also prioritizes involvement of local people as partners in handling local problems. This is explicated through its emphasis on 'collaboration with community', 'community participation', 'cooperation with community' etc. All these aspects can be group into one category called "community involvement"; this then becomes our third category. 
From above, it is clear that in general, community mobilization can broadly be grouped into three main categories, namely: use of indigenous resources, peer support and community involvement. This means that any community mobilization definition should at least be anchored on one or more of the three main principles highlighted above. But beyond that, it is important to operationalize the concept in a manner that allows the researcher to capture the unique community constitutes and health outcomes under investigation.

Taking all the above into consideration, we come up with the following definition: Community mobilization in maternal health is defined as any maternal health promotion strategy which makes use of indigenous resources, peer support, and/or actively allows community members to participate in designing and implementation of maternal health initiatives. Therefore, community mobilization in this dissertation is anchored on either one or more of the following three principles: a) Use of indigenous resources such as TBAs b) Community involvement which is seen through collaborative partnerships between health professionals and communities in designing and implementation of maternal health initiatives. c) Reliance on peer support in the form of financial, psychological, social support etc. Below we explain the relevance of these principles in detail.

\section{Use of indigenous resources}

Several scholars have underscored the importance of relying on indigenous resources such as TBAs (Ana, 2011; Akpala, 1994; Cheelo, et al., 2016). The central argument here is that in communities that have weak health systems, use of indigenous resources increases the availability, affordability, and accessibility of maternal health care services in resource-poor settings; a factor which is necessary in improving maternal health outcomes among women with HIV (Calvert \& Ronsmans, 2013; Harpham, et al., 2006; Ana, 2011; Bergstrom \& Goodburn, 2001)

\section{Community involvement}

Research has demonstrated how involvement of beneficiaries in maternal health initiatives has improved outcomes. Community involvement is seen through careful dialogue between the designers of maternal health programs and their target groups in order to tailor interventions to local needs and realities. This should be done during planning and implementation of the maternal health program. It has been shown that communities are more likely to utilize and adopt maternal health interventions if the interventions resonate with their local realities. For example, two systematic 
reviews (Rifkin, 2014; Marston, et al., 2013) have shown positive impact of community involvement on maternal health outcomes. Particularly, utilization of community health workers within SSA in planning and scaling up of services improved maternal health outcomes. These community health workers were able to take maternal health services directly to pregnant women in the community without requiring them to travel to health centers (Rifkin, 2014; Marston, et al., 2013). The community health workers provided services in the form of simple checkups, provision of maternal health information, voluntary counselling and testing of HIV etc. (Lewycka, et al., 2013). Other evidence from SSA shows that when locals are involved in the planning and implementations of programs, there is a high probability of adherence and acceptance of the program among community members (Muzyamba, et al., 2015). Further evidence from Malawi (The-nation, 2013; Lewycka, et al., 2013) shows how health centers worked with community members in rural areas to improve access to care by use of community bicycles which were used to transport pregnant women to health centers. This initiative was said to have reduced maternal mortality in rural areas (Thenation, 2013; Lewycka, et al., 2013).

\section{Peer support}

Peer support is conceptualized as assistance by one community member to another (Cabral, et al., 2018). This is usually in the form of financial, emotional, logistical, psychological, material etc. assistance. In extant literature, peer support has been associated with increased capacity to identify maternal problems, increased agency for resource-mobilization, increased capacity to address social environmental causes of ill health etc. (Campbell, et al., 2013; Campbell, et al., 2004; Campbell, et al., 1999; Cabral, et al., 2018). Further evidence indicate that peer support in poor settings leads to better HIV and maternal related knowledge, reduced stigma and discrimination, adherence to treatment, access to useful nutrition and resources; factors which lead to better maternal health outcomes for HIV positive women (Campbell \& MacPhail, 2002; Dutcher, et al., 2011). More specifically, a study from India and South Africa showed how peer support within marginalized communities helped challenge stigma and discrimination among sex workers and people living with HIV (Campbell \& Cornish, 2012). This is because peer support allowed for collective action among the marginalized in challenging different health-inhibitors in society (Campbell \& Cornish, 2012).

This definition of community mobilization and its three specific principles are used (collectively and sometimes singularly) throughout the dissertation as linchpins for the specific chapters. All the 
chapters rely upon this definition to give guidance to specific investigations, and to collectively add to the general aim of the dissertation which is to investigate the role of community mobilization on maternal health outcomes of women living with HIV.

\subsection{Community mobilization and maternal health in Zambia}

Maternal health is conceptualized as the general wellbeing of a woman during pregnancy, childbirth and afterbirth (WHO, 2013). Thus maternal health is understood as a continuum consisting of three points of care: antenatal, childbirth and postnatal (WHO, 2015). The WHO categorizes maternal health outcomes into two categories (WHO, 2015; WHO, 1978):

a) Process indicators for maternal health; these capture changes in behavior of pregnant women and new mothers. These changes in behavior are usually a direct result of activities of a given maternal health promotion activity and they may include indicators such as: adoption of maternal health-enhancing behavior, better access to health facility, adherence to antiretroviral therapy if HIV positive, utilization of antenatal and postnatal care services etc. Although useful, these indicators in themselves do not provide information on the results and impact of the activity (Mant, 2001; WHO, 2015).

b) Quantifiable biomedical maternal bealth outcome indicators; these capture the eventual health status of the target population and can be divided into (WHO, 2013; WHO, 1978):

- primary outcomes (incl. complications during pregnancy and during childbirth, duration of postpartum stay at hospital/community care home and maternal depression, such as antenatal depression and postpartum depression);

- secondary outcomes (incl. emergency obstetrics care, under-five mortality, maternal mortality);

- other outcomes (transmission of HIV from mother to child).

This dissertation focuses on the link between community mobilization and maternal health in Zambia. It starts by a broad investigation of all the three components of community mobilization (use of indigenous resources, community-participation and peer support) and based on resulting 
findings and recommendations, it narrows down and specifically focuses on indigenous resources, in particular TBAs.

General socioeconomic outlook of Zambia

In order to contextualize the maternal health situation in Zambia, it is important to first understand Zambia's socioeconomic outlook. Zambia is a landlocked country located in southern Africa. It covers an area of about $752,612 \mathrm{~km}^{2}$. (UN, 2015). Currently, it has a population of 15 million people with $52 \%$ of them being female. Although Zambia is estimated to be one of the most urbanized countries in the region with $40 \%$ of its population living in urban areas, the majority of the people still live in rural areas (Mujenja, 2014). Zambia is ranked as a lower-middle income country with a per capita Gross Domestic Product (GDP) of around US\$1,7004 (Mphuka \& Kaonga, 2017). Between the year 2005 and 2013, the country registered a GDP growth rate averaging more than $6 \%$ annually. Despite all this, the country has continued to register high poverty rates (Mphuka \& Kaonga, 2017). More specifically, 60\% of the population is reported to be living below the poverty line (Mphuka \& Kaonga, 2017), with the majority of them (around 70\%) living in rural areas. The economic performance of the country is heavily dependent on copper exports which account for over $70 \%$ of export earnings. The rate of unemployment has remained high in the country and it currently stands at 7.8\% making it one of the highest in the region (Mujenja, 2014). The majority of the employed population is found in the informal sector, particularly in agriculture, forestry and fisheries sectors which collectively account for $52 \%$ of the informally employed. Zambia has also continued to register high inequality rates with a Gini coefficient score of around 0.65 (UN, 2015). The literacy rate stands at 55.3\%, with illiteracy being much more pronounced among females than males (RTM, 2015). According to the Center for Disease Control and Prevention (CDC), the top causes of death in Zambia are HIV/AIDS, malaria, tuberculosis, neonatal and maternal complications, diarrheal disease, cardiovascular diseases and diabetes (CDC, 2017).

Maternal health outlook in Zambia

Zambia, like many other SSA countries still records relatively high maternal deaths. The 2013-2014

Zambia Demographic Health Survey (ZDHS) reported a Maternal Mortality Ratio (MMR) of 398 
deaths per 100000 live births. The biggest victims are rural women in the age group 15 to 49 (ZDH, 2013). HIV/AIDS has been cited as one of the biggest drivers of high maternal morbidity and mortality rates including child mortality (UNICEF, 2014). HIV/AIDS makes women susceptible to opportunistic infections such as malaria, diabetes mellitus, anemia, tetanus, tuberculosis etc. all of which increase the chances of maternal morbidity and mortality. Other direct causes of maternal mortality include more direct complications such as haemorrhage, sepsis, obstructed labor etc. (Banda, 2015).

Most researchers hold that with optimal utilization of professional maternal care services, the majority of the cases of maternal morbidity and mortality in Zambia could be prevented. However, as most studies have demonstrated, there is still a large number of births being handled by TBAs instead of trained personnel in health institutions (UNICEF, 2014; Banda, 2015). For example, it estimated that in Zambia as much as 21 to $24 \%$ of births are handled by TBAs (ZDHS, 2007; Chama-Chiliba, 2014) and some other sources suggest that the numbers could even be higher (Banda, 2015).

The Zambian health system

Maternal care challenges in Zambia can be better understood in relation to the general health care system. The Zambian health system comprises mostly of public health facilities, with private healthcare accounting for less than 4\% of the market share (Banda, 2015). The Zambian health system like in many other SSA countries is decentralized into three levels of public healthcare delivery. These levels are divided into primary (which is at district level), secondary (provincial level), and tertiary (central) healthcare facilities. Management of health centers at these three levels is also decentralized with District Medical Board overseeing the primary healthcare delivery at district level, The Provincial Medical Board at provincial level, National Medical Board at national level (UNAIDS, 2016). The role of the Ministry of Health is to provide general oversight at all levels, policy-making and regulation of the health sector. The health service delivery and referral system follows the same hierarchy comprising of health posts and centers at community level, district hospitals, provincial hospital at provincial level and the tertiary hospital at national level (Banda, 2015; UNAIDS, 2016). This system allows for health centers to be spread within the country to ensure maximum uptake and delivery of services to different households. In urban areas, the nearest 
health center is located within 5 kilometer of every household, whereas in rural areas the average distance in 18 kilometer (ZDH, 2013).

The health sector in Zambia is financed through direct government funding, with external donors providing significant budget support. For the year 2016, external resources stood at 34\% of total resources for health. $38 \%$ of health financing was raised through tax and $28 \%$ through out-ofpocket expenditure. Although the government abolished user-fees in 2012, higher-level public facilities retain "fee-for-service" wings, in which they provide higher quality of care and shorter wait times for patients who can afford them (UNAIDS, 2016). Patients are also in general be made to pay for several other services. Public health centers also lack adequate personnel, equipment and drugs leading to poor quality care (UNAIDS, 2016). This is why the private sector (although occupying a small market-share) remains a significant contributor to healthcare provision. $75 \%$ of private healthcare expenditure is out-of-pocket with around 25\% coming from insurance coverage (mostly from employers) (Fagan \& Zeng., 2015; Chitah \& Jonsson, 2015). This means that health insurance only applies to private clinics which account for less than $4 \%$ of healthcare provision (in which the majority pay out of pocket) (ZDH, 2013; Freedom-to-create, 2016; Aantjes, et al., 2016). Currently in Zambia, there exists no national health insurance scheme (Aantjes, et al., 2016; Chitah \& Jonsson, 2015). The non-existence of a national health insurance scheme in Zambia is influenced by different political shifts since the attainment of multi-party politics in 1991 (Chisi, 2018; Lusaka-times, 2017). In 1990, the then government (United National Independence Party -UNIP) was in the process of drafting a national insurance bill before they were voted out of office paving way for the newly formed right-leaning Movement for Multi-Party Democracy (MMD) which embraced Structural Adjustment Programs (SAPs) upon assuming office (Lusaka-times, 2017; Chisi, 2018). This meant that through liberalizing what was originally a socialist-inclined economy, plans of universal coverage through a national insurance scheme were abandoned in preference for out-of-pocket payments (Lusaka-times, 2017). This structure persisted until the recent change of government in 2011 which saw the coming in of the newly-elected Patriotic Front (PF) government. With change in government, discussions on the need for a national insurance scheme were introduced culminating into what is known as the National Health Insurance (NHI) Bill, 2017 (Chisi, 2018). The bill is currently under debate in Parliament with many experts suggesting that the bill will be signed into law in mid-2018 (Mwansa, 2017; Lusaka-times, 2017; Chisi, 2018). 
Maternal health is one of the government's priorities in Zambia (Banda, 2015). The Zambian ministry of health recommends that women must access skilled maternal services from the onset of pregnancy until postnatal period (Banda, 2015). The majority of health centers are fitted with maternity-wings and antennal clinics in which antenatal care, childbirth and postnatal care are delivered by skilled personnel (Fagan \& Zeng., 2015; Banda, 2015). At all three points of care during maternity, women are encouraged to access skilled attendants. This helps identify and prevent possible negative maternal health outcomes. The national guidelines recommend that all women are attended to by skilled health workers such as doctor, nurse, midwife or clinical officer.

When compared to other countries in SSA, Zambia retains a lot of similarities both in terms of health system structure, including maternal health and HIV indicators (WHO, 2013). TBAs occupy a relatively large space in maternal care in all countries in the region (UNAIDS, 2016; WHO, 2015). Like many other countries in the region, Zambia too, depends heavily on foreign budgetary support in order to finance the health sector. Further, Zambia like her neighbors in the southern African region (Zimbabwe, Botswana, South Africa, and Swaziland) continues to record high HIV prevalence rates (UNICEF, 2014; ZDH, 2013; WHO, 2015). The southern African region, which includes Zambia, has the highest HIV rates in the world.

\subsection{Gaps in research on community mobilization and maternal health in Zambia}

As Cheelo et al (2016) observe, in most poor communities in Zambia, there exist long traditions of coping and inventing resources, which work to counterbalance the chronic absence of "scientific" information, state support, infrastructure, modern and efficient health systems, etc. Over the years, communities in the peripherals of Africa have developed strategies of survival based on their cultural traditions, local knowledge and networks, which they rely on in responding to their daily challenges. In these communities, relying on networks of solidarity based in neighborhood conviviality and kinship relations, has long been a useful avenue for providing care and support (Jovchelovitch, 2000; Ana, 2011; Cheelo, et al., 2016).

Campbell (2012) however cautions that local knowledge should not be viewed as an unmixed blessing. Some forms of local practices and knowledge can be harmful to maternal health. She thus 
calls for a democratic co-existence of local and scientist knowledge in a manner that is locallyfeasible and beneficial to health.

This is why it is important to establish dialogues and links between local understandings and the outside researchers through community mobilization in maternal health research. Community mobilization thus offers a useful opportunity to establish constructive dialogues between what "we know" and what "they know" (Rifkin \& Pridmore, 2001). In the absence of this exchange of perspectives and views, maternal health interventions in these communities will continue to meet inaction, mistrust, resistance and failure (Campbell \& Gibbs, 2009; Muzyamba, et al., 2015). While much is known about how scientific knowledge and activities can improve maternal health outcomes, deeper understanding of the role of community is still missing (Kendall, et al., 2014). Questions on how community mobilization may be useful, especially for women living with HIV remain unanswered.

\subsection{Dissertation goal and objectives}

Given the lack of a clear understanding of how community mobilization can be useful in maternal health promotion in resource-poor countries like Zambia, especially for women living with HIV (who are more vulnerable), scholars are increasingly emphasizing the need to address this gap in the literature. Thus the main goal of this dissertation is to provide insights on the role of community mobilization in the promotion of maternal health in women with HIV in Zambia.

To achieve the main goal, the following research objectives are formulated:

\section{- Objective 1: To outline the role of community mobilization in SSA countries:}

Given the fact that, currently, there is a lack of synthesized empirical evidence of the role of community mobilization on maternal health outcomes of women living with HIV in SSA (Kendall, et al., 2014; Ackerman \& Kiragu, 2012), a thorough search, analysis and documentation of this evidence was necessary. This was an important basis for demonstrating what has been studied and not studied, where exactly the main gaps lay and in which directions the existing evidence points visà-vis community mobilization and maternal health in SSA. Systematic review was used as a research technique for this purpose. 
- Objective 2: .To investigate the role of community mobilization on maternal health care among women living with HIV in rural areas in Zambia:

While the evidence on the role of community mobilization was more conclusive in HIV-negative women, similar evidence for women living with HIV was missing (Kendall, et al., 2014; Ackerman \& Kiragu, 2012). We use a qualitative study design to investigate the role of community mobilization in maternal health care of women living with HIV in resource-poor settings by using Mfuwe, Zambia, as a case study. Mfuwe was a good case study for this purpose because it has some of the highest poverty levels, HIV and maternal mortality rates in the country (ZDHS, 2007; MoH, 2014). In more detail, Mfuwe is a village located in Mambwe district in the South Luangwa national park in the Eastern province of Zambia. It is made up of 6 settlements, namely; Kuyenda, KwaChindeni, Chamilandu, kwaBilimungwe, Tafika and kwaKaingo. The village of Mfuwe is located in Zambia's largest national park, the South Luangwa National park. This means that Mfuwe is one of the least industrialized regions in Zambia with the majority of the population living subsistence life-styles. It is estimated that close to $80 \%$ of the population in the area lives below the poverty line $(\mathrm{MoH}$, 2014). Farming is the main economic activity for the villagers. There exits only one hospital in Mfuwe (Kamoto hospital) catering for a population of over 207,000 people spread roughly around an arear of $370 \mathrm{~km}^{2}$. The hospital is understaffed and lacks adequate equipment $(\mathrm{MoH}, 2014)$. It is also able to provide basic In-Patient facilities but refers more difficult cases to the next general hospital in Chipata district located about $107 \mathrm{~km}$ away from Mfuwe. The village registers high HIV prevalence rates, including high under-five mortality rates ( $\mathrm{ZDH}, 2013 ; \mathrm{MoH}, 2014)$. The regional HIV rate stands at around $15 \%$ to $17 \%$ whereas the under-five mortality rate stands at 398 deaths per 100,000 live births $(\mathrm{MoH}, 2014)$. Given its high poverty, HIV and maternal mortality rates, Mfuwe was a good case study as it provided us with an opportunity to investigate the role of community mobilization in the promotion of maternal health care among HIV positive women in resource-poor settings.

- Objective 3: To investigate the usefulness of TBAs on maternal health care of women living with HIV in rural areas in Zambia:

Out of the three components of community mobilization, indigenous resources, and in particular TBAs, play a dominant and controversial role in maternal care of women with HIV in Zambia (Cheelo, et al., 2016; Sialubanje, et al., 2015; Bergstrom \& Goodburn, 2001). Thus it becomes 
important to provide more insights on the role of TBAs on the maternal care of women living with HIV. This objective is achieved through the use of a qualitative research design to investigate the relevance of TBAs to women living with HIV in resource poor settings by using Mfuwe, Zambia, as a case study. Just as explained above in objective 2, Mfuwe's high poverty, HIV and maternal mortality rates makes it a good case study for the purposes of investigating the usefulness of TBAs in resource poor settings.

- Objective 4: To investigate and compare factors affecting choice of care (TBAs or professional care service) between HIV negative women and women living with HIV:

There is growing evidence which suggests that HIV positive women are more vulnerable than those who are not (Kendall, et al., 2014). However, the relationship between HIV status and maternalcare-utilization is not very well understood. It is not clear whether factors associated with professional maternal care utilization are similar for HIV positive and HIV negative women. Thus it becomes important to investigate the differences in factors affecting choice of maternal care (TBAs or professional care service) between HIV positive and HIV negative women. Other than that, it is also necessary to investigate the effect of HIV positive status on the utilization of professional maternal care. For this reason, we make use of the 2013-2014 ZDHS and quantitative methods to investigate factors which affect the choice of maternal care service between women with HIV and those who are HIV negative. The ZDHS is a dataset containing nationally representative population health data for Zambia.

- Objective 5: To investigate and compare the effect of choice of care (TBAs or professional care service) between HIV negative women and women living with HIV on under-five mortality:

After establishing factors affecting choice of care between HIV negative and women living with HIV, it becomes necessary to assess the effect of this choice on biomedical outcomes such as underfive mortality. For this purpose, we take the discussion further by investigating the impact of choice of care on under-five mortality by comparing outcomes between women with HIV and those who are negative. For the same reason as explained above, here we also make use of the 2013-2014 ZDHS and quantitative methods. 


\subsection{Contribution to existing body of literature}

This dissertation contributes to the larger and ongoing debate on the role of community mobilization in maternal health care. Specifically, it focuses on the role of community mobilization on maternal health care of women living with HIV in resource-poor settings. Previously, there has been little focus on this subject, even though women living with HIV are more vulnerable. (Kendall, et al., 2014; Ackerman \& Kiragu, 2012). The first specific gap that exists within this scope is the lack of synthesized empirical evidence on the role of community mobilization on maternal health in SSA in general. Thus by relying on systematic review technique, the first contribution of the dissertation is to map-out and synthesize the evidence available in the extant literature on the role of community mobilization in promoting maternal health in SSA. This illuminates the differences in existing evidence on outcomes between HIV positive and HIV negative women. The dissertation also demonstrates to what extant community mobilization has been useful for both HIV positive and HIV negative women in SSA, and at the same time, it highlights areas in which evidence for the efficacy of community mobilization is still lacking. Other than that, the other contribution in this line is to highlight and provide insights on the general operationalization of the concept of community mobilization in maternal health care in SSA.

Although community mobilization is gaining dominance in public health discourse, there exists a gap in understanding stakeholders' experiences regarding community mobilization vis-à-vis maternal health care of HIV positive women. Scholars have been emphasizing that in order for public health interventions to be successful; there is a need to account for worldviews of local stakeholders. However, despite all this, little is known about the lived experiences of HIV positive women themselves and other local stakeholders in resource poor settings regarding how useful community mobilization is for maternal health. Thus another important contribution of this dissertation is filling this specific gap in literature. This is done through a qualitative study in Mfuwe, Zambia. In this vain, the dissertation provides insights on the various ways community mobilization serves as both a maternal health-enhancing and maternal health-inhibiting tool. It also provides insights on the different ways community mobilization is operationalized in such poor contexts.

There is relatively less controversy on the usefulness of the other two principles of community mobilization (Peer support and community involvement). However, use of indigenous resources, 
particularly TBAs has divided public health scholars (Ana, 2011; Harrison, 2011). Others argue for, while others argue against (Harrison, 2011). In the wake of the HIV pandemic, calls to exclude them from the line of care have intensified (Sialubanje, et al., 2015; Ana, 2011; Cheelo, et al., 2016). This is because of the need to promote PMTCT. This has led to TBAs being outlawed in Zambia and other countries within SSA (Cheelo, et al., 2016). Other scholars have criticized this move suggesting that in poor settings where health systems are weak, excluding TBAs curtails the only available mode of care (albert its limitations), especially in rural areas (Ana, 2011). However, there is very little evidence to justify either of the two positions, particularly for women with HIV. Questions still remain regarding how useful TBAs are to women with $\mathrm{HIV}$, including questions regarding the factors that affect choice of care (TBAs or professionals) among HIV positive women. There is still very little known on the effect of using TBAs (as opposed to professionals) on under-five mortality. This dissertation contributes to these discussions by providing evidence both qualitatively and quantitatively of the usefulness of TBAs, factors associated with uptake of TBAs (or professionals) and the effect of uptake of TBAs (or professionals) on under-five mortality in poor settings.

\subsection{Structure of the dissertation}

This dissertation comprises of the results of individual studies investigating the topic from different

perspectives as defined by the dissertation objectives presented above. Different chapters chronologically build on each other to provide a thorough synthesis of the findings explored throughout the study.

\section{Chapter 2: The role of community mobilization in maternal health care provision of women living with HIV in SSA, a systematic review.}

In this chapter, we systematically review the literature to assess and explore available evidence on the role of community mobilization on maternal outcomes of women living with HIV in SSA in general. We begin by mapping out the existing evidence from a broader scope in the entire SSA region in order for us to see evidence from other countries which are similar to Zambia. 
Methodology

To achieve the objectives of this chapter, we conducted a search of existing literature in PuBMed, Scopus, Web of Science, MEDLINE, COCHRANE, Allied Health Literature, and Cumulative Index to Nursing. Our inclusion criteria was based on the following: a study should have been from SSA, published in English language, shown evidence of community mobilization, reported maternal health outcomes, should have been published between 1990 to 2015 in a peer reviewed journal, used an experimental or quasi-experimental design. After the selection, we then divided the selected publications into category 1 (HIV negative) and category 2 (HIV positive). Content analysis technique was then used for the analysis.

\section{Limitation}

Due to the strictness of our inclusion criteria, we might have missed some useful publications. However, despite all this, this chapter provides useful insights in understanding available empirical evidence on the role of community mobilization on maternal outcomes of women living with HIV in SSA.

\section{Chapter 3: Community mobilization and maternal care of women living with HIV in poor settings: The case of Mfuwe, Zambia.}

In this chapter, we narrow down the investigation by exploring the relevance of community mobilization in the promotion of maternal health care among women living with HIV in resourcepoor settings by using Mfuwe, Zambia, as a case study.

Methodology

In order to address the objective of this chapter, we collected qualitative data in Mfuwe (Description of Mfuwe can be found in part 1.5 of this chapter). Mfuwe made a good case for this purpose due to its high HIV, poverty and maternal mortality rates (see 1.5). Participants of the Focus Group Discussions (FGDs) were drawn from different parts of Mfuwe. Data collection consisted of 3 FGDs all involving HIV positive women who had experienced one or more of the components of community mobilization. The first FGD focused on peer support, the second one on utilization of indigenous resources, and the last one on community involvement. Both the first FGD (on peer 
support) and the second one (on utilization of indigenous resources) each consisted of 13 participants. The last one (on community involvement) had 11 participants bringing the total number of participants to 37. Participants were asked different questions regarding how useful community mobilization was to them. Thematic analysis technique with the help of NVivo was used to analyze the data.

\section{Limitation}

The limitation arising from this chapter is that because we only collected data from one village, in one province out of the 10 provinces of Zambia, our findings lacked variety of experiences with community mobilization in Zambia in general. That notwithstanding, we believe that this chapter provides useful insights and is a first step towards understanding the different ways community mobilization hinders/promotes maternal care of HIV positive women in resource-poor settings in Zambia.

\section{Chapter 4: The relevance of TBAs to women living with HIV in resource poor settings: The case of Mfuwe, Zambia.}

Chapter 4 focuses on investigating the relevance of indigenous resources, particularly TBAs, to women living with HIV in resource-poor settings by using Mfuwe, Zambia as a case study. The controversial question of whether TBAs are useful or not to women with HIV in Zambia is addressed.

\section{Methodology}

We selected our sample from Mfuwe (see 1.5 for a thorough description of Mfuwe) through purposive and convenient sampling techniques. The participants were drawn from different parts of Mfuwe. Our sample was divided into 4 sub-groups. These groups included a) HIV positive women who had only used TBAs during their last pregnancy (12 participants). b) HIV positive women who used only professional care as opposed to TBAs during their last pregnancy (11 participants). c) TBAs (8 participants). d) Health workers (9 participants). The reason for this division and diversity in participants was to increase the variety of responses. These groups formed the basis of our data 
collection. For group A we collected data through a FGD. Questions around their choice on, and experience with, the use of TBAs were asked. For group B, we also collected data through a FGD, questions were centered on trying to understand why they avoided using TBAs. Data from TBAs were collected through interviews in which TBAs were asked to reflect on their usefulness to HIV positive women. Also through interviews, health workers were asked to reflect on the usefulness of TBAs to HIV positive women. Analysis of the data was done through thematic analysis.

\section{Limitation}

Related to the limitations form chapter 3, the collection of data from a single village located in one province of Zambia may have limited the variety and representativeness of our responses. However, despite all this, we believe that this chapter provides valuable insights in understanding the usefulness of indigenous resources, particularly TBAs, to women living with HIV in resource-poor settings.

\section{Chapter 5: Skilled birth attendants or TBAs? Factors associated with choice of antenatal, delivery and postnatal health services between HIV negative and HIV positive women.}

In this chapter, we investigate factors associated with choice of care during antenatal, delivery and postnatal periods for both HIV positive and HIV negative women. We also investigate the effect of HIV positive status on the utilization of professional maternal care during antenatal, delivery and postnatal periods.

\section{Methodology}

For the purpose of this investigation, we made use of the ZDHS 2013/2014. We investigate this issue by focusing on HIV positive and HIV negative women. Women whose HIV status were not determined or did not consent to taking part in the HIV test were not included in our final sample. However, before dropping this group of respondents who had an undetermined HIV status, we provide a summary of statistics showing how they differed from the rest of the sample. The undertrained group was dropped because the focus of this chapter (and the entire dissertation) was on respondents whose HIV status was determined. This approach allowed us to accurately assess 
the influence of HIV on different maternal health aspects in Zambia, and to also compare experiences between those who have HIV and those who do not have HIV.

For the analysis, we performed two different quantitative analyses a) Regression analysis: to identify and compare factors associated with the likelihood of utilizing professional care during antenatal, at birth and postnatal between HIV positive and negative women. b) Propensity score matching: to investigate the effect of being HIV positive on the choice of care (Professional care or TBAs).

\section{Limitation}

Our final sample was reduced in size due to the fact that we dropped women who did not consent to having their HIV status tested. This may have had an effect on the representativeness of the sample. That notwithstanding, this chapter provides useful insights in understanding factors affecting choice of care by HIV positive and negative mothers.

\section{Chapter 6: Professional care or TBAs? The impact of choice of care on under-five mortality of their children, a comparison between HIV positive and HIV negative women.}

In this chapter, we investigate the effect of utilization of professional maternal care or TBA care during antenatal, delivery and postnatal periods on under-five mortality for HIV positive and HIV negative women.

Methodology

Similar to chapter 5, for the purpose of our investigation, we made use of the ZDHS 2013/2014. Building up from chapter 5, we focused our analysis on HIV positive and HIV negative women (for the same reason as in chapter 5). With the use of the ZDHS 2013/2014 dataset we conducted propensity score matching (PSM) to investigate the effect of utilization of professional care or TBA during antenatal, childbirth, and postnatal on under-five mortality. 


\section{Limitation}

The limitations of this chapter are similar to the limitations in chapter 5 as highlighted above. However, despite all that, this chapter was useful in highlighting the effect of utilization of professional maternal care or TBA care during antenatal, delivery and postnatal periods on underfive mortality.

\section{Chapter 7: General discussion.}

In this chapter, we present a general discussion arising from findings cutting across all the chapters in this dissertation. A thorough discussion of the main findings is presented in a synthesized manner. We also highlight policy implications resulting from the main findings including areas needing further investigation. The chapter ends by presenting a section on final remarks highlighting the main findings of the dissertation. 


\section{Chapter 2}

The role of community mobilization in maternal care provision of women living with HIV in Sub-Saharan Africa- A systematic review

\section{This chapter draws upon:}

Muzyamba, C., Groot, W., Tomini, S.M, \& Pavlova, M. (2017). The role of community mobilization in maternal care provision for women in sub-Saharan Africa- A systematic review of studies using an experimental design. BMC Pregnancy and Childbirth, 17(274). 


\begin{abstract}
While the role of community mobilization in improving maternal health outcomes of HIV positive women in SSA is continuously emphasized, little is known about how legitimate these claims are. The aim of this chapter is to systematically review the empirical evidence on this issue.

A systematic search was conducted in PuBMed, Scopus, Web of Science, MEDLINE, COCHRANE, Allied Health Literature, and Cumulative Index to Nursing.

Our search identified 14 publications on the role of community mobilization in maternal care provision for both HIV positive and HIV negative women in SSA. Regarding HIV negative women, the literature has demonstrated that community mobilization is a useful strategy for promoting both positive maternal process results and maternal health outcomes. Most of the literature on women with HIV has focused only on demonstrating the causal link between community mobilization and process results. There has been very little focus on demonstrating the causal link between community mobilization and maternal outcomes for women living with HIV. Overall, the results show that while there is some empirical evidence on a causal link between community mobilization and maternal health outcomes for HIV negative women, this kind of evidence is still missing for HIV positive women. Moreover, as shown by the studies, community mobilization as a maternal health strategy is still in its infancy.
\end{abstract}

Given the gaps identified in our review, we recommend further research with the aim of providing sound evidence on the role of community mobilization in improving maternal health outcomes of women with HIV in SSA. 


\subsection{Background}

Despite improvements in funding and policy recommendations by international organizations such as the WHO, maternal health remains a challenge in low income countries (ZDH, 2013; WHO, 2015; UNAIDS, 2013). Studies show that on average, in SSA countries, 720 women die each day during pregnancy and childbirth from causes which are largely preventable (Kendall \& Langer, 2015). The worst maternal health outcomes are found in SSA (WHO, 2013; Kendall, et al., 2014). A combination of vulnerabilities and health system weaknesses including poor health infrastructure, poverty, inequality, and HIV are seen as the causes of high maternal mortality (Kendall, et al., 2014). Further, women living with HIV are four times more likely to die during pregnancy and childbirth than HIV negative women (Kendall \& Danel, 2004). HIV positive women suffer intersecting vulnerabilities. The combined burden of pregnancy-related complications and HIV status is intensified by stigma and discrimination, which prevent some women from seeking help (Lindegren, et al., 2012).

Intersecting vulnerabilities are further compounded by the dominance of the biomedical approach in handling maternal health challenges (Colbourn, et al., 2013). This approach undermines the potential benefits of local knowledge and strategies (Calvert \& Ronsmans, 2013). Some scholars contend that lack of community involvement has led to failed maternal health interventions in SSA, including maternal health of women living with HIV (Rifkin \& Pridmore, 2001; Altman, et al., 2015; Lewycka, et al., 2013). There is a traditional tendency inherent in the dominant maternal health approaches to undermine local competencies. More specifically, as an antidote to deplorable maternal health outcomes in poor SSA settings, researchers have continued to recommend conventional solutions such as infrastructure improvement, construction of more hospitals and roads, and promotion of women's rights (Abdool-Karim, et al., 2010; Harrison, 2011; Campbell \& Graham, 2006 ). While in theory there is no contention on the usefulness of such conventional solutions, evidence has indicated that in practice, little can be done to operationalize these ideal solutions in a sustainable way in poor settings (Rifkin \& Pridmore, 2001; Kendall \& Danel, 2004; Sibleycorresponding \& Sipe, 2006). This is partly because most of these recommendations are costly and thus the majority of the resource-poor governments have been reluctant to implement them. As a result, these solutions remain largely idealistic, especially when applied while ignoring local experiences. 
Despite the dominant approach to maternal care, several studies have drawn attention to the role of communities. These studies report on how involvement of communities, use of indigenous resources and reliance on peer support help to improve health outcomes (Ackerman \& Kiragu, 2012; Campbell \& Cornish, 2012; Lassi, et al., 2014; WHO, 1978; WHO, 2015). This observation has ignited the hypothesis that capitalizing on community competencies can complement conventional maternal health efforts especially in SSA where health systems are inefficient and sometimes inaccessible to many women living with HIV in the peripherals of the societies (Lewycka, et al., 2013; Ibrahim, et al., 1992; Lippman, et al., 2013).

This is why community mobilization is increasingly being seen as a useful complement to conventional maternal health initiatives (Ackerman \& Kiragu, 2012; Campbell, 2014). Some examples of initiatives that rely on community mobilization include: a) the "MaiKhanda program" in Malawi, which is a comprehensive locally-run maternal care project where TBAs provide maternal services to communities (Rosato, et al., 2006); b) the "Zambulance project", which connects rural Zambian villages to health centers through a locally manufactured bicycle with an attached trailer used to carry patients and pregnant women to remote health centers (CHMI, 2015); c) the "MaiMwana" project in Malawi, which is an intervention aimed at providing peer support to mothers in rural Malawi (Rosato, et al., 2006).

Specific to women living with HIV, Rifkin (2012) also argues that in the absence of an exchange of perspectives and views between professionals and communities, maternal health initiatives for women living with HIV in resource-poor African communities will continue to meet inaction, mistrust, resistance and failure. It is however not known to what extent community mobilization can be a useful strategy for women living with HIV (Kendall, et al., 2014; Kendall \& Danel, 2004). It is not clear which components of community mobilization actually improve the maternal health of women living with HIV nor how this improvement is achieved (Ackerman \& Kiragu, 2012; Altman, et al., 2015).

The aim of this chapter is to provide an overview of the empirical evidence on the role of community mobilization in the maternal care provision of women living with HIV in SSA. We only include studies with an experimental design in order to identify causal effects. Strong evidence for causal inference is a useful basis for establishing definitive conclusions (Hooijmans \& Ritskes- 
Hoitinga, 2013). The evidence on the role of community mobilization in maternal care provision in general is also reviewed.

Our review is imperative for both policy and research. Researchers have hypothesized that through the generation of locally acceptable, feasible, useful and relevant knowledge and experience, including partnerships with health professionals, community mobilization might be the missing link in maternal health care (Campbell \& Cornish, 2012). Therefore, our review provides a basis for comparing the role of community mobilization in maternal care provision between HIV negative women and women living with HIV. We also highlight specific areas that need further research. The review can help guide policy and practice in designing maternal health interventions which are relevant, feasible and accessible to local communities in SSA (Kendall, et al., 2014). The chapter further adds to the gap in literature about how to best operationalize the concept of community mobilization in the context of SSA.

\subsection{Methods}

To identify studies to include in our review, a search was conducted in PuBMed, Scopus, Web of Science, MEDLINE, COCHRANE, Allied Health Literature, and Cumulative Index to Nursing. We conducted a search using the following key-words: community mobilization and maternal health. In addition to this, synonyms of the above phrases were added based. A complete chain of words used in the search process can be found in Table 2.1.

Table 2.1 Search strategy

Community mobilization OR community networks OR community groups OR Community coalitions OR community-based OR participatory OR Traditional birth attendants OR community mobilization OR community OR Community engagement OR indigenous strategies OR Local initiatives OR collective action AND

[postnatal care OR Prenatal OR ANC OR emergency obstetrics care OR maternal mortality OR complications during pregnancy OR duration of postpartum stay at hospital OR duration of postpartum stay at home OR community care OR Transmission of HIV from Mother to Child] 
The procedure included search of articles using different word combinations. This was followed by screening of abstracts which lead to exclusion of some papers. Further, thorough reading of retained papers was conducted in order to arrive at the final papers to be included in the study.

To be included in our study, the publications must have:

- $\quad$ reported studies conducted in SSA

- reported results in English

- reported on community-based initiatives that engaged one or more community groups in concrete participatory activities in designing maternal care initiatives, or used indigenous resources in maternal care provision, or relied on peer support for pregnant women or new mothers.

- have been peer reviewed

- must have made use of an experimental research design, i.e. a randomized trial or a quasiexperimental design..

- must have been conducted between 1990 and 2015 reflecting the period when HIV became a serious epidemic in SSA.

- must have evaluated the initiative in terms of process indicators and quantifiable biomedical maternal health outcome indicators as defined in chapter one of the thesis.

The selected publications were then divided into category two studies; category one included studies focusing on HIV negative women, and category two consisted of studies focusing on women living with HIV. The text of the publications was screened based on the same inclusion criteria presented above, and the final list of publications within each category was defined. In Figure 2.2 below, we provide a diagram showing the summary of the search procedure. 
Figure 2.1 Flow Chat for inclusion and exclusion of articles
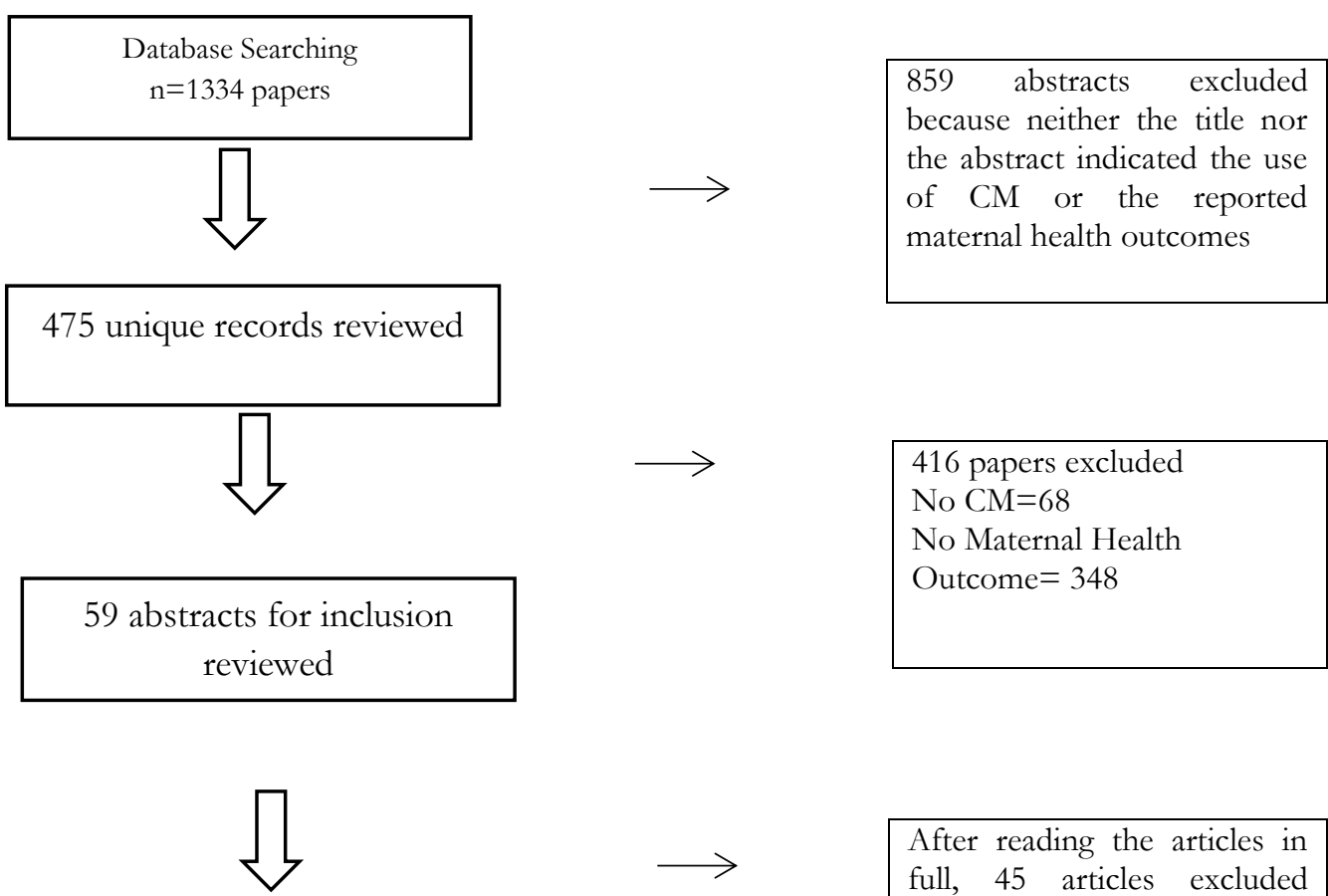

After reading the articles in full, 45 articles excluded because they do not meet the inclusion criteria

14 articles meet the inclusion criteria

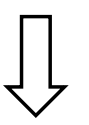

\section{Category 1 (HIV-)}

9 articles (for analysis)
Category 2 (HIV+)

5 articles (for analysis) 
We analyzed the text of the publications using content analysis. Content analysis is an approach that helps to synthesize data around key themes. This helps to systematically and objectively describe the study phenomenon (Hodder, 1994). A coding frame was established illuminating the following themes: community mobilization conceptualization, study designs, generalizability of results, process and outcome maternal health indicators. We also followed the PRISMA guidelines to ensure the quality of our review (PRISMA, 2015).

\subsection{Results}

In total, 1334 publications were initially identified, after which 859 publications were excluded because neither the title nor the abstract indicated the use of community mobilization or the reported maternal health outcomes. This left us with 475 publications. After reviewing their abstracts in detail, we excluded another 416 articles leaving us with 59 articles. The full text of the 59 articles were read in detail which led to further exclusion of 46 papers for not meeting the inclusion criteria, thereby leaving us with 14 publications for analysis. These papers were divided into two categories: those that involved HIV negative women (category one) and those that involved women living with HIV (category two). For category one HIV negative, we had nine articles, and for category two women living with HIV, we had five articles. A detailed description of the findings of the publications and their results can be found in table 2.2, 2.3, and 2.4 below.

Table 2.2 Summary of general characteristics of result

\begin{tabular}{|l|l|l|l|}
\hline \multicolumn{1}{|c|}{$\begin{array}{c}\text { Operationalization of } \\
\text { Community Mobilization }\end{array}$} & $\begin{array}{c}\text { Number of } \\
\text { publications }\end{array}$ & \multicolumn{1}{c|}{ Category 1(HIV-) } & Category 2(HIV+) \\
\hline $\begin{array}{l}\text {-The role of group/peer support } \\
\text { for pregnant women or new } \\
\text { mothers }\end{array}$ & 5 & $\begin{array}{l}\text { (Colbourn, et al., 2013), (Lewycka, et al., } \\
\text { 2013) }\end{array}$ & $\begin{array}{l}\text { (Rotheram-Borus, et al., } \\
\text { 2014), (Kaayaa, et al., 2013), } \\
\text { (Richter, et al., 2014) }\end{array}$ \\
\hline $\begin{array}{l}\text {-The role of Traditional Birth } \\
\begin{array}{l}\text { Attendants (TBA) in maternal } \\
\text { care provision }\end{array}\end{array}$ & 5 & $\begin{array}{l}\text { (Schaider, et al., 1999), (Dehne, et al., } \\
1995),(\text { Akpala, 1994), (Ibrahim, et al., } \\
1992)\end{array}$ & (Perez, et al., 2008) \\
\hline $\begin{array}{l}\text {-The role of partnership between } \\
\text { community and professionals in } \\
\text { designing initiatives }\end{array}$ & 4 & $\begin{array}{l}\text { (Schmid, et al., 2001), (Wangalwa, et al., } \\
\text { 2012) (Kidane \& Morrow, 2000) }\end{array}$ & (Torpey, et al., 2010) \\
\hline
\end{tabular}


Table 2.3 Summary results for HIV negative (Category 1) and HIV positive women (category 2)

\begin{tabular}{|c|c|c|}
\hline \multicolumn{3}{|l|}{ HIV negative (category 1 ) } \\
\hline Process outcomes: & $V$ alue reported & Publication reference number \\
\hline Health-enhancing behavioral & $\begin{array}{l}\text { Positive change } \\
\text { (e.g. increased access to health } \\
\text { facility, enhanced the pregnant } \\
\text { women's knowledge on how to } \\
\text { handle maternal complications) }\end{array}$ & $\begin{array}{l}\text { (Schmid, et al., 2001) (Wangalwa, et al., 2012) } \\
\text { (Dehne, et al., 1995) (Akpala, 1994) (Ibrahim, et } \\
\text { al., 1992) }\end{array}$ \\
\hline \multicolumn{3}{|l|}{ Outcome indicators } \\
\hline Depression rate & Reduced depression & $\begin{array}{l}\text { (Colbourn, et al., 2013) (Lewycka, et al., 2013) } \\
\text { (Kidane \& Morrow, 2000) }\end{array}$ \\
\hline Maternal mortality & Reduced maternal mortality & (Lewycka, et al., 2013) (Schaider, et al., 1999) \\
\hline Hemorrhage/sepsis & Reduced hemorrhage & (Schaider, et al., 1999) \\
\hline \multicolumn{3}{|l|}{ HIV Positive (category 2) } \\
\hline Process outcomes: & Value reported & Publication reference number \\
\hline Health-enhancing behavioral & $\begin{array}{l}\text { Positive change: } \\
\text { (increased maternal health } \\
\text { knowledge, Increased utilization } \\
\text { and access to health-enhancing } \\
\text { resources e.g. antenatal \& primary } \\
\text { healthcare, PMTCT, information } \\
\text { on safe delivery services) }\end{array}$ & $\begin{array}{l}\text { (Rotheram-Borus, et al., 2014) (Kaayaa, et al., } \\
\text { 2013) (Richter, et al., 2014) (Perez, et al., 2008) } \\
\text { (Torpey, et al., 2010) }\end{array}$ \\
\hline Outcome Indicators & Value reported & Publication reference number \\
\hline & Reduced depression & (Rotheram-Borus, et al., 2014) \\
\hline Maternal mortality & Reduced maternal mortality & \\
\hline Hemorrhage/sepsis & Reduced hemorrhage & \\
\hline
\end{tabular}


Table 2.4 Detailed results for HIV negative women (Category 1)

\begin{tabular}{|c|c|c|c|c|c|}
\hline Citation & \begin{tabular}{|l|} 
Country \\
of origin
\end{tabular} & Study Design & $\begin{array}{l}\text { Community } \\
\text { Mobilization } \\
\text { Component }\end{array}$ & Process results & Outcome \\
\hline $\begin{array}{l}\text { 1. (Schmid, et al., } \\
\text { 2001) }\end{array}$ & Tanzania & longitudinal & $\begin{array}{l}\text { Community Capacity } \\
\text { Building \& } \\
\text { Empowerment } \\
\text { support for village } \\
\text { health workers; (2) } \\
\text { developing } \\
\text { community-based plans } \\
\text { for transportation to } \\
\text { health facilities }\end{array}$ & $\begin{array}{l}\text { Significant improvement in } \\
\text { access to health facilities due } \\
\text { to increased transport options } \\
\text { Increased attention to } \\
\text { Obstetric complications by } \\
275\end{array}$ & \\
\hline $\begin{array}{l}\text { 2.. (Colbourn, et } \\
\text { al., 2013) }\end{array}$ & Malawi & $\begin{array}{l}\text { randomized } \\
\text { controlled trial }\end{array}$ & $\begin{array}{l}\text { Established } \\
\text { participatory women's } \\
\text { groups to mobilize } \\
\text { communities around } \\
\text { maternal and newborn } \\
\text { health }\end{array}$ & & $\begin{array}{l}\text { A combined } \\
\text { community and facility } \\
\text { approach using } \\
\text { participatory women's } \\
\text { groups and quality } \\
\text { improvement at health } \\
\text { centers reduced } \\
\text { newborn mortality }\end{array}$ \\
\hline $\begin{array}{l}\text { 3. (Lewycka, et al., } \\
\text { 2013) }\end{array}$ & Malawi & $\begin{array}{l}\text { randomized } \\
\text { trial }\end{array}$ & $\begin{array}{l}\text { Established } \\
\text { Community women's } \\
\text { groups to ensure } \\
\text { provision of } \\
\text { socioeconomic support }\end{array}$ & $\begin{array}{l}\text { Better health outcomes for } \\
\text { infants } \\
\text { reduction in disease for both } \\
\text { mother and child } \\
\text { Better health-seeking } \\
\text { behavior } \\
\text { Increased Uptake of HIV } \\
\text { testing }\end{array}$ & $\begin{array}{l}\text { Reduced MMR, NMR } \\
\text { and IMR in treated } \\
\text { group. Community } \\
\text { mobilization improved } \\
\text { maternal and child } \\
\text { health outcomes in } \\
\text { poor rural populations } \\
\text { in Africa. }\end{array}$ \\
\hline $\begin{array}{l}\text { 4. (Wangalwa, et } \\
\text { al., 2012) }\end{array}$ & Kenya & \begin{tabular}{|l|} 
randomized \\
control trials
\end{tabular} & $\begin{array}{l}\text { Involvement of } \\
\text { Community Health } \\
\text { Workers in provision } \\
\text { of maternal health } \\
\text { services }\end{array}$ & $\begin{array}{l}\text { Increased visits to health } \\
\text { center, increased deliveries by } \\
\text { skilled personnel, } \\
\text {-increased essential maternal } \\
\text { and neonatal care practices }\end{array}$ & \\
\hline $\begin{array}{l}\text { 5.. (Kidane \& } \\
\text { Morrow, 2000) }\end{array}$ & Ethiopia & $\begin{array}{l}\text { randomized } \\
\text { controlled trial }\end{array}$ & $\begin{array}{l}\text { Mother to Mother } \\
\text { support in recognizing } \\
\text { maternal health risks }\end{array}$ & & $\begin{array}{l}\text { Reduced MMR, NMR } \\
\text { and IMR in treated } \\
\text { group }\end{array}$ \\
\hline $\begin{array}{l}\text { 6.. (Schaider, et } \\
\text { al., 1999) }\end{array}$ & Angola & longitudinal & $\begin{array}{l}\text { Involvement of } \\
\text { traditional birth } \\
\text { attendants (TBAs) } \\
\text { prenatal, delivery, and } \\
\text { postnatal care }\end{array}$ & & $\begin{array}{l}\text { Better MMR, NMR } \\
\text { and IMR outcomes }\end{array}$ \\
\hline $\begin{array}{l}\text { 7. (Dehne, et al., } \\
\text { 1995) }\end{array}$ & Sahel & longitudinal & $\begin{array}{l}\text { Involving TBAs to } \\
\text { promote safe } \\
\text { motherhood }\end{array}$ & $\begin{array}{l}\text {-increased levels of retained } \\
\text { knowledge of risk factors, } \\
\text { hygiene and malaria } \\
\text { prophylaxis in 2-year follow- } \\
\text { up survey. }\end{array}$ & \\
\hline 8. (Akpala, 1994) & Nigeria & longitudinal & $\begin{array}{l}\text { "Involved traditional } \\
\text { birth attendants } \\
\text { (TBAs) }\end{array}$ & $\begin{array}{l}\text {-Increased referrals to health } \\
\text { centers } \\
\text {-increased use of family } \\
\text { planning }\end{array}$ & $\begin{array}{l}\text { Reduced haemorrhage, } \\
\text { oedema, extended } \\
\text { labor cases }\end{array}$ \\
\hline $\begin{array}{l}\text { 9. (Ibrahim, et al., } \\
\text { 1992) }\end{array}$ & Sudan & longitudinal & $\begin{array}{l}\text { Involvement of Village } \\
\text { TBAs to detect high- } \\
\text { risk pregnancy and } \\
\text { newborns } \\
\text { complications }\end{array}$ & $\begin{array}{l}\text {-Increased reporting of } \\
\text { complications } \\
\text {-Increased detection of } \\
\text { complications }\end{array}$ & $\begin{array}{l}25 \% \text { reduction in cases } \\
\text { of stillbirth and } \\
\text { neonatal death }\end{array}$ \\
\hline
\end{tabular}


Table 2.5 Detailed results for HIV positive women (Category 2)

\begin{tabular}{|c|c|c|c|c|c|}
\hline Citation & $\begin{array}{l}\text { Country } \\
\text { of origin }\end{array}$ & Study Design & $\begin{array}{l}\text { Community Mobilization } \\
\text { Component }\end{array}$ & Process results & Outcome \\
\hline $\begin{array}{l}\text { 1. (Rotheram- } \\
\text { Borus, et al., } \\
\text { 2014) }\end{array}$ & $\begin{array}{l}\text { South } \\
\text { Africa }\end{array}$ & $\begin{array}{l}\text { randomized } \\
\text { controlled } \\
\text { trial }\end{array}$ & $\begin{array}{l}\text { Involvement of fellow HIV } \\
\text { positive pregnant women } \\
\text { to mobilize and provide } \\
\text { support to fellow HIV } \\
\text { positive mothers. }\end{array}$ & $\begin{array}{l}\text {-Women in Treatment } \\
\text { Group (TG) exhibited } \\
\text { Increased knowledge on } \\
\text { how to improve the health } \\
\text { of their children } \\
\text { - Increased access to } \\
\text { information and resources } \\
\text { to improve their health } \\
\text { during maternity }\end{array}$ & $\begin{array}{l}\text {-Mothers in Treatment } \\
\text { Group (TG) exhibited } \\
\text { reduced maternal } \\
\text { depression when } \\
\text { compared to their } \\
\text { counter-parts }\end{array}$ \\
\hline $\begin{array}{l}\text { 2. (Kaayaa, et } \\
\text { al., 2013) }\end{array}$ & Tanzania & $\begin{array}{l}\text { randomized } \\
\text { controlled } \\
\text { trial }\end{array}$ & $\begin{array}{l}\text { Creation of peer support } \\
\text { group that provided a safe } \\
\text { space for women with high } \\
\text { levels of psychological } \\
\text { distress to discuss and } \\
\text { share strategies for } \\
\text { addressing common } \\
\text { concerns related to PMTCT } \\
\text { among HIV positive } \\
\text { pregnant women. }\end{array}$ & $\begin{array}{l}\text {-Increased disclosure } \\
\text { among HIV positive } \\
\text { pregnant women in the } \\
\text { treatment group as } \\
\text { compared to those in the } \\
\text { control group. } \\
\text {-Women in Treatment } \\
\text { Group experienced a } \\
\text { significantly higher rate of } \\
\text { overall personal satisfaction } \\
\text { with response to disclosure, }\end{array}$ & $\begin{array}{l}\text { - a marginally significant } \\
\text { reduction in the level of } \\
\text { depressive symptoms for } \\
\text { HIV-positive pregnant } \\
\text { women participating in a } \\
\text { group counseling } \\
\text { intervention (Treatment } \\
\text { Group) } \\
60 \% \text { of women in the } \\
\text { intervention group were } \\
\text { depressed post- } \\
\text { intervention, versus } 73 \% \\
\text { in the control group } \\
\text { [Relative Risk (RR) } 0.82 \text {, } \\
95 \% \text { confidence interval } \\
\text { (CI): } 0.671 .01, \text { p0.066]. H }\end{array}$ \\
\hline $\begin{array}{l}\text { 3. (Richter, et } \\
\text { al., 2014) }\end{array}$ & $\begin{array}{l}\text { South } \\
\text { Africa }\end{array}$ & $\begin{array}{l}\text { cluster } \\
\text { randomized } \\
\text { controlled }\end{array}$ & $\begin{array}{l}\text { The intervention consisted } \\
\text { of four antenatal and four } \\
\text { postnatal small group } \\
\text { sessions led by Peer } \\
\text { Mentors, in addition to } \\
\text { Standard Care. HIV } \\
\text { positive pregnant Women } \\
\text { were recruited during } \\
\text { pregnancy and } 70 \% \text { were } \\
\text { reassessed at } 1.5 \text { months } \\
\text { post-birth. }\end{array}$ & $\begin{array}{l}\text { Compared to Standard Care } \\
\text { WLH, EI (treatment Group) } \\
\text { were more likely to ask } \\
\text { partners to test for HIV (OR } \\
=1.84 ; \text { two-sided } p= \\
0.014 \text { ), }\end{array}$ & $\begin{array}{l}\text { Compared to Standard } \\
\text { Care WLH, EI (treatment } \\
\text { Group) were more likely } \\
\text { to have infants with } \\
\text { height-for-age z-score } \geq- \\
2(\mathrm{OR}=3.30 ; p=0.006) \\
\text { and were less likely to } \\
\text { report depressed mood } \\
\text { (OR }=2.55 ; p=0.003) . \\
\text {-Healthcare utilization } \\
\text { was similar across } \\
\text { conditions. } \\
\text {-Significant improvement } \\
\text { in PMTCT }\end{array}$ \\
\hline $\begin{array}{l}\text { 4. (Torpey, et } \\
\text { al., 2010) }\end{array}$ & Zambia & Longitudinal & $\begin{array}{l}\text { Healthcare workers } \\
\text { (HCWs) and lay providers } \\
\text { conduct rapid HIV testing. } \\
\text { support for pregnant } \\
\text { women," }\end{array}$ & $\begin{array}{l}\text { Uptake of services } \\
\text { significantly improved } \\
\text { HIV testing among pregnant } \\
\text { women improved } \\
\text {-There was also significant } \\
\text { improvement in the } \\
\text { percentage of HIV positive } \\
\text { pregnant women referred } \\
\text { for clinical care }\end{array}$ & \\
\hline $\begin{array}{l}\text { 5. (Perez, et } \\
\text { al., 2008) }\end{array}$ & $\begin{array}{l}\text { Zimbabw } \\
\text { e }\end{array}$ & $\begin{array}{l}\text { cluster } \\
\text { randomized } \\
\text { controlled }\end{array}$ & $\begin{array}{l}\text { Use of TBAs to help } \\
\text { promote PMTCT, antenatal } \\
\text { services and postnatal } \\
\text { services }\end{array}$ & $\begin{array}{l}\text { Uptake of PMTCT, antenatal } \\
\text { and postnatal services at } \\
\text { health facilities improved }\end{array}$ & \\
\hline
\end{tabular}


Overall characteristics of publications

Table 2.2 presents an overview of the general characteristics of the publications reviewed. The studies were published in peer reviewed journals between 1990 and 2015 and were all based on experimental research designs.

Regarding the definition of community mobilization as shown in chapter 1, overall, the studies operationalized community mobilization in accordance with the three main principles namely; collaboration between community and professionals in designing maternal care initiatives, use of indigenous resources in maternal care provision (e.g. TBA), and reliance on peer support for pregnant women and new mothers. In total, five publications operationalized community mobilization as group/peer support (social, psychological, and financial), another five operationalized community mobilization as the use of indigenous resources in maternal care provision (e.g. TBAs), and another five conceptualized community mobilization as partnership between community and health professionals in the design and implementation of maternal care initiatives.

The role of community mobilization among HIV negative women (Category 1) and HIV positive women (Category 2):

Table 2.3 presents a summary of the indicators used to study the process and outcome of community mobilization among both HIV negative women and women living with HIV.

With regard to HIV negative women, some of the publications reported process indicators which involved adoption of health-enhancing behavior among mothers. The others reported outcome indicators, which included reduction in maternal depression, reduced rates of hemorrhage, reduced neonatal mortality and reduced maternal mortality. On the other hand, the majority of publications on women living with HIV reported process indicators, which included among other things, adoption of maternal health-enhancing behavior among HIV positive mothers. In addition, a few reported outcome indicators such as reduced depression among HIV pregnant women.

Peer support was explicated in the form of regular meetings in women's groups where pregnant women provided each other with emotional, physical, social and psychological support to deal with high levels of psychological distress and other practical needs. They also shared strategies for 
addressing common concerns related to antenatal and primary healthcare, including PMTCT among women with HIV. Although there was more emphasis on support for PMTCT for women with HIV, in general, the type of peer support ( financial, psychological, and material) given was to a large extent similar for both HIV negative and women positive women (Colbourn, et al., 2013; Lewycka, et al., 2013; Rotheram-Borus, et al., 2014; Kaayaa, et al., 2013; Richter, et al., 2014).

For HIV negative women, peer support improved emotional strength and enhanced pregnant women's knowledge on how to handle maternal complications such as antepartum and postpartum hemorrhage, obstructed labor, and sepsis (Colbourn, et al., 2013). Further, peer support arising from participation in women's groups in the community significantly reduced the risk of mortality among newly born children (Colbourn, et al., 2013; Lewycka, et al., 2013). Overall, the majority of publications in this systematic review concluded that peer support in HIV negative women led to improvements in maternal and child health outcomes due to improved access to emotional, psychological, social and physical support, which enabled pregnant women to access information, services and resources that are necessary for improving maternal health outcomes.

Three publications regarding women with HIV reported that peer support among other things, helped to increase access to health-enhancing resources (such as antenatal and primary healthcare, PMTCT, information on safe delivery services) and knowledge, it also increased utilization of health services by providing pregnant women with transport to health centers and safe delivery packages. Women with HIV who had peer support also experienced reduced maternal depression (RotheramBorus, et al., 2014; Kaayaa, et al., 2013; Richter, et al., 2014).

- Use of TBAs in maternal care provision

The studies that reported on TBAs demonstrated how TBAs helped to increase women's knowledge on risk factors during pregnancy, knowledge on hygiene, use of malaria prophylaxis among HIV negative pregnant women who were outside the catchment area of standard health care (Dehne, et al., 1995; Akpala, 1994; Ibrahim, et al., 1992). One publication highlighted that the use of TBAs helped to reduce maternal depression, hemorrhage, and maternal mortality among HIV negative women (Schaider, et al., 1999). These studies concluded that in general, TBAs contribute positively to maternal health outcomes of HIV negative women in the peripherals of SSA. 
Among women living with HIV, the only publication that was found concluded that using TBAs enhanced the coverage of maternal health care for women living with HIV especially in areas where many pregnant women chose to have home deliveries (Perez, et al., 2008). TBAs were considered useful because they encouraged women with HIV to take medication (e.g. zidovudine), which helped to prevent mother-to-child transmission of HIV during pregnancy. The evidence examined in this systematic review however does not report exactly on whether and how the TBAs managed to deal with complications such as hemorrhage, sepsis and PMTCT. The only study on women living with HIV was also silent on what mechanisms were available to TBAs for referral purposes in cases of emergency.

- Collaboration between community and professionals in designing and/or implementing initiatives

The role of collaboration in the design and implementation of maternal care initiatives for HIV negative women was studied in four publications (Schmid, et al., 2001; Wangalwa, et al., 2012; Kidane \& Morrow, 2000; Shamba, et al., 2013). Collaboration helped to design initiatives that improved access to professional treatment. Such initiatives included transportation of pregnant women by community members to health centers in case of obstetric emergencies. This sort of collaboration increased the attention to other complications such as sepsis and hemorrhage. This was because the collaboration allowed for easy exchange of knowledge and information regarding these complications between professionals and the community (Schmid, et al., 2001; Wangalwa, et al., 2012; Kidane \& Morrow, 2000; Shamba, et al., 2013). Further, it was deduced from the publications that through the collaboration between the community and professionals, there was an increase in antenatal services and institutional delivery (Schmid, et al., 2001; Wangalwa, et al., 2012). Other studies showed that through the collaboration between health workers and local community members, there was a significant reduction in child mortality of up to 57\% (Kidane \& Morrow, 2000). Another study from Tanzania concluded that through collaboration with community caregivers, health-inhibiting practices during home deliveries were mitigated (e.g. use of unclean thread to tie the umbilical cord, putting "substances" on the cord) (Shamba, et al., 2013). Overall, it is evident from the publications that collaboration between professionals and communities in the design of maternal care initiatives improved access to health information, treatment and services, as 
well as increased attention to maternal health complications, thereby making this a viable strategy in an attempt to improve maternal health outcomes of HIV negative women.

On the other hand, only one publication evaluated the role of community involvement in promoting maternal health of women living with HIV (Torpey, et al., 2010). This study also only reported positive process results in the form of improved uptake of institutional health services and acceptance of maternal health interventions; both of which are assumed to be important in improving maternal health of women living with HIV. It is therefore clear that the focus of research on community involvement and maternal health outcomes of women with HIV was limited to the explication of process results only, without much on outcomes. There is still a gap in linking collaboration in maternal care initiatives to outcome results such as reduced maternal mortality, reductions in complications such as sepsis and hemorrhage in women with HIV.

\subsection{Discussion}

Overall, this systematic review of experimental design studies has produced results which differ somewhat between women living with HIV and HIV negative women. We observe that to date, there is sound causal evidence in support of community mobilization as a useful maternal health care strategy for HIV negative women. On the other hand, strong evidence for women with HIV is still missing. The fact that strong evidence linking community mobilization to maternal health outcomes for women with HIV is still missing confirms Kendall and Langer's (2015) assertion that the intersection of HIV and pregnancy has generally been ignored in social science research (Kendall \& Langer, 2015). This is despite the fact that women with HIV are more susceptible to morbidity and mortality during pregnancy (Kendall, et al., 2014). Below we demonstrate in detail the differences in empirical evidence between HIV negative women and women living with HIV using the three principles of community mobilization.

Firstly, evidence indicates that for HIV negative women, peer support from fellow pregnant women improves maternal health outcomes. Our findings are consistent with a growing body of literature which shows that peer support is necessary in reducing rates of maternal depression, antepartum and postpartum hemorrhage, obstructed labor and sepsis in HIV negative women (Campbell \& Mzaidume, 2002). This is normally achieved through the provision of economic and psychological 
support to peers, including sharing of different strategies in order to deal with negative maternal outcomes. It is clear from the existing literature that peer support is useful for HIV negative women. However, the same cannot be said of women with HIV. Given the relatively high risk associated with HIV/AIDS, and this coupled with the lack of studies focusing on women with HIV, it remains unclear whether peer support can also be useful in reducing maternal complications in women with HIV, and if so, in which ways. This however does not imply that peer support is completely useless for women with HIV. The indication from our results is that peer support is still useful in promoting process results which include enhanced coping, increased access to emotional and economic support, adherence to treatment, utilization of health services (Rotheram-Borus, et al., 2014; Kaayaa, et al., 2013; Richter, et al., 2014). While most scholars attach less importance to processes within different maternal health interventions, it should be noted however that these process outcomes are not completely unrewarding. They embody social conditions that are necessary for maternal health improvement (Campbell \& Cornish, 2010). In particular, the processes observed in this review are important for women living with HIV who are usually victims of isolation, stigma and discrimination. Peer support thus gives rise to social spheres which provide opportunities for a critical dialogue about maternal health issues among women with HIV (O'Gorman, et al., 2010; Campbell \& Cornish, 2012). Peer support also necessitates the reassessment of harmful cultural and social norms affecting women with HIV (Campbell \& Mzaidume, 2002). While it is true that in general peer support leads to conditions necessary for improving maternal health in women with HIV, this fact alone does not offer any basis for drawing a causal link between peer support and maternal health of women living HIV. Existing evidence does not provide a knock-on effect of peer support on maternal health outcomes such hemorrhage, sepsis, and maternal mortality for women with HIV. Evidence linking peer support to maternal health outcomes of women with HIV is still missing in the literature. The evidence provided in support of peer support vis-à-vis women with HIV seems necessary but not sufficient to unequivocally establish peer support as a useful strategy for improvement of maternal outcomes among women with HIV. More research needs to be undertaken to examine this relationship in order to shade light on how peer support provides opportunities for improving maternal care of women with HIV. To this effect, in chapter 3 we provide more evidence of how peer support provides opportunities for improved maternal care of women with HIV. 
The other important principle of community mobilization is the involvement of TBAs in maternal care provision. Our results in this regard were concomitant with recent studies indicating that TBAs are particularly useful for enhanced maternal care for HIV negative women, especially in areas lacking efficient health systems (Dehne, et al., 1995; Akpala, 1994; Ibrahim, et al., 1992). TBAs were particularly useful in reducing maternal morbidity and mortality in HIV negative women. However, this evidence only speaks for HIV negative women, whereas no focus has been placed on women living with HIV. The impact of TBAs on maternal health outcomes in women with HIV (who require antiretroviral therapy and cesarean birth in order to promote PMTCT) remains understudied (Lippmann, et al., 2012; Perez, et al., 2008). There is a need for more research to establish the link between use of TBAs and positive maternal health outcomes in women with HIV. Although a stronger case for TBAs is still lacking, it does not automatically mean that TBAs are irrelevant to women with HIV in SSA. To the contrary, this result only means that to date, there is no study that establishes a significant causal link between TBAs and maternal health outcome of women with HIV. We also note that in SSA, it is counterproductive to encourage only institutional delivery. Institutional delivery in poorly equipped, hard-to-reach, remote, and overcrowded health facilities with poor adherence to quality is far from optimal. Given this, TBAs are sometimes the only feasible, cheap, practical and readily available source of maternal care in the peripherals of Africa and as such, it seems more advantageous in the context of SSA to make use of TBAs and professional midwives complementary to each other (Wangalwa, et al., 2012; Perez, et al., 2008). Therefore, a more nuanced understanding of maternal health interventions for women with HIV in SSA is needed. However, before achieving this, it is vital that we increase our understanding on how exactly TBAs can improve maternal health of women with HIV and what kind of training should be provided to them. In order to address this concern, chapter 4 and 5 are dedicated to show reasons why women with HIV rely on TBAs. Further, in chapter 6 we provide more evidence of the effect of TBAs on under-five mortality in women with HIV. Thus the three chapters collectively increase our understanding on the usefulness of TBAs to women with HIV.

Lastly, collaboration between professionals and the community in the design and implementation of maternal care initiatives, which is another principle of community mobilization, also produced varied results for HIV negative women and for women with HIV. The causal link between collaboration and maternal health outcomes for HIV negative women is established (Schmid, et al., 2001; Wangalwa, et al., 2012; Kidane \& Morrow, 2000; Shamba, et al., 2013). To date, collaboration with 
regard to women with HIV is only credited for the adoption of health-enhancing behavior. Although not a maternal health outcome in itself, behavioral change is an essential step towards improving maternal health. At the same time, it should be noted that behavioral change does not epitomize improved maternal outcome, it is merely a process through which improvement in maternal health can be achieved. This means that currently, it is less lucid to claim a collaborationprecipitated maternal health improvement in women with HIV on the basis of behavioral change. Therefore, we posit that more evidence is needed to understand how useful collaboration could be for women with HIV. Thus, in chapter 3 we provide more evidence of how collaboration provides opportunities for improved maternal care of women living with by using Zambia as a case study.

Limitations

Our review has several limitations that need to be acknowledged. Key among them is the fact that the search only included publications in English. This may have led to the omission of studies published in other languages within SSA. The search also just focused on studies published in peerreviewed journals thereby leaving out any grey literature. Therefore, it is possible that some literature focusing on the role of community mobilization on maternal health outcomes of HIV positive women in SSA may have been omitted. We also did not find studies reporting undesirable process or outcome results. It should be acknowledged in this regard that positive results are more easily published while negative results tend to remain underreported.

\subsection{Conclusion}

As shown in our systematic review, currently, the evidence on the role of community mobilization on maternal outcomes of HIV negative women in SSA is more conclusive than for women with HIV. This is embodied in all principles of community mobilization that we analyzed. So far, not much empirical work has been done to provide compelling evidence regarding the impact of community mobilization on maternal outcomes (i.e. sepsis, hemorrhage, maternal and under-five mortality) for women living with HIV. That notwithstanding, there is some evidence suggesting that all three principles of community mobilization provide necessary process results for improving maternal health of women with HIV. It is indeed true that the process results create necessary 
conditions for improving maternal health. However, evidence on process indicators alone without subsequent causal evidence on the outcomes is not sufficient, and as such, cannot be used as a basis for advocating community mobilization as a useful maternal health care strategy for women with HIV in SSA. Thus, more research needs to be undertaken to examine whether community mobilization actually leads to better maternal health outcomes in women with HIV and how exactly this change is achieved. Consequently, when it comes to relying on community mobilization for policy recommendation, we observe that there is not enough evidence to recommend community mobilization as a strategy for maternal health care provision for women in SSA. 


\section{Chapter 3}

Community mobilization and maternal care of women living with HIV in poor settings: The case of Mfuwe, Zambia

This chapter draws upon:

Muzyamba, C., Groot, W., Tomini, S.M, \& Pavlova, M. (2018). Community mobilization and maternal care of women living with HIV in poor settings: The case of Mfuwe, Zambia. BMC Health Services Research, 18(153). 


\begin{abstract}
Research has shown that community mobilization is a useful strategy in promoting maternal care of HIV negative women in resource poor settings; however, similar evidence for women living with HIV is missing. Therefore, in this chapter we provide this evidence by exploring the relevance of community mobilization in the promotion of maternal health care among women living with HIV in resource-poor settings by using Mfuwe, a rural village in Zambia as a case study.
\end{abstract}

By relying on Focus Group Discussions (FGDs), qualitative data were collected from Mfuwe, Zambia. The data were digitally recorded, transcribed and later translated from CheChewa (local language) to English. We relied on thematic analysis to analyze the data.

By focusing on community mobilization, our results showed that within their social fabrics, resource-poor communities often contain unrecognized and sometimes ignored strategies which are contextually-feasible and have been used for generations to promote maternal care for HIV positive women. Further, it was evident that although the three forms of community mobilization were largely and uniquely useful in promoting maternal health care of women living with HIV, they also presented unique and various shortcomings.

We demonstrated that community mobilization was largely and often characterized as a force for good (e.g. providing support, improving access to maternal care etc.) and sometimes for bad (e.g. reinforced harmful misconceptions, superstition and clichés ). Thus we recommend that community mobilization needs to be factored into maternal health care policies for HIV positive women in resource poor settings either to optimize their potential benefits or to minimize their potential harm. 


\subsection{Background}

In resource-poor settings where health systems are inefficient, research has shown that community mobilization can be a useful strategy for improving maternal care of HIV negative women (Colbourn, et al., 2013). Chapter 2 of this dissertation and other studies from SSA have shown that similar evidence for HIV positive women is still lacking despite them being more vulnerable given their HIV status (Kendall \& Danel, 2004; Kendall \& Langer, 2015). Besides the lack of evidence of the effect of community mobilization on maternal health care service provision for HIV positive women, there is a lack of evidence on local stakeholders' (HIV positive women) own perspectives of community mobilization vis-à-vis maternal health care (Kendall \& Danel, 2004; Nhamo, et al., 2010; Lassi, et al., 2014). Such evidence is needed in order to design locally-suitable and feasible maternal care programs for women living with HIV in resource-poor settings. Therefore, the aim of this chapter is to explore the processes and relevance of community mobilization (via its 3 principles as defined in chapter 1 and 2) in the promotion of maternal health care among HIV positive women in resource-poor settings by using Mfuwe, Zambia as a case study. We explore the local perceptions of community mobilization and how HIV positive women interpret its relevance. For this purpose, we use qualitative data collected in Mfuwe, Zambia (for more details about Mfuwe, see chapter 1). Mfuwe makes a good case study because it is a resource-poor rural area with high HIV rates and maternal deaths (CSO, et al., 2009; MoH, 2014).

This chapter makes use of the social psychological framework known as "community health competence" (Nhamo, et al., 2010; Campbell \& Cornish, 2012). The framework is already widely used in HIV research to emphasize the role that informal community group participation plays in HIV/AIDS response (Campbell, 2014; Campbell \& Cornish, 2010; Cornish, et al., 2014). In this chapter, we apply the framework on maternal health of HIV positive women, i.e. the framework guides our analysis and presentation of the results. "Community health competence" is a conceptual framework which enables researchers to assess how health services produce (or fail to produce) health-enhancing environments for local people by relying on "local culture, context and local survival strategies" and collaboration with external experts (Nhamo, et al., 2010). This framework emphasizes dialogue and horizontal partnership between indigenous and external efforts in creating health-enhancing opportunities (Campbell \& Cornish, 2010; Nhamo, et al., 2010). 
The framework holds that dialogue between peers, reliance on readily available resources and active collaboration with external experts facilitate the development of heath-enhancing environments more sustainably (Campbell \& Cornish, 2012). This is because the dialogue and collaboration allows vulnerable people (in our case HIV positive women) to critically reflect on their challenges and strengths (Campbell \& Cornish, 2012). The framework indicates that in creating "community maternal health competence" for HIV positive women, the following conditions should be evident: (1) Peer-support should be seen to serve as a maternal health-enabler through sharing of maternal health related knowledge among HIV positive women; (2) There should be recognition and use of available "indigenous individuals and social skills" (indigenous resources) (Campbell, et al., 2015, p. 5) in responding to maternal health needs of HIV positive women in community; (3) Communities should develop links and work together with external experts in "the public and NGO sectors" to ensure active community-involvement in planning and implementation of maternal health initiatives (Campbell, et al., 2015, p. 5).

In this chapter, we structure our analysis based on the three conditions espoused in this framework by assessing how peer support, use of indigenous resource and community involvement either promote or hinder maternal health care for HIV positive women in Mfuwe. More specifically, the framework is used to structure the analysis on how community mobilization (peer support, use of indigenous resources, and community involvement) either facilitates or hinders promotion of maternal care for HIV positive women in Mfuwe.

\subsection{Methods}

Ethical consideration

We obtained ethical clearance from the National Health Research Authority of Zambia, and from the Zambian ERES CONVERGE IRB (see appendix A). Informed consent was sought from the participants before participation, and at the same time, participants were clearly informed of their right to discontinue their participation in the interview at any point should they wish to (see appendix B). 
Sampling

The study was conducted in Mfuwe with participants coming from all the 6 settlements in the village. In order to select our sample, we relied on a purposive sampling technique by establishing contact with two Zambian-based organizations (CIDRZ- Centre for Infectious Disease Research in Zambia and PPAZ- Planned Parenthood Association of Zambia) which were working with HIV positive women in promoting their maternal health care. The two organizations had contact with women who were indirect and direct beneficiaries of the services of these two organizations. Participants were selected with the help of the two local NGOs. Women who met the criteria (HIV positive and experienced one or more of the components of community mobilization) and expressed interest in participating in the study were invited to participate. In order to increase the diversity of opinions expressed by participants and to allow for varied discussions, the diversity of participants was ensured through diversifying the age, educational level, marital status, and employment status of participants.

The women were divided into three FGDs all involving HIV positive women who had experienced one or more of the components of community mobilization. The first FGD focused on peer support, the second one on utilization of indigenous resources, and the last one on community involvement. Both the first FGD (on peer support) and the second one (on utilization of indigenous resources) each consisted of 13 participants. The last one (on community involvement) had 11 participants bringing the total number of participants to 37 . The summary of this including social demographic characteristics of participants can be found in table 3.1 below. 
Table 3.1: Participants demographics

\begin{tabular}{|c|c|c|c|c|}
\hline ID & Age & Education Level & Employment status & Marital status \\
\hline \multicolumn{5}{|c|}{$1^{\text {st }}$ FGD (On Peer Support) } \\
\hline 1 & 24 & primary education & Employed & Married \\
\hline 2 & 29 & Primary education & Employed & Not married \\
\hline 3 & 34 & No education & Unemployed & Married \\
\hline 4 & 33 & No education & Unemployed & Married \\
\hline 5 & 27 & No Education & Employed & Widowed \\
\hline 6 & 23 & Primary Education & Employed & Married \\
\hline 7 & 26 & No education & Employed & Not married \\
\hline 8 & 27 & Primary education & Unemployed & Not Married \\
\hline 9 & 22 & Secondary Education & Employed & Married \\
\hline 10 & 26 & Primary Education & Unemployed & Married \\
\hline 11 & 33 & No Education & Employed & Married \\
\hline 12 & 38 & Secondary Education & Employed & Married \\
\hline 13 & 29 & Secondary Education & Unemployed & Married \\
\hline \multicolumn{5}{|c|}{$2^{\text {nd }}$ FGD (Utilization of indigenous resources) } \\
\hline 14 & 34 & Primary education & Unemployed & Married \\
\hline 15 & 28 & Secondary Education & Employed & Not Married \\
\hline 16 & 24 & Primary Education & Unemployed & Married \\
\hline 17 & 33 & Primary Education & Employed & Widowed \\
\hline 18 & 38 & No Education & Employed & Not Married \\
\hline 19 & 27 & No Education & Unemployed & Married \\
\hline 20 & 23 & Primary Education & Employed & Not Married \\
\hline 21 & 20 & Primary Education & Employed & Widowed \\
\hline 22 & 29 & No Education & Unemployed & Not Married \\
\hline 23 & 43 & Secondary Education & Employed & Married \\
\hline 24 & 26 & Vocational training & Employed & Married \\
\hline 25 & 51 & No Education & Unemployed & Married \\
\hline 26 & 38 & No Education & Unemployed & Not married \\
\hline \multicolumn{5}{|c|}{$3^{\text {rd }}$ FGD (Community-Involvement) } \\
\hline 27 & 29 & Primary Education & Employed & Not married \\
\hline 28 & 27 & Secondary Education & Employed & Widowed \\
\hline 29 & 43 & Primary Education & Unemployed & Married \\
\hline 30 & 33 & Primary Education & Employed & Married \\
\hline 31 & 35 & No Education & Employed & Not married \\
\hline 32 & 36 & No Education & Unemployed & Married \\
\hline 33 & 38 & Primary education & Employed & Not Married \\
\hline 34 & 20 & Secondary Education & Employed & Married \\
\hline 35 & 27 & Primary Education & Unemployed & Married \\
\hline 36 & 36 & No Education & Unemployed & Not married \\
\hline 37 & 43 & Secondary Education & Employed & Married \\
\hline 38 & 33 & Secondary Education & Employed & Not married \\
\hline
\end{tabular}




\section{Data collection}

All FGDs lasted for an average of 90 to 100 minutes. The discussions were conducted in Chichewa (the local language) and English was used where possible. Topic guides was used during FGDs but at the same time, discussion of emergent areas of interest to the participants was allowed (see Appendix C for peer support FGD guide, Appendix D for use of TBAs FGD guide, and Appendix E for community involvement FGD guide). In line with the framework presented above, we structured topic guides that endeavored to elucidate how peer support, use of indigenous resource and community involvement either promote or hinder maternal health care for HIV positive women. This was done through asking questions that allowed participants to explain the different ways they experienced the different components of community mobilization, how useful they found the components and what the challenges were. We also ensured that follow-up questions were asked for clarification purposes, and to also encourage respondents to expand on some of their answers. All FGDs were digitally recorded.

Analysis

We first transcribed the data and then translated them into English, after which we used NVivo to conduct thematic analysis (Braun \& Clarke, 2006). By relaying on our theoretical framework, we focused our attention on assessing how peer support, use of indigenous resource and community involvement either promote or hinder maternal health care for HIV positive women in Mfuwe. For this, we identified codes using NVivo. Each specific component of community mobilization gave rise to basic themes that highlighted several and diverse ways in which community mobilization either promoted or hindered maternal care. These basic themes were then systematically clustered to form more structured and elaborate organizing and global themes. The resulting themes show the diverse ways community mobilization promoted and hindered maternal care. After re-reading and refining the themes, we identified 20 organizing themes and 6 global themes (see Table 3.2).

\subsection{Results}

Table 3.2 below shows a summary of the results while a thorough explanation of these findings follows after the table. 
Table 3.2 Summary of results (coding framework)

\begin{tabular}{|c|c|c|c|}
\hline $\begin{array}{l}\text { Community } \\
\text { Mobilization } \\
\text { Component }\end{array}$ & Global Theme & Organizing Theme & $\begin{array}{l}\text { Basic Theme } \\
\text { identified in the FGDs }\end{array}$ \\
\hline \multirow[t]{13}{*}{ Peer Support } & \multirow[t]{9}{*}{$\begin{array}{l}\text { Peer-support as a maternal } \\
\text { health-enabler }\end{array}$} & \multirow[t]{3}{*}{$\begin{array}{l}\text { Supported promoted } \\
\text { dialogue }\end{array}$} & $\begin{array}{l}\text { Dialogue helped challenge and re- } \\
\text { evaluate inaccurate stereotypes and } \\
\text { harmful clichés }\end{array}$ \\
\hline & & & $\begin{array}{l}\text { Dialogue enabled sharing information } \\
\text { regarding best practices during maternal } \\
\text { care }\end{array}$ \\
\hline & & & $\begin{array}{l}\text { Dialogue gave rise to empathy and } \\
\text { availability of strong friendship ties with } \\
\text { people in similar situation }\end{array}$ \\
\hline & & Provided support to peers & $\begin{array}{l}\text { Peer support promoted emotional, } \\
\text { psychological, physical and economic } \\
\text { support among HIV positive women } \\
\text { during maternity }\end{array}$ \\
\hline & & \multirow[t]{2}{*}{$\begin{array}{l}\text { Promoted treatment- } \\
\text { adherence }\end{array}$} & $\begin{array}{l}\text { Peer support encouraged regular and } \\
\text { consistent uptake of ARVs before and } \\
\text { after birth }\end{array}$ \\
\hline & & & $\begin{array}{l}\text { Peer support served as a continuous } \\
\text { reminder for uptake of ARVs }\end{array}$ \\
\hline & & \multirow[t]{3}{*}{ Fostered alliances } & $\begin{array}{l}\text { Peer support allows for the formation of } \\
\text { alliances among peers to advocate for an } \\
\text { end to sexual cleansing }\end{array}$ \\
\hline & & & $\begin{array}{l}\text { Working together to fight stigma and } \\
\text { discrimination through advocacy and } \\
\text { other means }\end{array}$ \\
\hline & & & $\begin{array}{l}\text { Fighting patriarchy and promoting } \\
\text { women empowerment }\end{array}$ \\
\hline & \multirow[t]{4}{*}{$\begin{array}{l}\text { Peer support as a maternal- } \\
\text { health inhibitor }\end{array}$} & $\begin{array}{l}\text { Re-enforced superstition } \\
\text { regarding institutional- } \\
\text { delivery }\end{array}$ & $\begin{array}{l}\text { Peers reinforced the negative } \\
\text { superstition regarding health facilities e.g } \\
\text { Clinics practice witchcraft and infant } \\
\text { deaths for ritual purposes etc. }\end{array}$ \\
\hline & & $\begin{array}{l}\text { Reinforced a sense of } \\
\text { helplessness and } \\
\text { dependency }\end{array}$ & $\begin{array}{l}\text { Experiencing and seeing fellow peers' ill } \\
\text { outcomes reinforces helplessness and } \\
\text { hopelessness in others }\end{array}$ \\
\hline & & \multirow[t]{2}{*}{$\begin{array}{l}\text { Promoted harmful sexual } \\
\text { practices }\end{array}$} & $\begin{array}{l}\text { Promoting Traditional practice of dry } \\
\text { sex }\end{array}$ \\
\hline & & & Promoting Sexual cleansing \\
\hline \multirow[t]{6}{*}{$\begin{array}{l}\text { Use of indigenous } \\
\text { resources }\end{array}$} & \multirow[t]{6}{*}{$\begin{array}{l}\text { Utilization of indigenous } \\
\text { resources as a maternal } \\
\text { health-enabler }\end{array}$} & \multirow[t]{4}{*}{$\begin{array}{l}\text { Trained TBAs provided } \\
\text { support }\end{array}$} & $\begin{array}{l}\text { Provide pragmatic services in the form } \\
\text { of psychological and emotional support }\end{array}$ \\
\hline & & & Provide adherence-to-treatment support \\
\hline & & & $\begin{array}{l}\text { Help in providing priority attention to } \\
\text { HIV positive women upon } \\
\text { recommendation at the facility }\end{array}$ \\
\hline & & & $\begin{array}{l}\text { Provide continuous home-based } \\
\text { maternal care }\end{array}$ \\
\hline & & $\begin{array}{l}\text { Trained TBAs provided } \\
\text { maternal health } \\
\text { information }\end{array}$ & $\begin{array}{l}\text { Provide useful maternal health } \\
\text { information }\end{array}$ \\
\hline & & $\begin{array}{l}\text { Trained TBAs as a conduit } \\
\text { for referrals }\end{array}$ & Help to refer patients to facilities \\
\hline
\end{tabular}




\begin{tabular}{|c|c|c|c|}
\hline $\begin{array}{l}\text { Community } \\
\text { Mobilization } \\
\text { Component }\end{array}$ & Global Theme & Organizing Theme & $\begin{array}{l}\text { Basic Theme } \\
\text { identified in the FGDs }\end{array}$ \\
\hline & \multirow{5}{*}{$\begin{array}{l}\text { Utilization of indigenous } \\
\text { resources as a maternal } \\
\text { health-inhibitor }\end{array}$} & \multirow[t]{2}{*}{$\begin{array}{l}\text { TBAs obscured } \\
\text { institutional delivery }\end{array}$} & $\begin{array}{l}\text { Presence of TBAs prevents government } \\
\text { from improving insertional care }\end{array}$ \\
\hline & & & TBAs lack skills to Help in PMTCT \\
\hline & & \multirow{3}{*}{$\begin{array}{l}\text { TBAs lacked skills, } \\
\text { equipment and medical } \\
\text { supplies to handle } \\
\text { complications }\end{array}$} & $\begin{array}{l}\text { TBAs lack skills to Help Easily conduct } \\
\text { HIV tests }\end{array}$ \\
\hline & & & $\begin{array}{l}\text { TBAs lack skills to Help in the provision } \\
\text { of ARVs }\end{array}$ \\
\hline & & & $\begin{array}{l}\text { TBAs cannot Help in conducting } \\
\text { caesarean births }\end{array}$ \\
\hline \multirow[t]{12}{*}{$\begin{array}{l}\text { community } \\
\text { involvement }\end{array}$} & \multirow[t]{10}{*}{$\begin{array}{l}\text { Community involvement as } \\
\text { a maternal health-enabler }\end{array}$} & \multirow[t]{3}{*}{$\begin{array}{l}\text { Promoted use of } \\
\text { Zambulance }\end{array}$} & $\begin{array}{l}\text { Use of Zambulance to transport } \\
\text { pregnant mothers to facilities for } \\
\text { antenatal, childbirth and postnatal care }\end{array}$ \\
\hline & & & $\begin{array}{l}\text { Zambulance help to provide utility } \\
\text { transportation services for drugs in } \\
\text { difficult terrains }\end{array}$ \\
\hline & & & $\begin{array}{l}\text { Provision of safe spaces for discussing } \\
\text { best ways of providing shelter to } \\
\text { pregnant women and new mothers }\end{array}$ \\
\hline & & \multirow{7}{*}{$\begin{array}{l}\text { Promoted use of 'waiting } \\
\text { shelter' (shelters where } \\
\text { expectant mothers can stay } \\
\text { while they await delivery.) }\end{array}$} & $\begin{array}{l}\text { Provision of care and support to other } \\
\text { women within the community through } \\
\text { the shelters }\end{array}$ \\
\hline & & & $\begin{array}{l}\text { Use of local leaders and other significant } \\
\text { people in communities to promote use } \\
\text { of shelters }\end{array}$ \\
\hline & & & $\begin{array}{l}\text { Provision of nutrition and other supplies } \\
\text { necessary during child birth in shelters }\end{array}$ \\
\hline & & & $\begin{array}{l}\text { Provision of mosquito nets to prevent } \\
\text { HIV positive women against Malaria }\end{array}$ \\
\hline & & & $\begin{array}{l}\text { Encourage uptake of institutional } \\
\text { delivery among HIV positive women }\end{array}$ \\
\hline & & & $\begin{array}{l}\text { Work together with others to encourage } \\
\text { other HIV positive mothers seek } \\
\text { antenatal and postnatal care }\end{array}$ \\
\hline & & & $\begin{array}{l}\text { Community involvement was just } \\
\text { symbolic as it failed to actively and } \\
\text { realistically involve locals }\end{array}$ \\
\hline & \multirow[t]{2}{*}{$\begin{array}{l}\text { community involvement as a } \\
\text { maternal health-inhibitor }\end{array}$} & Reinforced tokenism & $\begin{array}{l}\text { More powerful NGOs and health } \\
\text { workers obscured the voices of the weak } \\
\text { and vulnerable }\end{array}$ \\
\hline & & $\begin{array}{l}\text { Reinforced negative power } \\
\text { relations }\end{array}$ & \\
\hline
\end{tabular}


Peer support

In an effort to fight different challenges that HIV positive women faced during maternity, most women in the FGD on peer support refer to peer-support as a safe space for dialogue amongst peers, which enables sharing of helpful maternal health-related information specific for HIV positive women (such as PMTCT), and challenge misconceptions regarding HIV and pregnancy. The dialogue with peers also enabled these women to take ownership of previously alien HIV treatment and maternal health information. Some of these women also pointed out that the peer-support within the women's groups in the villages was based on empathy and real friendship, a factor which was necessary to balance their vulnerability as they previously felt disenfranchised and marginalized within their own communities due to their HIV positive status. This is especially emphasized in some quotes from some of the women in the Mfuwe HIV/AIDS women's group:

"It is easy to see that for a long time, people in this village were stigmatizing and discriminating against us, but now because we speak with one voice, we are able to confront this evil. We also support each other through exchanging information on HIV and pregnancy, so that is good"

Participant: 3

In Mfuwe, proper and highly efficient maternal care facilities were lacking $(\mathrm{MoH}, 2014)$, peer support was thus viewed as a useful component of maternal care. Mfuwe is faced with several challenges that include hard-to-reach health centers, poor transport systems, and lack of adequate health workers $(\mathrm{MoH}, 2014)$. According to the majority of the women, challenging these limitations through peer support allowed them to develop agency (the motivation and capacity) to foster improved care for themselves and also to assert their needs in relation to their HIV-vulnerability. This is embodied in the following quote:

"what is important to us as a group is that we remain supportive to each other through different forms. We have no ambulances and the clinic is far, but we always chip-in to belp each. I have also personally benefited emotionally and also physically because my colleagues where present to offer me good nutrition and encourage me to take my medication throughout the process"

Participant: 9 
Although peer support was largely characterized as a source of maternal health care support, two participants highlighted some shortcomings associated with peer-support. Specifically, peer-support was said to reinforce misconceptions, superstition and stigma regarding professional maternal care services and sexual reproductive health in general. These respondents pointed out that, through their interaction with other HIV positive women, they developed suspicions regarding condom use, and antiretroviral treatment, which they argued was against their traditional values. They observed that negative maternal outcomes from their peers (fellow HIV positive women) robbed them of confidence and hope for better maternal outcomes for themselves. This resulted in them losing the agency to challenge maternal health obstacles present in their communities.

"You know sometimes people are ignorant about the best ways to bandle our conditions, thus they continue to spread harmful information about treatment. I heard that some people were being told that if you take ART (Antiretroviral therapy) then you will die earlier because it kills you slowly from the inside"

Participant: 13

Use of indigenous resources

Given the limitations in the health system in this rural area, the majority of women in the FGD on the use of indigenous resources intimated that TBAs played a vital role in ensuring quality and affordability of maternal care. Respondents reported that TBAs played a huge role in provision of supportive services to HIV positive women such as social, psychological and emotional support, including referrals to health centers.

"They (TBAs) continue to offer us emotional and psychological support. I remember when I just came out of labor and was brought home; it is Mrs. X (anonymized local TBA) our community TBA who took care of me. I was feeling very depressed not knowing whether my child will also become (HIV) positive, but she supported me and encouraged me that all will be well. And I always thank her for that"....

"The local TBA always checked on me to make sure that I was taking my drugs. I felt very cared for"

Participant: 14 
Most respondents praised TBAs for providing useful sexual reproductive health information, encouraging HIV positive women to attend antenatal, childbirth and postnatal care in facilities, as well as supporting HIV positive women to adhere to treatment. This is captioned in quote from some respondents who pointed out that:

After she (the TBA) discovered that I was HIV positive, she explained to me the dangers of giving birth at home and as such, encouraged me to start going for antenatal and to give birth at the clinic"

Participant 17

"The local TBA always checked on me to make sure that I was taking my drugs. I felt very cared for"

\section{Participant 14}

It was also clear however that a few other respondents were critical of TBAs. Particularly, three of them were concerned about how effective the TBAs were in the community since trained TBAs did not possess necessary skills and medical supplies to conduct caesarean births (a necessary procedure for PMTCT) and handle other complications such as sepsis, hemorrhage etc.

"it would have been much better if TBAs could operate on me and allow me to give birth using caesarean birth. But they do not have the skills. This is why we go to the clinic. HIV is very problematic and weed to ensure that is perfect care for people like us"

\section{Participant 19}

A few other respondents were also troubled by the governments' directive to avoid TBAs in preference for clinical care. They stated that although desirable, clinical care was impractical in their case since most clinics were remotely located, overcrowded and lacked essential medication. They also pointed out that the staff in clinics were unfriendly and did not provide quality care.

"nurses are even worse. They always angrily shout at us and show no sympathy for our situation"

Participant: 20 


\section{Community involvement}

During the FGDs, most participants in the FGD on community involvement stated that they specifically collaborated with experts on the following two maternal health initiatives: the “Zambambulance" initiative and the 'waiting shelter' project.

The Zambulance (a makeshift ambulance consisting of carriage pulled by a bicycle operated by local people) which is a joint project between the community and the local clinic actively involved local people during planning and implementation. Local drivers volunteered on a rolling basis to transport pregnant women to health facilitates for antenatal, childbirth and postnatal care. Most of the respondents stated that the Zambulance initiative was responsible for increasing access to maternal health services, including access for several HIV positive women who would have otherwise been left unattended to due to infrastructural barriers that existed in Mfuwe.

"Our clinic doesn't have an ambulance, and to make matters worse, it is very far from our village. This is why we are using the Zambualnce to transport each other to clinics. Women who are HIV positive have been given priority"

Participant 28

The creation of "waiting shelters" close to clinics by local people to complement the shortage of bed spaces in the health facility was also hailed for improving access and affordability to maternal care, including care for HIV positive women. Local people while working with experts had set up "waiting shelters" which provided informal support to women (including HIV positive women) in the form of nutrition, psychological and other services necessary for women about to give birth or who recently gave birth. Most respondents praised the manner in which local people and experts collaborated on this idea which proved useful to their community.

"Unlike what happens in other villages, our village has done well in collaborating with the clinic, nurses and doctors to bring about the waiting shelter. I was there for six days after giving birth and the volunteers were very nice to me"

Participant 29 
Two other participants however criticized these initiatives by branding them tokenistic. They claimed that although collaborative initiatives were well-intended and with great potential, their successful implementation was constrained by the fact that villagers sometimes found themselves on the wrong side of the power-relations. Specifically, powerful NGOs always dictated the direction of the projects while suggestions from locals were often looked down upon. Furthermore, poverty, very few economic opportunities for volunteers and lack of wider political support negatively affected possibilities of scale-up. Respondents asserted that some initiatives (such as Zambulance and waiting shelter) remained symbolic and superficial and did not address the major root-causes of poor maternal care for HIV positive women.

'It's good that we have such initiatives but to be honest, the problems in this village are deep-rooted in poverty and lack of jobs for most of the volunteers and us. So what can a poor woman like me say to influence the activities? We have not really addressed the real problems, that is why sometimes you see that we have no food in the shelters and volunteers are fewer these days"

\section{Participant 37}

\subsection{Discussion}

In this chapter, we assessed the ways through which community mobilization via its three components (peer-support, utilization of indigenous resources and community-involvement) promote or hinder maternal care for HIV positive women in Mfuwe. Our findings suggest that Mfuwe, a community faced with a health system that has critical material, symbolic and institutional limitations, does have within its social strides several unrecognized and sometimes ignored local solutions. These local solutions have over the years formed the cornerstone of maternal health care for women living with HIV.

The mainstream narrative has traditionally reflected an embodiment of western-precipitated and 'universally optimal' solutions that usually include scaling up of 'scientific' and biomedical approaches (while ignoring local strategies and context) as a basis for improving maternal care (Choguya, 2014; Harrison, 2011). This narrative has obscured discussion on what the relevance of community mobilization has been in maternal care of HIV positive women in resource poor settings (Bolu, et al., 2007). In line with the principles of the maternal community health competence 
framework, our results indicate that building maternal health competence for HIV positive women in local settings requires formal recognition of roles played by experts as well as local actors. This means taking full cognizance of the shortcomings and strengths of both experts and local strategies while paying attention to local context. The results in this chapter show that the three components of community mobilization each have strengths and shortcomings in the context of maternal health care of HIV positive women in Mfuwe, Zambia.

\section{Peer support}

For example, peer-support was crucial in providing much needed empathetic social, psychological and emotional supportive services to HIV positive women who in most cases faced stigma due to their HIV status and sometimes suffered the negative consequences of an inefficient health system. This is in line with the findings from chapter 2 of this dissertation, in which we show that in countries heavily affected by HIV such as South Africa and Tanzania, peer support is useful in providing care and support outside the formal health system (Rotheram-Borus, et al., 2014; Kaayaa, et al., 2013; Richter, et al., 2014). Further, by engaging in dialogue with their peers, HIV positive women were able to develop agency and collectively challenge common obstacles to maternal care. Similar evidence from a randomized controlled trial in South Africa shows how HIV positive mothers rely on the support of each other to challenge stigma, discrimination, and other barriers to treatment (Richter, et al., 2014). At the same time, although peer support generally seems to be a useful maternal health care enabler, it can also act as a negative force. Particularly, it was evident from some respondents that by engaging with peers, several health-inhibiting and harmful sexual and reproductive misconceptions, superstition and stigma were reinforced. This inevitably highlights the challenge that characterizes common practice in public health circles where maternal health initiatives such as peer-support are viewed as a binary (either bad or good). This practice obscures variety. Peer-support, especially if aimed at maternal care of HIV positive women can simultaneously be a force for good and bad. Although for most women the advantages of peersupport seem to outweigh the disadvantages, ignoring its shortcomings would however be counterproductive. Campbell and Cornish (2012) come to the same conclusion from a study in India and South Africa. 


\section{Indigenous resources}

Another fact worth noting from our findings is how indigenous resources particularly TBAs are characterized in Zambia, how they are used to solve local maternal care challenges and their resulting shortcomings. In the absence of a well-functioning professional health care system, HIV positive women have continued to rely on historically and culturally established local assets such as TBAs which have been passed on from generation to generation (Choguya, 2014; Banda, 2015; Sialubanje, et al., 2015). TBAs are characterized as useful by HIV positive women in the provision of 'soft services' that include treatment-adherence-support, provision of maternal health information, challenging stigma, discrimination and patriarchy, logistical support, nutritional and referral services to facilities. This finding is line with results from chapter 2 of the dissertation in which it was shown that 'TBAs were responsible for 'lighter' forms of support to women with HIV (Perez, et al., 2008). Other studies from within the SSA region also come to the same conclusion (Richter, et al., 2014; Ana, 2011; Balogun \& Odeyemi, 2010; Kayombo, 2013; Gill, et al., 2011; Cheelo, et al., 2016). It is also clear that TBAs have limitations reflected in their lack of appropriate skills and resources to tackle pregnancy complications and effectively promote PMTCT. This is why the government of Zambia has outlawed their practice (Sialubanje, et al., 2015). The action by the government of Zambia (which is influenced by the World Health Organization (WHO) policy on TBAs), however, may worsen rather than improve the condition of the local people of Mfuwe as professional health care is either lacking or riddled with limitations (Sialubanje, et al., 2015). Two other studies from Zambia (Cheelo, et al., 2016; Sialubanje, et al., 2015) on TBAs raise similar sentiments. Further still, other studies from different parts of SSA have shown that TBAs form a useful link of care in African societies, thus there is more to benefit from relying on them rather than excluding them from the line of care (Kayombo, 2013; Ana, 2011).

\section{Community involvement}

Further, we showed how local people in Zambia characterize and operationalize community involvement in their effort to promote maternal care. Here we established what the community health competency promulgates; which is that local communities often possess useful portfolios which need to be scaled up through horizontal collaboration with experts. Specifically, communities in Mfuwe, Zambia were actively involved and collaborated with external professionals to promote 
maternal health care of HIV positive women mainly through two distinctive strategies, namely the "Zambambulance" initiative and the 'waiting shelter' initiative. This strategy was important in ensuring that HIV positive women who would have otherwise given birth at home were attendant to by professionals in order to promote PMTCT. The two initiatives also had significant local-buy-in and were considered highly useful by the locals. This observation is in consonance with what Renedo \& Jovchelovitch (2007) and Campbell and Cornish (2012) in their studies on African communities show, which is that by collaborating and "strengthening indigenous responses", there is increased propensity for HIV positive women to embrace the potential benefits of a given maternal health care strategy. This finding is also in line with results from chapter 2 of this dissertation in which it was demonstrated that collaboration increases uptake of maternal health services. This therefore calls for enhanced recognition on the part of policy makers, NGOs and other stake-holders of the role that partnership plays in promoting enhanced maternal care of HIV positive women. That notwithstanding, in the process of promoting partnership with locals, certain risks seem eminent as expressed by our respondents. There is always the risk of reinforcing tokenism and establishing a base for the struggle of powers between the more-powerful voices (usually experts) and the weaker voices (usually local uneducated villagers). Such events as Campbell and Cornish (2012) observe usually result in situations where more powerful factions invariably dictate the direction of initiatives (in a gaze of partnership) whereas the poor and vulnerable local people are used only as 'rubberstamps'.

This means that it is imperative to achieve an optimal stage where expert and indigenous factions can mutually dialogue, and proactively and consciously develop spaces for consensualization in promoting partnership for purposes of improving maternal care of HIV positive (Campbell \& Cornish, 2010; Cornish, et al., 2014). This is key in assuring local buy-in, sustainability and success of a maternal health care initiative. Active involvement of locals provides the momentum and agency for local people to embrace and define in their own terms what is important to them regarding maternal care (Muzyamba, et al., 2015; Lehmann, et al., 2009; Mbiydzenyuy, 2012). This process effectively shades light on what strategies are locally feasible, much to the benefit of local HIV positive women. Jovchelovitch (2012) states that it is folly to ignore local strengths and partnerships, an action which she intimates has become a toxic cornerstone of mainstream maternal health care strategies. Externally-defined local people's needs and implementation strategies take away their agency to change their situation and discourages ownership of initiatives. This does not however mean that external support is irrelevant; on the contrary, external support is important in several 
ways (political support, transfer of skills and knowledge etc.). Local communities are faced with limitations (as is external support); this is why we contend that in a quest to improve maternal health care of HIV positive women, horizontal collaboration and strengthening of indigenous responses rather than obscuring them seems more profitable. This further supports and strengthens the community health competence's claim that there is more to benefit from building on local strategies through collaboration rather than obscuring them.

\section{A synthesized view of all the three components}

Drawing inferences from the manner in which the three components of community mobilization promote/hinder enhancement of maternal care of HIV positive women, it appears that the change process is neither linear nor replicable across different social settings. It embodies "variety, complexity and fragmentation" (Campbell, 2014, p. 6). Social settings in which HIV positive women reside differ across time and space, and that is why the act of uncritically adopting grand conclusions of maternal health initiatives with the aim of replication seems disingenuous. For example, just because the "Zambulance" initiative works in Zambia does not necessarily mean it will work in other countries as well. This is in line with what Foucault $(1980,1982)$ postulates, which is that pathways for social transformation across time and space are complex, and failure to take into account this complexity is counterproductive. It is because of this observation that community mobilization's main principle of promoting "a pastiche of context-specific tactics and homegrown strategies" as a way of promoting maternal care of HIV positive women seems valuable (Campbell, 2014, p. 8). This means that the understanding and application of community mobilization through its three components prioritizes social contexts (which offer different opportunities and challenges for maternal care of HIV positive women) stands in contradiction with mainstream's characterization of maternal health initiatives as 'one-size-fits-all'.

All in all, our findings are in line with what the community health competence framework stands for. Specifically, the stakeholders interviewed in this chapter believe that public health initiatives that genuinely allow for local participation and reliance on indigenous portfolios are likely to promote sustainable access to maternal health care. As suggested by the stakeholders in this chapter, the core principles of the community health competence produce social spaces for brainstorming on 
strategies that are practical and feasible by relying on already existing community resources and collaboration with experts. Consequently, through the community health competence framework, our chapter confirms the benefits of paying attention to diverse ways in which community mobilization hinders and promotes maternal health of HIV positive women in a very contextspecific way. This is particularly important for policy as it will allow for scale-up on strategies that promote care for HIV positive women and mitigation for those that hinder maternal care.

\section{Limitations}

We also acknowledge some potential limitations associated with this chapter. Firstly, our findings are based only on the views of HIV positive women residing in one village based in one, out of the ten provinces of Zambia. This fact limits the variety of experiences with community mobilization in Zambia in general. However, we argue that this chapter provides useful insights and the first step in understanding the different ways community mobilization hinders/promotes maternal care of HIV positive women in resource-poor settings.

\section{Conclusion}

We set out to assess the ways through which community mobilization via its three components promotes/hinders maternal care of HIV positive women in Mfuwe, Zambia. Given the material, symbolic and institutional limitations that define the health system in Zambia, community mobilization (through its three components) was a dominant feature in maternal health care response of HIV positive women in rural Zambia. Specifically, it was shown that community mobilization was largely and often characterized as a force for good (e.g. providing support, improving access to maternal care etc.) and sometimes for bad (e.g. reinforced harmful misconceptions, superstition and stigma). In line with the community health competence, our evidence suggests that community mobilization needs to be factored into maternal health care policies for HIV positive women in resource poor settings either to optimize their potential benefits or to minimize their potential harm.

Within their social fabrics, resource-poor communities often contain unrecognized and sometimes ignored local strategies which are contextually-feasible and have been used for generations to promote maternal care for HIV positive women. Ignoring these portfolios or pathologizing local 
knowledge systems may be self-defeating. It is also worth noting that the different components of community mobilization have different effects on maternal care efforts of HIV positive women in different social settings, which is something that needs to be accounted for. Further, we argue that the maternal care change-process for HIV positive women is neither linear nor replicable across time and space. It is characterized by "variety, complexity and fragmentation" (Campbell, 2014, p. 6). This type of change-process consequently questions the legitimacy of common practice in mainstream public health circles to 'replicate' and establish 'one-size-fits-all' maternal initiatives for HIV positive women based in different settings. This act of embracing these uncritical grandconclusions and 'replicable' maternal health strategies is unrewarding in the real world. This is why we argue that embracing the complexity, variety and fragmentation by relaying on community mobilization which prioritizes "a pastiche of context-specific tactics and homegrown strategies" as a way of promoting maternal care of HIV positive women seems valuable (Campbell, 2014, p. 8) 


\section{Chapter 4}

The relevance of TBAs to women living with HIV in resource poor settings: The case of Mfuwe, Zambia

This chapter draws upon:

Muzyamba, C., Groot, W., Tomini, S.M, \& Pavlova, M. (2017). The usefulness of traditional birth attendants to women living with HIV in resource-poor settings: the case of Mfuwe, Zambia. BMC Tropical Medicine and Health, 45(37). 


\begin{abstract}
Although there is increased attention on the role of TBAs in maternal care, most of the research has mainly focused on providing evidence of the relevance of TBAs to women in general without a specific focus on women who are HIV positive (despite them being most vulnerable). Therefore, the aim of this chapter is to fill this gap by assessing the relevance of TBAs to women living with HIV in resource poor settings by using Zambia as a case study.
\end{abstract}

Our data collection consisted of two FGDs, one involving HIV positive women utilizing TBAs and the other with women not utilizing TBAs. Additionally, in-depth interviews were conducted with TBAs and health workers. Thematic analysis was used to analyze the data.

In general, women living with HIV positively characterized the services of TBAs. In the face of an inefficient health system, TBAs were seen to be useful in providing efficient, cheap and quality care, counselling, referral and logistical support, including treatment-adherence support.

In Zambia, TBAs and professional care are not mutually exclusive but complementary. There is no doubt that HIV positive women need professionals to handle complications and offer antiretroviral treatment to ensure PMTCT. However, additional "soft" services offered by TBAs are equally important in the promotion of maternal health care for HIV positive women. Thus, it seems there is more to gain by systematically allowing TBAs work alongside professionals in a well-coordinated and complementary manner. 


\subsection{Background}

In SSA, questions of who should assist during childbirth, as well as where and under what circumstances childbirth should take place have long been debated (Crowe, et al., 2012). Central to this debate is the role that TBAs should and could play during this process. The WHO defines TBAs as individuals within the community who assist mothers in maternal care and have learned their skills through apprenticeship which mostly involves informal training on how to take care of pregnant women, conduct deliveries and provide postnatal services (WHO, 2013; Mbiydzenyuy, 2012).

As shown chapter 3 of this dissertation, including emerging research work from Zambia (Cheelo, et al., 2016; Sialubanje, et al., 2015), scholars remain divided on the usefulness of TBAs especially for women with HIV who have extra needs such as antiretroviral treatment to ensure PMTCT. On one hand, there is a strand of scholars (Harrison, 2011) who argue that TBAs lack the necessary knowledge and skills to promote maternal health in women with HIV. This narrative by TBAopponents has dominated the maternal health discourse in countries like Zambia as epitomized by the transposition of this policy into national maternal health policy (which emphasizes institutionalcare over TBAs) (USAID, 2008; Family-Care-International, 2013; Cheelo, et al., 2016).

On the other hand, another strand of scholars (Ana, 2011; Bergstrom \& Goodburn, 2001) believes that TBAs are indispensable in resource-poor settings like Zambia, especially considering the fact that in such areas, health-facilities are remotely located, poorly-staffed, poorly-equipped, overcrowded and inaccessible. This makes TBAs the only feasible, practical and accessible source of maternal health care. Some scholars emphasize this point by suggesting that any attempt to abandon TBAs in resource-poor settings creates a danger of wiping out the only available source of care (Choguya, 2014; Bergstrom \& Goodburn, 2001; Ana, 2011; Cheelo, et al., 2016). However, questions on whether TBAs can be relevant to women living with HIV in resource-poor settings remain unanswered. Therefore, the aim of this chapter is to help fill this gap by assessing the relevance of TBAs to women living with HIV in resource poor settings by using Mfuwe, Zambia as a case study.

As highlighted in chapter 1 of the dissertation, Mfuwe, a village located in Mambwe district of the eastern province of Zambia is a good case study because of its high maternal mortality, HIV and poverty rates. 
Framework

To achieve the aims of this chapter, we make use of the Public Value framework. The Public Value framework is an analytical framework which allows public health scholars to assess the usefulness of different public health services (Kelly, et al., 2012). It is premised on the idea that the usefulness of a given public health care service should be understood from the quality, access, efficiency and cost of the service (Mahdon, 2006). More specifically, quality in health care is viewed as the degree to which a given health service responds to, and satisfies the needs of the recipient (Gupta \& Rokade, 2016); whereas access is seen as the existence of the opportunity to obtain a given health care service (Gulliford, et al., 2002; Kelly, et al., 2012). Efficiency on the other hand is seen as the ability of a given health service to effectively respond to, and deliver upon the needs of patients (Hussey, et al., 2009), whereas cost is viewed from the affordability of the service by the recipient (Gawande, et al., 2009). In this chapter, we use this framework as a heuristics device guiding our analysis and presentation of results. Specifically, our thematic analysis of the data is centered on quality, access, efficiency and cost of TBAs services to women with HIV. The framework allows us to assess stakeholder's understanding and characterization of the usefulness of TBAs on the basis of the four aspects of the framework. The framework also guides our presentation of results (see table 4.2).

\subsection{Methods}

\section{Ethical clearance}

We obtained ethical clearance from the National Health Research Authority of Zambia, and from the Zambian ERES CONVERGE IRB (see appendix A). Other than that, informed consent was sought from the participants before participation (See appendix B). Further, participants were informed of their right to discontinue their participation at any point should they wish to do so.

\section{Sampling}

We selected our sample from Mfuwe (see chapter 1 for a thorough description of Mfuwe) through purposive and convenient sampling techniques. The participants were drawn from different parts of Mfuwe. In general, participants were drawn from all the 6 settlements within Mfuwe (Kuyenda, KwaChindeni, Chamilandu, kwaBilimungwe, Tafika and kwaKaingo). Our sample was divided into 4 sub-groups. These groups included a) HIV positive women who had only used TBAs during their 
last pregnancy, b) HIV positive women who had only used professional care as opposed to TBAs during their last pregnancy, c) TBAs and d) Health workers. The reason for this division was to increase the variety of responses.

Recruitment and rationale for group A: HIV positive women who had only used TB As during their last pregnancy

In recruiting our participants, we relied on the help and network of the local NGO CIDRZ which had contact with several people living with HIV in the area due to its work on HIV advocacy and support. The NGO helped us establish contact with a number of women who were HIV positive. From this group, we purposively selected those who stated that throughout their last pregnancy, they only used TBAs. On the basis of availability and willingness to participate, we selected a total of 12 participants. The 12 constituted our FGD part A. The participants ranged from 19 to 41 years of age. They also varied in educational level, employment and marital status (see table 4.1). The rationale behind our selection of this group was to allow us investigate the reasons why they chose to use only TBAs during their last pregnancy and to what extent the services of TBAs were useful to them.

Recruitment and rationale for group B: HIV positive women who used only professional care as opposed to TBAs during their last pregnancy

A similar strategy as above was followed in recruiting this group. We were put in contact with women living with HIV by CIDRZ. From this group, we selected those who stated that they had never used TBAs (only professional health workers) during their last pregnancy. On the basis of availability and willingness to participate, we selected a total of 11 participants. The 11 constituted our FGD part B. This group consisted of women aged 18 to 40 years of age. The participants also varied in terms of educational level, marital and employment status (See table 4.1). The rationale behind recruiting this group was for us to understand their reasons for avoiding TBAs including their perspectives and attitude towards TBAs. Their perspectives helped enrich our understanding on how TBAs are characterized in Mfuwe by those who avoid them. 
TBAs were recruited through the help of 3 local headmen. We got in touch with 3 different headmen who had knowledge of activities of their subjects including TBAs in the area. We then made contact with several TBAs and only 8 responded positively and accepted to participate in our study. The 8 TBAs constituted group C (see table 4.1). The TBAs were later interviewed individually. The rationale behind recruiting this group was to gain deeper understanding of the services that TBAs provide and how they characterize the usefulness of their services to HIV positive mothers. It was also necessary to understand their limitations in the context of Mfuwe.

\section{Recruitment and rationale for group D: Health workers}

In recruiting health workers, we first made contact with the resident physician at Kamoto hospital in Mfuwe. The resident physician then put us in contact with other health workers within the hospital. We then requested the participation of the health workers. Based on availability and willingness to participate, we were able to recruit 9 health workers who were later interviewed.

Summary of sociodemographic characteristics of respondents

Table 4:1 below summarizes key baseline demographic features of our participants. As can be seen, our participants varied in social demographic characteristics. For example, the age ranged from 18 to 63 years with the majority of them being in their twenties and thirties. In terms of education attainment, the range was from 'no education at all' to 'university graduates'. A substantial number of them had acquired primary education. The number of married and unmarried women was comparable. Similarly, the number of women in employment was somewhat comparable to that of the unemployed. 
Table 4.1 Participants' demographics

\begin{tabular}{|c|c|c|c|c|}
\hline ID & Age & Education Level & Employment status & Marital status \\
\hline \multicolumn{5}{|c|}{ Women who had accessed services of TBAs during their maternity } \\
\hline 1 & 25 & Secondary education & employed & Widowed \\
\hline 2 & 23 & Primary education & Unemployed & Married \\
\hline 3 & 41 & No education & employed & Divorced \\
\hline 4 & 33 & No education & unemployed & Married \\
\hline 5 & 19 & Vocational Education & Employed & Married \\
\hline 6 & 33 & Primary Education & Employed & Widowed \\
\hline 7 & 26 & No education & Employed & Not married \\
\hline 8 & 20 & Primary education & Unemployed & Not married \\
\hline 9 & 22 & Secondary Education & Employed & Married \\
\hline 10 & 26 & Primary Education & Unemployed & married \\
\hline 11 & 40 & No Education & Unemployed & married \\
\hline 12 & 38 & Secondary Education & Unemployed & Married \\
\hline \multicolumn{5}{|c|}{ Women who had never accessed services of TBAs during their maternity } \\
\hline 13 & 27 & Secondary Education & Employed & Married \\
\hline 14 & 24 & Vocational Training & Unemployed & Married \\
\hline 15 & 18 & Secondary Education & Unemployed & Married \\
\hline 16 & 34 & Primary Education & Unemployed & Married \\
\hline 17 & 40 & No Education & Employed & Widowed \\
\hline 18 & 30 & Vocational Training & Unemployed & Married \\
\hline 19 & 27 & No Education & Unemployed & Not Married \\
\hline 20 & 23 & Primary Education & Employed & Not Married \\
\hline 21 & 22 & Secondary Education & Employed & Widowed \\
\hline 22 & 29 & No Education & Unemployed & Not Married \\
\hline 23 & 33 & Secondary Education & Employed & Married \\
\hline & AGE & Education Level & Years of Practice & \\
\hline \multicolumn{5}{|c|}{ Traditional Birth Attendant } \\
\hline 24 & 46 & Vocational training & 22 & \\
\hline 25 & 56 & Vocational Training & 19 & \\
\hline 26 & 48 & Vocational training & 18 & \\
\hline 27 & 39 & Vocational Training & 11 & \\
\hline 28 & 57 & Vocational Training & 26 & \\
\hline 29 & 53 & Vocational Training & 20 & \\
\hline 30 & 63 & Secondary Education & 30 & \\
\hline 31 & 55 & Vocational Training & 27 & \\
\hline 32 & 36 & Vocational training & 4 & \\
\hline \multicolumn{5}{|c|}{ Medical Professionals } \\
\hline 33 & 48 & University Education & 20 & \\
\hline 34 & 60 & University Education & 33 & \\
\hline 35 & 57 & University Education & 30 & \\
\hline 36 & 46 & University Education & 17 & \\
\hline 37 & 53 & University Education & 24 & \\
\hline 38 & 33 & University Education & 7 & \\
\hline 39 & 26 & University Education & 3 & \\
\hline 40 & 28 & University Education & 4 & \\
\hline
\end{tabular}




\section{Data collection}

The data collection consisted of FGDs (for group A and B), semi structured interviews for (C and D). The FGDs (both for group A and B) were each separately held at CIDRZ premises in Mfuwe. Each of the FGDs lasted an average of 90 minutes. All FGDs were conducted in Chichewa (the local language) and English were possible. Topic guides were used during the FGDs (See appendix F for topic guide for group $A$ and appendix $G$ for topic guide for group B). Interviews for group C (TBAs) on the other hand were conducted at the house of each of the TBAs (see appendix H for questionnaire). These interviews lasted an average of 30 minutes. The interviews were also conducted in Chichewa (the local language) and English where possible. Interviews for group D (health workers) were all held at Kamoto hospital in Mfuwe. These interviews lasted an average of 30 minutes (see appendix I for the questionnaire). The interviews were mostly conducted in English language and Chichewa was used were necessary. All the FGDs and interviews were digitally recorded and later transcribed and translated to English.

Data analysis

We used NVivo as a software tool to conduct thematic analysis. Thematic analysis was chosen because it effectively allows the researcher to neatly pinpoint, examine and describe phenomenon by use of themes which systematically elucidate the content of and give meaning to the data (Braun \& Clarke, 2006). The analysis was based on the Public Value framework. This means that a network of our findings was clustered around the following themes quality, access, efficiency and cost of care (See table 4.2). These 6 themes served as global themes in our thematic analysis. We then clustered 32 organizing themes around them. The 32 organizing themes elucidated the different ways TBAs were useful or not useful to our respondents.

\subsection{Results}

Table 4:2 summarizes key findings from our study on the basis of the Public Value framework. A thorough explanation of these findings is given below. 
Table 4.2 Summary of qualitative results

\begin{tabular}{|c|c|c|c|}
\hline $\begin{array}{l}\text { Respondent } \\
\text { Group }\end{array}$ & $\begin{array}{l}\text { Global } \\
\text { Theme }\end{array}$ & $\begin{array}{l}\text { Organizing } \\
\text { Theme }\end{array}$ & Basic Findings from the FGDs and Interviews \\
\hline \multirow{8}{*}{$\begin{array}{l}\text { Characterization } \\
\text { of TBAs by } \\
\text { HIV+ women } \\
\text { who had } \\
\text { accessed TBAs }\end{array}$} & \multirow{2}{*}{$\begin{array}{l}\text { Quality of } \\
\text { care }\end{array}$} & Quality of care & $\begin{array}{l}\text { - TBAs provide personalized care } \\
\text { - TBAs provide continuous care from antenatal, labor and postnatal } \\
\text { - TBAs Help in promoting adherence to treatment } \\
\text { - Provided supportive logistic and services }\end{array}$ \\
\hline & & Limitations in quality & $\begin{array}{l}\text { - Lack of skills to handle complications } \\
\text { - Lack of medical supplies and equipment to prevent mother to child } \\
\text { transmission }\end{array}$ \\
\hline & \multirow[t]{2}{*}{ Efficiency } & Efficiency & $\begin{array}{l}\text { - Provided psychological, emotional and economic support } \\
\text { - Referred and facilitated transportation to facilities } \\
\text { - TBAs work to end stigma, discrimination and patriarchy through } \\
\text { advocacy } \\
\text { Using advocacy to challenge structural drivers to poor maternal health } \\
\text { outcomes e.g. stigma, discrimination and patriarchy }\end{array}$ \\
\hline & & Limitations in efficiency & - Lack of advanced Medical equipment and supplies \\
\hline & \multirow[t]{2}{*}{ Cost } & Affordability & $\begin{array}{l}\text { - Were cheaper and in some cases free } \\
\text { - Payment or token of appreciation was not mandatory }\end{array}$ \\
\hline & & Limitations in affordability & - There was much barriers to cost \\
\hline & \multirow[t]{2}{*}{ Access } & Access & $\begin{array}{l}\text { - Easily Accessible } \\
\text { - Lives within the community } \\
\text { - Always available to provides care from antenatal to postnatal }\end{array}$ \\
\hline & & Limitations to access & - There was significant barriers access \\
\hline \multirow{8}{*}{$\begin{array}{l}\text { Characterization } \\
\text { of TBAs by } \\
\text { HIV+ women } \\
\text { who had never } \\
\text { accessed TBAs }\end{array}$} & \multirow[t]{2}{*}{$\begin{array}{l}\text { Quality of } \\
\text { care }\end{array}$} & Quality of care & $\begin{array}{l}\text { - Less verbally and physically abusive than professionals in facilities } \\
\text { - Provision of personalized care } \\
\text { - More guaranteed support from antenatal until postpartum } \\
\text { - Do provide resources and food } \\
\text { - More friendly and caring than facility-based care }\end{array}$ \\
\hline & & Limitations in quality & $\begin{array}{l}\text { - Professionals have more knowledge and skills to handle complications } \\
\text { than trained TBAs } \\
\text { - Professionals have access to equipment and medical supplies that can } \\
\text { deal with HIV vulnerability during pregnancy but TBAs don't }\end{array}$ \\
\hline & \multirow{2}{*}{ Efficiency } & Efficiency & - TBAs mostly viewed as inefficient \\
\hline & & Limitations in efficiency & $\begin{array}{l}\text { - TBAs cannot Help in PMTCT } \\
\text { - TBAs cannot Help Easily conduct HIV tests } \\
\text { - TBAs cannot Help in the provision of ARVs } \\
\text { - TBAs cannot Help in conducting caesarean births }\end{array}$ \\
\hline & \multirow[t]{2}{*}{ Cost } & Affordability & $\begin{array}{l}\text { - TBAs are cheaper than institutions where they require women to pay } \\
\text { clinical fees } \\
\text {-TBAs are cheaper as they don't require the patient to buy her own bucket, } \\
\text { delivery bugs }\end{array}$ \\
\hline & & Limitations in affordability & - There was much limitation on the basis of cost \\
\hline & \multirow[t]{2}{*}{ Access } & Access & $\begin{array}{l}\text { - Always available when called upon } \\
\text { - Follow the patients to their home }\end{array}$ \\
\hline & & Limitations to access & - There was much limitation on the basis of access \\
\hline \multirow{2}{*}{$\begin{array}{l}\text { Characterization } \\
\text { of TBAs by } \\
\text { TBAs }\end{array}$} & \multirow[t]{2}{*}{$\begin{array}{l}\text { Quality of } \\
\text { care }\end{array}$} & Quality of care & $\begin{array}{l}\text { - Provide pragmatic services in the form of psychological and emotional } \\
\text { support } \\
\text { - Provide adherence-to-treatment support } \\
\text { - Provide useful maternal health information } \\
\text { - Help in providing priority attention to HIV positive women upon } \\
\text { recommendation at the facility }\end{array}$ \\
\hline & & Limitations in quality & $\begin{array}{l}\text { - Limitation in skills } \\
\text { - Lack access to medical supplies and equipment }\end{array}$ \\
\hline
\end{tabular}




\begin{tabular}{|c|c|c|c|}
\hline $\begin{array}{l}\text { Respondent } \\
\text { Group }\end{array}$ & $\begin{array}{l}\text { Global } \\
\text { Theme }\end{array}$ & $\begin{array}{c}\text { Organizing } \\
\text { Theme }\end{array}$ & Basic Findings from the FGDs and Interviews \\
\hline & \multirow{2}{*}{ Efficiency } & Efficiency & $\begin{array}{l}\text { - Protection from domestic violence and abuse } \\
\text { - Provide useful information regarding maternal health promotion and } \\
\text { nutrition } \\
\text { - Provide transportation were possible to facilities } \\
\text { - Help in providing priority attention to HIV positive women upon } \\
\text { recommendation at the facility }\end{array}$ \\
\hline & & Limitations in efficiency & $\begin{array}{l}\text { - TBAs did not think that they had limitations in terms of efficiency. } \\
\text { However, } \\
\text { - TBAs felt that the government policy (to recommend only facility-based } \\
\text { care) creates cooperation problems with professionals, obscures training } \\
\text { opportunities for TBAs }\end{array}$ \\
\hline & \multirow[t]{2}{*}{ Cost } & Affordability & $\begin{array}{l}\text { - Cheap } \\
\text { - No fees required }\end{array}$ \\
\hline & & Limitations in affordability & - This limitation did not seem to apply to TBAs \\
\hline & \multirow[t]{2}{*}{ Access } & Access & $\begin{array}{l}\text { - Readily available to communities } \\
\text { - Provide services to everyone include those who would have otherwise } \\
\text { been left unattended to } \\
\text { - They view their work as a civic duty to the community } \\
\text { - Provide transportation were possible to facilities } \\
\text { - Help in providing priority attention to HIV positive women upon } \\
\text { recommendation at the facility }\end{array}$ \\
\hline & & Limitations to access & - This limitation did not seem to apply to TBAs \\
\hline \multirow{8}{*}{$\begin{array}{l}\text { Professional's } \\
\text { characterization } \\
\text { of TBAs }\end{array}$} & \multirow[b]{2}{*}{$\begin{array}{l}\text { Quality of } \\
\text { care }\end{array}$} & Quality of care & $\begin{array}{l}\text { - Can provide soft-services e.g psychological and emotional support } \\
\text { including treatment-adherence support } \\
\text { - Provision of referrals services }\end{array}$ \\
\hline & & Limitations in quality & $\begin{array}{l}\text { - As opposed to TBAs, professionals can conduct completed procedures } \\
\text { such as caesarean births } \\
\text { - As opposed to TBAs, professionals can effectively handle complications } \\
\text { - Have access to life-serving medical equipment used to conduct } \\
\text { complicated operations }\end{array}$ \\
\hline & \multirow{2}{*}{ Cost } & Affordability & More affordable than institutions \\
\hline & & Limitations in affordability & - They thought TBAs had no barriers in as a result of costs \\
\hline & \multirow{2}{*}{ Efficiency } & Efficiency & - They thought TBAs lacked efficiency \\
\hline & & Limitations in efficiency & Inadequate funding to cooperation between TBAs and professionals \\
\hline & \multirow[b]{2}{*}{ Access } & Access & - TBAs are easily accessible \\
\hline & & Limitations to access & $\begin{array}{l}\text { - Current government policy makes it difficult to access TBAs } \\
\text { - Policy frustrates cooperation between professionals and TBAs } \\
\text { - Counterproductive government policy on TBAs } \\
\text { - Creates barriers in accessing the most vulnerable women in remote areas }\end{array}$ \\
\hline
\end{tabular}


Women who accessed services of TBAs

Although the experience with TBAs varied among these women, we observed no major differences in opinions on the basis of age, marital status and education level. Looking at the results in terms of access, efficiency, quality and cost; our participants summed up benefits of using TBAs by stating that TBAs were easily accessible, cheaper than institutional care, provided support which included referrals and transportation to facilities, and treatment adherence support. Almost half of the participants from this group intimated that TBAs were involved in advocacy work to challenge stigma, discrimination and patriarchy. They argued that this particular action from TBAs was especially important because their HIV status made them susceptible to stigma and discrimination in their communities. In the words of one of the participants:

"There is still this stigma that is very bad and can cause so much pain. But you see, TBAs have been going round the village raising awareness about HIV and how stigma and discrimination is not good especially for us HIV positive pregnant women."

Participant: 7

Despite the largely positive characterization of their experiences with TBAs, some participants were cognizant of the fact that TBAs did not provide efficient services. TBAs lacked technical skills to handle complications. Our respondents felt that most of the complications that arose during the process of using TBAs were poorly attended to by TBAs because they lacked technical knowhow, equipment and necessary drugs. They highlighted how such complications would have easily been handled by trained personnel. Women in this category also questioned TBAs ability to perfectly handle, and provide accurate information on utilization of ARVs.

"People like us (who are HIV positive) always need to constantly take medication (antiretroviral therapy) and have cesarean births and for such, I think doctors are more helpful and this is what they are meant for"

Participant: 2 
Women who used professional care (instead of TBAs)

Although HIV positive women who never utilized TBAs also had varied responses, in general, most of them were critical of TBAs particularly questioning the efficiency and quality of care. Considering the vulnerability that comes with being HIV positive, TBAs were considered to be a risky option by these women. Their arguments centered on the idea that TBAs were not able to give accurate advice to women with HIV regarding specific complications that may arise during pregnancy. It is for this reason that they preferred professional care over TBAs. They also stated how TBAs lacked advanced knowledge on ARVs and correctly establishing the CD4 counts. This was necessary in maintaining good health and promotion of PMTCT during pregnancy. It is for this reason that they chose professional care over TBAs. However, in as much as they praised professional-care, these women remained critical of the logistical and economic difficulties involved in accessing professional-care in health facilities.

"Imagine if I experience some difficulties of whatever kind, do you think the TBA will know exactly what is wrong with me? Let alone give proper advice? Being HIV positive means that on a daily basis you need professional advice but I am not sure if TBAs can do this."

Participant: 13

"I also agree that going to facilities is really expensive and very difficult. I only managed because my partner owns a motor-bike, so imagine women without such options"

Participant: 14

Although the majority of the women who gave birth in facilities praised facility-based care, some of them criticized professionals for exhibiting poor quality care reflected in the form of "bad attitude". These women stated that they were neglected and abused by medical practitioners in health facilities. Specifically, three of them accused professionals of verbally and physically abusing them during labor.

"I was left alone without any attention when my water broke. It was in the night and the nurses were busy elsewhere. They were not present"

Participant: 16 
"They shouted at me and sometimes slapped me for not doing what they wanted me to do. I understand that they work under very difficult conditions too, but I think this is the job they signed up for and as such, they are required to be nicer and give very good services to their patients..."

\section{Participant: 18}

Traditional Birth Attendants (TBAs)

TBAs on the other hand stated that contrary to some assertions, they were responsible for providing quality, cheap and readily available care. In the same vain, TBAs also highlighted some of their limitations that could have prevented effective and good quality care. Specifically, they pointed to their inability to efficiently deal with complications that arise during pregnancy. However, in their defense, they claimed that their functions were often misunderstood and misrepresented by most people who usually accused them of duplicating medical professionals' roles. In so far as HIV positive women were concerned, TBAs categorically distinguished their services from professionalcare by highlighting that their functions were only limited to providing "soft services" (such as treatment-adherence support, nutritional support, counselling, psychological support, logistical support and referrals to facilities). They felt that their responsibilities and functions did not include surgical procedures. TBAs also pointed out that their services were complementary and not substitutional to those of professional-care-givers in health facilities.

"This is where we come in. we use the Zambulance to transport these HIV positive women to the clinics for specialized treatment. So our services are very pragmatic. We have been able to provide a range of services that include care during pregnancy, help with adherence in treatment, including provision of nutritional needs where possible”.

Participant: 26

"We do not duplicate the work of doctors. We do not perform cesarean procedures, this is beyond us. Our services in women with HIV are straightforward"

Participant: 28

Furthermore, TBAs also provided several examples of how in many cases they provided care to women who would have otherwise been left an unattended to due to the long distance to health 
centers, high costs and lack of staff at the health facilities. They stated that in such situations, they played an important role in provision of care to victims of a structurally inefficient health system.

Health professionals

Professional health workers in general were critical of TBAs by suggesting that services of TBAs were inefficient because TBAs lacked technical know-how. They stated how TBAs were less equipped and could not effectively respond to complications. Despite their criticism of TBAs, some of health workers acknowledged the importance of TBAs in maternal care of women with HIV in Mfuwe. Specifically, they highlighted how in the face of an inefficient health system, TBAs were useful in providing soft services such as psychological, social and logistical support.

".TBAs are the immediate belp available to women bere in Mfunve. So in most cases they are the only readily available source of help. I think there should be a way Government taps into this and officially involve them in the process of maternal care. They do provide a lot of help to HIV positive women. Most of the women who come here to the clinic are usually transported by the Zambulance organized by local TBAs. They are still a very important part of the maternal care channel. Also, when we put our patients on treatment, it's TBAs in the villages who ensure that these patients adhere to treatment because we are not physically present...."

Participant: 35

\subsection{Discussion}

In this chapter, we set out to assess the varied ways our respondents characterized the relevance of TBAs in maternal care of women living with HIV in Mfuwe, Zambia. This was done with the help of the Public Value framework which helped us assess usefulness of TBA services in terms of quality, access, efficiency and cost. Our respondents described the usefulness of TBAs in varied ways. Mostly, participants described how cheap and easily accessible TBAs were to women in Mfuwe. They also highlighted the different ways the services of TBAs were inefficient and of poor quality. 
Questions of usefulness of TBAs have long been debated as evidenced in chapter 2 and 3 of this dissertation. It is clear that TBAs still provide maternal services in areas where health systems are inefficient or absent, and it is in this context, that the usefulness of TBAs must be assessed. For example, Zambia outlawed the use of TBAs in 2010 but people in rural areas still use them (Cheelo, et al., 2016). It is for this reason that it is important to understand why TBAs are still being used and what services exactly they offer. Our findings in this chapter illustrate the main ways TBAs are considered useful in Mfuwe. Specifically, TBAs provide the following 'soft services' to women with HIV: treatment-adherence support, nutritional support, counselling, psychological support, logistical support and referrals to facilities. This means that these services form part of a pragmatic response to maternal health care in rural parts of Zambia. As other scholars (Gill, et al., 2011; Mbiydzenyuy, 2012) have pointed out elsewhere in SSA, maternal health care is a continuum which requires attention not only of medical professionals but also of TBAs (in the form of soft services). A growing body of literature (Mwai, et al., 2013) has consistently pointed out that most resource-poor settings can benefit from task-shifting through apportioning and recognizing suitable functions of TBAs. Evidence from chapter 2 and chapter 3 of this dissertation also highlights how TBAs continue to dominate maternal care in rural parts of Zambia. Further evidence from Yaunde Cameroon (Mbiydzenyuy, 2012) and from Zimbabwe (Perez, et al., 2008) demonstrates that TBAs within SSA have continued to bare a huge responsibility of care. Given the weak health systems in most parts of SSA, and especially in rural areas such as Mfuwe, TBAs have continued to provide maternal care (albeit with several limitations).

Despite the largely positive characterization of TBAs in Zambia, this chapter, including chapter 2 and 3 of the dissertation have highlighted several of their limitations. Other studies from different parts of SSA also confirm these limitations (Choguya, 2014; Balogun \& Odeyemi, 2010; Bergstrom \& Goodburn, 2001; Harrison, 2011). Particularly, they highlight that TBAs lack advanced equipment and drugs to perfectly handle illnesses and complications that may arise during pregnancy or birth. This is why there are increased calls to displace TBAs by scaling up professional care. Increasing the number of health workers in rural areas is expected to provide better care.

While calls to use only professional care instead of TBAs seem legitimate, our respondents confirmed some difficulties associated with professional care in Mfuwe. Specifically, they stated that professional care remained a more expensive option. It was also difficult for them to access 
professional care given the long distance to facilities and the lack of adequate number of staff, drugs and equipment in the facilities. This is why most of them opted to using TBAs despite their limitations. Other studies from Zambia including those from other parts of rural SSA (as evidenced by chapter 2) confirm the existence of these challenges in rural health facilities (Stekelenburg, et al., 2004; Sialubanje, et al., 2015; Sibleycorresponding \& Sipe, 2006). The said health-centers in these areas are mostly buildings lacking essential equipment, drugs and staff (Schmid, et al., 2001; Mdege, et al., 2013; Lehmann, et al., 2009). Considering this, questions of how useful TBAs can be in this context becomes necessary. Given that despite the ban on TBAs in Zambia most of the women (mostly out of necessity) still use TBAs, it seems important to find ways of incorporating TBAs in the official line of care so that they can be better regulated in their effort to complement professional health workers. This is consistent with suggestions from other scholars within SSA (Ana, 2011; Sialubanje, et al., 2015), including chapter 2 and chapter 3 of this dissertation. All these sources show that excluding TBAs from the line of care on the basis of their limitations means that opportunities to maximize their benefits and minimize their costs are effectively lost. It thus seems clear that there is much to lose when TBAs are not recognized and regulated within the line of care; as this will effectively force them to operate without any form of regulation. It can be seen that despite the Zambian government's efforts to ban TBAs and promote exclusive-institutional care, HIV positive women have continued to rely on TBAs due to structural barriers in accessing professional care in Zambia (Cheelo, et al., 2016; Banda, 2015). It seems clear from this chapter (including chapter 2 and 3) that because of the existing inefficient health system; local people characterize TBAs as useful stakeholders (despite their many limitations) in the provision of maternal health care to HIV positive women. This could serve as a basis for officially including them in the line of maternal care in order for them to complement the efforts of health professionals.

\section{Limitations}

In this chapter, we note the following potential limitations. Our findings are based only on the views of participants who were located in one of the ten provinces of Zambia, specifically in a small village of Mfuwe. Further, given that our target population is a hard-to-reach population given their HIV status and other logistical limitations, our sample size was only composed of 40 participants. This fact may have limited the variety of experiences with TBAs in Zambia in general. However, we argue 
that our study from Zambia was adequate and relevant in giving insights into the relevance of TBAs in maternal care of HIV positive women in rural settings.

\subsection{Conclusion}

This chapter shows that given the inefficient health system in Zambia, TBAs have continued to provide maternal care to women with HIV, albeit with several limitations. TBAs seem to have specialized in providing 'soft services' which include treatment-adherence support, nutritional support, counselling, psychological support, logistical support and referrals to facilities. We have shown that maternal care is not a zero-sum game, but a continuum in which both TBAs and professionals can play complementary roles. In this regard, it seems profitable for the government of Zambia to systematically integrate TBAs in maternal care of HIV positive women; doing this will ensure constant check on TBAs, improved cooperation between different stakeholders, improved access and quality of care to women. It will consequently make maternal care of HIV positive women more efficient because integrated tasks can be allocated in a well-coordinated and regulated manner. 


\section{Chapter 5}

Skilled birth attendants or TBAs? Factors associated with choice of antenatal, delivery and postnatal services between HIV+ and HIV- women in Zambia

\section{This chapter draws upon}

Muzyamba, C., Groot, W., Tomini, S.M, \& Pavlova, M. Skilled birth attendants OR TBAs? Factors associated with choice of antenatal, delivery and postnatal services between HIV + and HIV- women in Zambia; submitted for publication. 


\begin{abstract}
Countries in the developing world account for the majority of maternal deaths around the world, mainly due to their huge HIV burden. Several studies have shown that HIV positive women are more vulnerable and are more likely to die during maternity than those who are not. However, the relationship between HIV status and maternal-care-utilization is not very well understood. It is not clear whether factors associated with professional maternal care utilization during antenatal, delivery and postnatal are similar for HIV positive and HIV negative women. It is also not known whether being HIV positive has an impact on the choice of care (professional care or TBAs). Thus the aim of this chapter is to investigate the differences in factors affecting choice of care during antenatal, delivery and postnatal periods between HIV positive and HIV negative women. We also investigate the effect of HIV positive status on the utilization of professional maternal care during antenatal, delivery and postnatal.
\end{abstract}

Using the 2013-2014 ZDHS we perform two different quantitative analyses: a) Regression analysis: to identify factors associated with the likelihood of utilizing professional care during antenatal, at birth and postnatal periods. We do this for both HIV positive and negative women. b) Propensity score matching: to investigate the effect of being HIV positive on the choice of care (Professional care or TBAs)

Reasons for choosing professional care during antenatal, at birth, and postnatal between HIV positive and negative women are similar. Further, we show that although the probability of utilizing professional care for HIV positive women is slightly higher than those who are HIV negative, the difference is small. We also demonstrate that although institutional care is desirable and an ideal solution for HIV positive women, insisting on institutional care when the health facilities lack adequate trained personnel, drugs, and equipment is counterproductive. 


\subsection{Background}

Countries in the developing world account for over $99 \%$ of all maternal deaths around the world (WHO, 2013). The situation is even worse in countries like Zambia with high HIV rates (Jayachandran, et al., 2015). Research has demonstrated that this deplorable situation is exacerbated by the fact that women who are living with HIV are more susceptible to obstetric complications and opportunistic infections (WHO, 2013; Sebitloane, et al., 2009). Sebitloane et al. 2009 showed that negative maternal outcomes in HIV positive women are a result of both obstetric causes (puerperal sepsis, obstetric hemorrhage etc.) and non-obstetric causes which are mostly opportunistic infections (such as tuberculosis, tetanus, malaria etc.). In an effort to reduce the risk of mortality including PMTCT, the WHO has recommended consistent utilization of skilled maternal care services by all HIV positive women (WHO, 2010). This involves early and focused antenatal care, giving birth in a health facility under skilled supervision and use of skilled postnatal care. This is because maternal care is a continuum consisting of a process of care from conception to postpartum (Kendall, et al., 2014). Therefore, in order to reduce maternal mortality in HIV positive women, professional care should be present across all three stages (antenatal, birth and postnatal stage) (Kendall \& Danel, 2004).

There seems to be consensus among public health professionals that utilization of skilled maternal care services from the onset of pregnancy to the postnatal period reduces negative maternal health outcomes in HIV positive women. This results from the uptake of antiretroviral treatment and caesarean births, which together promote PMTCT and the health of the mother (Sebitloane, et al., 2009; Ticconi, et al., 2003). Despite this, skilled maternal health utilization has remained unsatisfactory in most parts of SSA (Kendall \& Langer, 2015). This means that the 'game-changing potential' of antiretroviral treatment aimed at radically reducing HIV-related maternal deaths is not being realized.

Despite the massive campaigns and the overwhelming evidence on the need for HIV positive women to utilize skilled maternal care, women continue to utilize TBAs (WHO, 2013; Tarekegn, et al., 2014; Bolu, et al., 2007). There are a number of studies that have indicated that HIV positive women are more vulnerable and likely to die during maternity than those who are not (Taulo, et al., 2009; Sahlua, et al., 2014). However, the relationship between HIV status and maternal health care 
utilization is understudied (Kendall \& Langer, 2015). It is not yet clear whether factors associated with professional maternal care utilization during antenatal, delivery and postnatal are similar between HIV positive and HIV negative women. It is also not yet known whether being HIV positive has an impact on whether to seek professional care or TBAs. Given the risk that comes with being HIV positive, it is expected that the propensity to seek professional care is higher for HIV positive compared to HIV negative women (Tarekegn, et al., 2014; Jayachandran, et al., 2015). However, the extent to which this is evident in Zambia is still unclear (Tarekegn, et al., 2014). Establishing this is a first step towards the formulation of effective policy aimed at promoting maternal health of the most vulnerable women (Kendall \& Langer, 2015).

The expectation is that there is a higher utilization of professional care among HIV positive women compared to HIV negative women during antenatal, birth and postnatal care (Green-top-GuidelineNo-39, 2010). This is to ensure access to life-saving antiretroviral treatment, cesarean birth and continuation of antiretroviral treatment to promote PMTCT and promote maternal health of HIV positive women who are most vulnerable (Kendall, et al., 2014; Green-top-Guideline-No-39, 2010). Thus the aim of this chapter is to a) investigate and compare factors associated with the choice of antenatal, delivery and postnatal health service between HIV positive and HIV negative women. b) Investigate the effect of HIV positive status on the utilization of professional maternal care during antenatal, delivery and postnatal period.

\subsection{Methods}

We use the 2013-2014 ZDHS. The ZDHS is a publicly available and nationally representative survey which was carried out national-wide in Zambia between 2013 and 2014. The survey was designed and carried out by the DHS team in collaboration with the Zambia Central Statistical Office (CSO), Ministry of Health $(\mathrm{MoH})$, the University of Zambia Teaching Hospital (UTH) Virology Laboratory, Department of Population Studies at the University of Zambia (UNZA) and the National Steering Committee (ZDHS, 2014, p. 2)

The survey includes women who are aged between 15-49 years. The ZDHS provides data on demographic and health indicators. The sample in the ZDHS 2013-2014 is a two-stage stratified 
cluster sample design. In the first stage, 722 Enumeration Areas (EAs) (305 in urban areas and 417 in rural areas) were selected from all the 10 provinces of Zambia. Stratification was done by dividing each of the 10 provinces into urban and rural areas resulting in 20 sampling strata. In the second stage, a complete list of households was used as a sampling frame upon which 25 households were selected for enumeration in each EA (ZDHS, 2014). It was at this stage that a representative sample of 18,052 households was finally selected.

Regarding HIV results; the HIV data were obtained by collecting blood samples during interviews from consenting participants and later testing the blood samples for HIV and then linking the sample results to the unique IDs of participants. If the respondent did not consent to testing, their HIV status was left unstated in the data and treated as missing (ZDHS, 2014). The HIV data are however not publicly available. These data were only availed after obtaining ethical clearance from the Zambia ethics board, Ministry of Health of Zambia and the ZDHS team. A confidentiality form to treat the data with strict confidentiality was signed after which the data were availed. We then linked the HIV data to the rest of the ZDHS data based on unique IDs as instructed and recommended by the ZDHS.

From the overall ZDHS data on all women (aged 15 to 49), we selected a sub-sample of women who had stated that they had given at least one birth in the last 5 years preceding the survey and were either HIV positive or negative. Women whose HIV status were not determined or did not consent to taking part in the HIV test were not included in our final sample. However, before dropping this group of respondents who had an undetermined HIV status, we provide a summary of statistics showing how the three groups (HIV positive, HIV negative and HIV-Undetermined) compare with each other. The third group was dropped because the focus of this chapter (and the entire dissertation) was on respondents whose HIV status was determined. This approach allowed us to accurately assess the influence of HIV on different maternal health aspects in Zambia, and to also compare experiences between those who have HIV and those who do not have HIV. A summary of the characteristics of the data is provided in table 5.1 below. These data enabled us to investigate the difference in maternal health care utilization (skilled delivery attendants or trained TBAs) between HIV-positive and HIV-negative women in Zambia. 
Table 5.1 Summary of characteristics (differences and similarities) between HIV positive, HIV negative and HIV-undetermined women aged 15-49 who gave birth in the last 5 years

\begin{tabular}{|c|c|c|c|c|c|c|}
\hline \multicolumn{7}{|c|}{ Anova tests } \\
\hline & & $\begin{array}{l}\text { HIV- } \\
\mathrm{N}=10,112 \\
\mathrm{M}(\mathrm{SD})\end{array}$ & $\begin{array}{l}\mathbf{H I V +} \\
\mathrm{N}=2,113 \\
\mathrm{M}(\mathrm{SD})\end{array}$ & $\begin{array}{l}\text { Undetermined } \\
\mathrm{N}=1,494 \\
\mathrm{M}(\mathrm{SD})\end{array}$ & $\mathbf{F}$ & $\begin{array}{l}\text { Posthoc test - } \\
\text { Tukey test }\end{array}$ \\
\hline Age & & $\begin{array}{l}\mathbf{2 8 . 0} \\
(9.34)\end{array}$ & $\begin{array}{l}28.9 \\
(9.32)\end{array}$ & $\begin{array}{l}27.9 \\
(8.53)\end{array}$ & $106.16^{* * *}$ & $\begin{array}{l}\text { HIV+ vs HIV_*** } \\
\text { Und' vs HIV-*** } \\
\text { Und' vs HIV+*** }\end{array}$ \\
\hline number of children & & $\begin{array}{l}\mathbf{5 . 9} \\
(2.76)\end{array}$ & $\begin{array}{l}4.8 \\
(2.79)\end{array}$ & $\begin{array}{l}5.2 \\
(2.67)\end{array}$ & $32.08 * * *$ & $\begin{array}{l}\text { HIV+ vs HIV_*** } \\
\text { Und' vs HIV_*** } \\
\text { Und' vs HIV+**** }\end{array}$ \\
\hline number of years in $\mathrm{fe}$ & mal education & $\begin{array}{l}7.8 \\
(2.12)\end{array}$ & $\begin{array}{l}7.7 \\
(2.09)\end{array}$ & $\begin{array}{l}7.7 \\
(2.05)\end{array}$ & $3.67 * *$ & $\begin{array}{l}\text { HIV+ vs HIV-*** } \\
\text { Und' vs HIV-*** } \\
\text { Und' vs HIV+*** }\end{array}$ \\
\hline \multicolumn{7}{|c|}{ Chi-square tests } \\
\hline & & HIV- & HIV+ & Undetermined & \multirow{2}{*}{\multicolumn{2}{|c|}{ Pearson chi2(2) }} \\
\hline & & $(\%)$ & $(\%)$ & $(\%)$ & & \\
\hline \multirow[t]{2}{*}{ Area of residence } & Rural & $5,359 \quad(53)$ & $1,098 \quad(51)$ & $\begin{array}{ll}777 & (52) \\
\end{array}$ & \multirow{2}{*}{\multicolumn{2}{|c|}{$252.56^{* * *}$}} \\
\hline & Urban & $4,752 \quad(47)$ & $1,098 \quad(49)$ & $717 \quad(48)$ & & \\
\hline \multirow[t]{5}{*}{ Wealth index } & Poorest & $1,742(17)$ & $374 \quad(18)$ & $254 \quad(17)$ & \multirow{5}{*}{\multicolumn{2}{|c|}{$483.34^{* * *}$}} \\
\hline & Poorer & $1,866 \quad(19)$ & $364 \quad(17)$ & $284 \quad(19)$ & & \\
\hline & Middle & $2,154 \quad(21)$ & $464 \quad(22)$ & $(22)$ & & \\
\hline & Richer & $2,053 \quad(21)$ & $467 \quad(21)$ & $(20)$ & & \\
\hline & Richest & $2,225 \quad(22)$ & $468 \quad(22)$ & $330 \quad(22)$ & & \\
\hline \multirow[t]{4}{*}{ Religion } & Catholic & $1,792 \quad(18)$ & $369 \quad(18)$ & 284 & \multirow{4}{*}{\multicolumn{2}{|c|}{5.21}} \\
\hline & Protestant & $8,209 \quad(81)$ & $1,722 \quad(82)$ & $1,195 \quad(80)$ & & \\
\hline & Muslim & $50 \quad(0.5)$ & $10 \quad(0.5)$ & $(0.5)$ & & \\
\hline & other & $(0.6)$ & $(0.6)$ & $(0.5)$ & & \\
\hline \multirow[t]{2}{*}{ Health insurance } & $\mathrm{No}$ & $9,808 \quad(97)$ & $2,066(98)$ & $1,449 \quad(97)$ & \multirow{2}{*}{\multicolumn{2}{|c|}{$17.15^{* * *}$}} \\
\hline & Yes & $303 \quad(3)$ & $46 \quad(2)$ & $45 \quad(3)$ & & \\
\hline \multirow[t]{2}{*}{ Birth by caesarean } & No & $9,576 \quad(95)$ & $1,427 \quad(67)$ & $1,359 \quad(91)$ & \multirow{2}{*}{\multicolumn{2}{|c|}{$16.20^{* * *}$}} \\
\hline & Yes & $536 \quad(5)$ & $686 \quad(33)$ & $134 \quad(9)$ & & \\
\hline \multirow{2}{*}{$\begin{array}{l}\text { Distance to health } \\
\text { facilities }\end{array}$} & Big problem & $4,348 \quad(44)$ & $795 \quad(38)$ & 598 & \multirow{2}{*}{\multicolumn{2}{|c|}{$86.88^{* * *}$}} \\
\hline & Not a big problem & $5,764 \quad(56)$ & $1,318 \quad(62)$ & $896 \quad(60)$ & & \\
\hline \multirow{2}{*}{$\begin{array}{l}\text { Drug availability at } \\
\text { health facility }\end{array}$} & Big problem & $4,142 \quad(41)$ & $586 \quad(28)$ & $\begin{array}{ll}478 & (32) \\
\end{array}$ & \multirow{2}{*}{\multicolumn{2}{|c|}{1.33}} \\
\hline & Not a big problem & $5,970 \quad(59)$ & $1,527 \quad(72)$ & $1,016 \quad(68)$ & & \\
\hline \multirow{2}{*}{$\begin{array}{l}\text { Attitude of workers } \\
\text { in health facility }\end{array}$} & Big problem & $3,369 \quad(33)$ & $549 \quad(26)$ & $\begin{array}{ll}433 & (29) \\
\end{array}$ & \multirow{2}{*}{\multicolumn{2}{|c|}{$44.67 * * *$}} \\
\hline & Not a big problem & $6,743 \quad(77)$ & $1,564 \quad(74)$ & $1,061 \quad(71)$ & & \\
\hline \multirow{2}{*}{$\begin{array}{l}\text { Choice of care } \\
\text { antenatal }\end{array}$} & TBA & $2,375 \quad(24)$ & $486 \quad(23)$ & $314 \quad(21)$ & \multirow{2}{*}{\multicolumn{2}{|c|}{$54.21 * * *$}} \\
\hline & Health professional & $7,737 \quad(76)$ & $1,527 \quad(77)$ & $1,180 \quad(79)$ & & \\
\hline \multirow{2}{*}{$\begin{array}{l}\text { Choice of care at } \\
\text { birth }\end{array}$} & TBA & $2,124 \quad(21)$ & $448 \quad(21)$ & $313 \quad(21)$ & \multirow{2}{*}{\multicolumn{2}{|c|}{2.87}} \\
\hline & Health professional & $7,989 \quad(79)$ & $1,665 \quad(79)$ & $1,181 \quad(79)$ & & \\
\hline \multirow{3}{*}{$\begin{array}{l}\text { Choice of care } \\
\text { postnatal }\end{array}$} & TBA & $2,395 \quad(24)$ & $507 \quad(24)$ & $433 \quad(22)$ & \multirow{3}{*}{\multicolumn{2}{|c|}{$67.36^{* * *}$}} \\
\hline & Health professional & $7,718 \quad(76)$ & $1,606 \quad(76)$ & $1,061 \quad(78)$ & & \\
\hline & No & $416 \quad(4)$ & $253 \quad(12)$ & $75 \quad$ (5) & & \\
\hline
\end{tabular}

\footnotetext{
${ }^{* * *} \mathrm{p}<0.01,{ }^{* *} \mathrm{p}<0.05,{ }^{*} \mathrm{p}<0.10$. Reported F-values are based on Anova tests for continuous variables and chi-squares for proportions/categorical variables.
} 
From our summary, it was evident that the mean age for women who were HIV negative, HIV positive and undetermined-status was 28,29 and 28 respectively. The mean number of children was 6 for HIV negative, 5 for HIV positive and 5 for undermined-status women. The number of years in formal education was around 8 years for all groups. In terms of area of residence, in all cases, more people resided in rural areas than they did in urban areas (between 51-53\%). The population for wealth index was almost evenly distributed across all categories; it ranged from 17-18\% for poorest, $17-19 \%$ for poorer, $21-22 \%$ for poor, $21-22 \%$ for middle, $20-21 \%$ for rich and $22 \%$ for richest. Over $80 \%$ of the women in all categories were protestants; with catholic accounting for between 18 $19 \%$ and other religions and Islam accounting for $0.5 \%$ each. In terms of health insurance, $97-98 \%$ of the population had no insurance in all categories. $5 \%$ of the women who were HIV negative had caesarean births during their last birth; the number for those with undetermined status was $9 \%$, whereas for those with HIV it was about 33\%. 44\% of HIV negative women, 38\% of HIV positive and $40 \%$ undetermined-status women stated that distance to health facility was a big problem. Attitude of health workers was a big problem to $33 \%$ of HIV negative, $26 \%$ of HIV positive and $29 \%$ for undetermined-status women. Between $76-79 \%$ of women in all categories utilized professional care during antenatal, the number was 79\% during birth and $76-78 \%$ during postnatal.

\section{Selection of explanatory variables}

For the selection of explanatory variables, we relied on previous studies on maternal health utilization (Bolu, et al., 2007; Jayachandran, et al., 2015; Tarekegn, et al., 2014), and also made use of the Andersen's behavioral model of health which holds that usage of any given health service is based on three dynamics: predisposing factors (such as socio-demographic factors), enabling factors (such as wealth, access to health insurance) and healthcare needs (chronic illnesses, functional disability etc.) (Andersen, 1995). We therefore include the following predisposing factors in our study: age, number of children, number of years in formal education, area of residence, religion, birth by cesarean, distance to health facility, drug availability in health facility, attitude of health workers. The enabling factors were wealth index and access to health insurance. While having given birth at least once in the last 5 years is seen as a proxy for the need factor.

The ZDHS includes a section on maternal health service utilization for the most recent birth. In this section, questions were asked on who attended to the women during antenatal, birth and postnatal 
periods. The options in general included: Health professional and TBAs. Therefore, we separately use this dummy variable (health professional or TBA) for all the three stages of maternal health utilization (antenatal, birth, and postnatal stage).

We undertake two different analyses: Probit analysis: to identify the factors that influenced the likelihood of utilizing professional care during antenatal, at birth and postnatal (for both HIV positive and HIV negative women). On the basis of this probit analysis, we further generated marginal effects to ascertain the probabilities of utilization of professional care during antenatal, at birth and postnatal. Propensity Score Matching: to investigate the effect of being HIV positive on choice of maternal health services between professional care and TBA during antenatal, at birth and postnatal. For this, we calculate the Average Treatment Effect on the Treated (ATT).

More specifically, Propensity Score Matching (PSM) is used to allow us to statistically formulate a control group (HIV negative women) by matching the observed characteristics of the treated participants (HIV positive women) to the control group. This is based on similar values of the propensity score (Rosenbaum, 2002). Heckman et al. (1998) define PSM as the probability of selection into the treated group, which in this case means the probability of being HIV positive. The variables we use for matching include age, educational level, area of residence, and wealth. The selection of variables was guided by theory and consensus in extant literature regarding what factors are likely to increases chances of being HIV positive (Campbell \& Mzaidume, 2002 ). It is worth noting that the "unbiased inference" arising from propensity score matching is informed by the assumption that the potential outcomes are independent of treatment assignment conditional on observable characteristics (Caliendo, et al., 2008). It is also crucial that there must exist a "commonsupport" in the propensity score distributions of participants from the treatment and control groups (Heckman, 1976).

We used Stata to estimate the ATT using the Nearest Neighbor Matching technique. This method matches individuals in the control to the treated group and then discards controls which are not selected as matches (Rosenbaum, 2002). Under the Nearest Neighbor Matching technique, the individual from the comparison group is chosen which then acts as a matching partner for a treated individual that happens to be closest in terms of the propensity score (DiPrete \& Gangl, 2004). We use the 1:1 nearest neighbor matching which selects for each individual in the treated $i$, the control 
individual with the smallest distance from the individual $i$. It is also important to note that although the 1:1 Nearest Neighbor Matching is fairly straightforward, it however has the disadvantage of discarding a large number of observations and as such, may lead to reduced power (Huber, et al., 2012).

The reliability of the estimated effect of the HIV positive status on choice of maternal care when using PSM depends on selection of observables (Caliendo, et al., 2008). We checked for the common support assumption by inspecting the propensity score distribution (Rosenbaum \& Rubin, 1983), and also relied on pstest and psmatch2 to test for the balancing property (Garrido, et al., 2014). To check the robustness of the ATT, we used two other matching methods to compare and see if our findings are consistent; these are Kernel Matching and Stratification Matching (Khanker, et al., 2010). We therefore compare with Kernel matching which uses the weighted average of the individuals in the control group as a basis for constructing a counterfactual. Kernel matching makes use of more information which allows it to lower the variance (Caliendo, et al., 2008). Stratification matching on the other hand partitions the common support into different strata and then computes the program's impact within each those strata (Khanker, et al., 2010). What goes on specifically within the strata is that the effect of the HIV positive status is established as the mean difference in outcomes (use of skilled birth attendant or TBA) between the control and the treated individuals. An average of the interval impacts which is weighted gives the overall HIV status impact by taking the share of the individuals in each interval as weights (Huber, et al., 2012).

\section{Hidden bias and sensitivity Test}

The weakness with PSM is that it does not correct for bias due to unobserved characteristics. In order to overcome this bias, conducting sensitivity analysis of hidden bias is recommended. This is achieved by establishing the level of unobserved heterogeneity that would change the statistical significance of the treatment effects (ATT) (Caliendo, et al., 2008). Therefore, we adopt the technique proposed by Altonji et al. (2005) to estimate how sensitive the estimates are to selection on unobservables. This technique links selection on observed factors to selection on unobserved factors. For this we estimate a bivariate probit model and imposed constraints on the correlation between unobserved factors that influence the probability of being in the treatment group and the outcome. 


\subsection{Results}

By the probit analysis we identify factors that are associated with the likelihood of utilizing professional care during antenatal, at birth and postnatal periods for both HIV positive and HIV negative women (see appendix J). We calculate marginal effects of the explanatory variables to ascertain the probabilities of utilization of professional care during antenatal, at birth and postnatal periods. For the results see table 5.2 below.

Table 5.2 Marginal effects of the probit models ${ }^{1}$

\begin{tabular}{|c|c|c|c|c|c|c|c|}
\hline \multirow{2}{*}{\multicolumn{2}{|c|}{$\begin{array}{l}\text { Professional care }=1 \\
T B A=0\end{array}$}} & \multicolumn{2}{|c|}{ Antenatal } & \multicolumn{2}{|c|}{ At Birth } & \multicolumn{2}{|c|}{ postnatal } \\
\hline & & HIV- & HIV+ & HIV- & HIV+ & HIV- & HIV+ \\
\hline \multicolumn{2}{|l|}{ Age } & $0.01 * * *$ & $0.02^{*}$ & $0.00^{*}$ & $0.00 *$ & $0.03 * * *$ & $0.02 *$ \\
\hline \multicolumn{2}{|c|}{ number children } & $0.06^{* *}$ & $0.08^{* *}$ & $0.06^{* * *}$ & $0.07 * *$ & 0.00 & 0.08 \\
\hline \multicolumn{2}{|c|}{$\begin{array}{l}\text { Number of years in } \\
\text { formal education }\end{array}$} & $0.02 * *$ & $0.03^{* * *}$ & $0.02 * * *$ & $0.08^{*}$ & $0.05^{* * *}$ & $0.08^{* *}$ \\
\hline \multicolumn{2}{|c|}{$\begin{array}{l}\text { Type of residence } \\
(0=\text { Rural, } 1=\text { Urban })\end{array}$} & $0.03^{* * *}$ & $0.04 *$ & $0.08^{* * *}$ & $0.09 * * *$ & $0.02 * * *$ & $0.03^{* * *}$ \\
\hline \multirow[t]{4}{*}{ Wealth $^{\mathrm{a}}$} & Poorer & 0.00 & 0.00 & 0.03 & 0.00 & 0.05 & 0.01 \\
\hline & Middle & 0.01 & 0.00 & 0.00 & 0.00 & 0.01 & 0.00 \\
\hline & Richer & 0.00 & 0.01 & 0.05 & 0.01 & 0.74 & 0.03 \\
\hline & Richest & $0.00^{* *}$ & $0.02^{* *}$ & $0.01 *$ & $0.01^{* *}$ & $0.03^{* *}$ & $0.02 * *$ \\
\hline \multirow[t]{3}{*}{ Religion $^{b}$} & Protestant & 0.01 & 0.00 & 0.02 & -0.01 & -0.00 & -0.00 \\
\hline & Muslim & 0.00 & 0.02 & -0.01 & 0.09 & 0.07 & -0.02 \\
\hline & Other & 0.00 & 0.00 & -0.00 & -0.04 & 0.03 & -0.01 \\
\hline \multicolumn{2}{|c|}{$\begin{array}{l}\text { Possession of } \\
\text { insurance }\end{array}$} & $0.01 *$ & 0.08 & 0.00 & 0.07 & 0.08 & 009 \\
\hline \multicolumn{2}{|c|}{ Birth by caesarean } & $0.03 * *$ & $0.04 * *$ & $0.06^{* * *}$ & $0.08^{* * *}$ & $0.06^{* * *}$ & $0.04^{* * *}$ \\
\hline \multicolumn{2}{|c|}{$\begin{array}{l}\text { Availability of Drugs in } \\
\text { health centers }\end{array}$} & 0.00 & 0.00 & 0.10 & 0.00 & 0.03 & 0.02 \\
\hline \multicolumn{2}{|c|}{$\begin{array}{l}\text { Attitude of workers in } \\
\text { health centers }\end{array}$} & 0.02 & 0.01 & 0.00 & 0.00 & 0.03 & 0.01 \\
\hline \multicolumn{2}{|c|}{ Distance to facility } & 0.08 & 0.06 & 0.09 & 0.08 & 0.00 & 0.07 \\
\hline
\end{tabular}

${ }^{* * *} \mathrm{p}<0.01,{ }^{* *} \mathrm{p}<0.05,{ }^{*} \mathrm{p}<0.10$.

a reference is poorest; ${ }^{\mathrm{b}}$ reference is catholic

\footnotetext{
${ }^{1}$ Dependent variable is probability of utilizing professional care. Maximum likelihood probit was used during
} estimation 
Across all three stages of maternity, except in a few situations, reasons for choosing professional care over TBAs were mostly similar between HIV positive and HIV negative women. For example, for both HIV positive and HIV negative women; age, number of children, years of formal education, wealth, caesarean birth and area of residence influenced women's choice of taking up professional care.

Specifically, during antenatal, a 1 year increase in age increased the probability of utilizing professional care by $1 \%$ for HIV negative women and by $2 \%$ for HIV positive women. Similarly, increasing the number of children by 1 increased the probability of utilizing professional antenatal care by $6 \%$ for HIV negative women and by $8 \%$ for HIV positive women. Further, a 1 year increase in years of formal education increased the probability of utilizing professional care by $2 \%$ among HIV negative women and by 3\% among HIV positive women. Residing in urban areas increased the probability of utilizing professional care by 3\% among HIV negative women and 4\% for HIV positive women. Being richest as compared to being poorest increased the probability of utilizing professional antenatal care in HIV negative women by less than 1\% for HIV negative and by $2 \%$ for HIV positive women. Possession of insurance increased the probability of utilizing professional antenatal care by $1 \%$ among HIV negative women. It was also evident from our results that birth by caesarean increased the probability of utilizing professional antenatal care by $3 \%$ in HIV negative women and $4 \%$ in HIV positive women.

At birth, an increase in age by 1 year increased the probability of utilizing professional care by less than $1 \%$ for both HIV negative and HIV positive women. Similarly, an increase in number of children by 1 increased the probability of utilizing professional care by $6 \%$ for HIV negative women and $7 \%$ for HIV positive women. On the other hand, increase by 1 year in formal education increased the probability of utilizing professional care by $2 \%$ in HIV negative women and by $8 \%$ in HIV positive women. Further, residing in urban areas increased the probability of utilizing professional care by $8 \%$ for HIV negative women and $9 \%$ for HIV positive women. Being richest as compared to being poorest increased the probability of utilizing professional antenatal care in both 
HIV positive and HIV negative women by 1\%. Similarly, caesarean birth increased probability of utilizing professional care by $6 \%$ among HIV negative women and $8 \%$ for HIV positive women.

During postnatal, we observed that a 1 year increase in age increased the probability of utilizing professional care by 3\% for HIV negative women and $2 \%$ for HIV positive women. Similarly, a 1 year increase in years in formal education increased the probability of utilizing professional care by 5\% among HIV negative women and 8\% among HIV positive women. Residing in urban areas also increased the probability of utilizing professional care by $2 \%$ among HIV negative women and 3\% among HIV positive women. Further, being richest as compared to being poorest increased the probability of utilizing professional care by $3 \%$ for HIV negative women and by $2 \%$ for HIV positive women. Lastly, caesarean birth increased the probability of utilizing professional care by $6 \%$ for HIV negative women and by $4 \%$ for HIV positive women.

As explained in the methods section, we used Propensity Score Matching (PSM) technique to estimate the effect of HIV positive status on maternal health seeking behavior during antenatal, at birth and postnatal period. From table 5.3 we can see the effect of HIV status on maternal health seeking behavior during the three stages. To assess the quality of our matching process, see appendix K.

Table 5:3 Average Treatment effect on the Treated (ATT) results

\begin{tabular}{|l|l|l|l|}
\hline & $\begin{array}{l}\text { Professional-care } \\
\text { Usage rate for the } \\
\text { treated }\end{array}$ & $\begin{array}{l}\text { Professional-care } \\
\text { Usage rate for the } \\
\text { untreated }\end{array}$ & $\begin{array}{l}\text { ATT: Percentage point } \\
\text { (p.p) increase in } \\
\text { professional care usage }\end{array}$ \\
\hline Antenatal & 0.772 & 0.762 & $\mathbf{0 . 0 1 0 1 * * *}$ \\
\hline At birth & 0.790 & 0.777 & $\mathbf{0 . 0 1 3 0 * *}$ \\
\hline Postnatal & 0.775 & 0.766 & $\mathbf{0 . 0 0 9 0 * *}$ \\
\hline
\end{tabular}

${ }^{* * *} \mathrm{p}<0.01,{ }^{*} \mathrm{p}<0.05,{ }^{*} \mathrm{p}<0.10$

The results in table 5.3 indicate that being HIV positive increases the probability of utilizing skilled antenatal care by 1.01 percentage points (p.p), representing a professional-care usage rate of about $77.2 \%$. Being HIV positive increases the probability of utilizing skilled maternal care during birth by 
1.30p.p representing a professional-care usage rate of $79.0 \%$. Being HIV positive increases the probability of uptake of skilled postnatal care by $0.90 \mathrm{p} . \mathrm{p}$ representing a professional-care usage rate of $77.5 \%$. All of these effects are statistically significant.

To check for the robustness of the ATT in this chapter, we made use of two alternative matching techniques namely Kernel Matching and Stratification Matching (Khanker, et al., 2010). The two matching techniques produced similar ATT results in direction and magnitude (see appendix L). We further carried out the Altonji test to see if there was any bias resulting from unobservables; the Altonji sensitivity test indicated that our results were robust to selection on unobservables (see appendix M).

\subsection{Discussion}

Our aim in this chapter was to investigate and compare factors associated with the choice of care during antenatal, delivery and postnatal (between HIV positive and HIV negative women). We also investigated the effect of HIV positive status on utilization of professional maternal care during antenatal, delivery and postnatal. We discuss these results in that order.

Our findings highlight the fact that during antenatal care, at birth and postnatal periods, factors that influence uptake of professional care are similar between HIV negative and HIV positive women. They range from age, number of children, years of formal education, wealth, caesarean birth and area of residence. The only difference we observed was regarding access to insurance, where it was evident that access to insurance increased access to professional antenatal care for HIV negative women whereas for HIV positive women, there was no significant result observed in this regard. In general, our findings suggest that regardless of women's HIV status, being older, having more children, highly educated, wealthier, having caesarean birth and residing in urban areas increases the

probability of utilizing professional care. Our results are consistent with other studies on maternal health seeking behavior.

Particularly, regarding age and number of children, our results suggests (as other scholars have argued elsewhere) that women who are older and those with more children tend to utilize professional care more in order to overcome old-age pregnancy risks such as preeclampsia (Bayrampour, et al., 2012; Ogawa, et al., 2017). 
Further, other scholars within Zambian and SSA in general also come to the same conclusions regarding other factors. Just like other scholars have shown (Aantjes, et al., 2016; Chama-Chiliba, 2014), our results indicate that more educated and wealthier women tend to utilize professional care more. This could be as a result of wealthier women's ability to overcome costs barriers which characterize health services in most parts of Africa (Chama-Chiliba, 2014). This chapter also aligns itself with other studies that have shown that in Zambia, women choose to utilize health professionals based on the availability and accessibility of professional health services (ChamaChiliba, 2014; Cheelo, et al., 2016). This is also consistent with findings of chapter 2, 3 and 4 of this dissertation; where it was established that the relatively huge cost of professional maternal care in Zambia and other SSA (especially in rural areas) prevents women from accessing professional maternal care. Thus in urban areas where health-centers are more accessible, women tend to utilize professional health services more as compared to rural areas where TBAs are a more readily available (Sahlua, et al., 2014; Bergstrom \& Goodburn, 2001). Failure to overcome such structural barriers to care means that some women living with HIV in Zambia fail to access the technicallychallenging and much-needed antiretroviral treatment and cesarean procedure during delivery to prevent HIV transmission from mother to child (Ticconi, et al., 2003; Banda, 2015). Further, other scholars including the WHO recommend that professional postnatal care should be adhered to strictly in order to promote the health of HIV positive mothers and their children. It is required that all infants born to HIV-positive mothers should immediately receive a course of antiretroviral treatment (Avert, 2016; Tarekegn, et al., 2014). Further, depending on the situation, breastfeeding infants must receive a daily dosage of nevirapine and zidovudine from birth for six weeks. All children born to HIV positive mothers must also undergo regular HIV tests at six weeks, 18 months and one final one after 24 months (Avert, 2016; Bolu, et al., 2007). Thus given the situation in which some of rural women in Zambia utilize TBAs instead of professional health workers, questions have been raised regarding the practicality of ensuring that the above steps are adhered to strictly (Avert, 2016; Jayachandran, et al., 2015).

Our results further indicate that being HIV positive increases the probability of uptake of professional care during antenatal, delivery and postnatal by a small margin. It is however worthnoting that although the probability of accessing skilled maternal care (as opposed to TBAs) among HIV positive women is higher than those who are HIV negative, the difference is small (WHO, 2013; Kendall, et al., 2014). It is expected that all women who are HIV positive utilize skilled 
maternal health services in order to reduce the possibility of optimistic infections, mortality and promote PMTCT (Green-top-Guideline-No-39, 2010, p. 3). This is usually through uptake of antiretroviral treatment and caesarean births. Contrary to expectations, our results indicate that there is no substantial difference in maternal-health- seeking behavior between HIV positive and HIV negative women. HIV positive women do not substantially seek professional care more than HIV negative women; this is despite the fact that HIV positive women are more vulnerable than HIV negative women.

Viewed from an ideal perspective, it would seem legitimate to suggest, like many other scholars do, that HIV positive women should always utilize health professionals (Avert, 2016; Banda, 2015). However, this will, as other studies have shown (Sialubanje, et al., 2015; Stekelenburg, et al., 2004) be ignoring the many barriers that HIV positive women are directly faced with in Zambia (low income, inaccessibility of facilities, lack of drugs and personnel in facilities etc.) (Stekelenburg, et al., 2004; Sialubanje, et al., 2015). In a sense, just as other studies have highlighted (Stekelenburg, et al., 2004; Sialubanje, et al., 2015), it is counterproductive to encourage and send women to health facilities' if these facilities lack proper medication, equipment and personnel, and not while they remain expensive. It has been documented by previous studies that in Zambia, especially in rural areas, health facilities lack adequate trained personnel, drugs, and equipment (Stekelenburg, et al., 2004; Sialubanje, et al., 2015). Thus sending women to health facilities which are anything but, is in contradiction with the aims of maternal health promotion programs. In the Zambian case, it seems legitimate to focus more on providing care that is available and accessible to local women rather insisting on 'institutional care' which could be unavailable or inaccessible. There is a need for more consideration of feasible and practical care given the context of Zambia. Beyond understanding the reasons why HIV positive women choose TBAs, it is also important to understand the effect of this choice on maternal outcomes such as under-five mortality. Our findings in this chapter are vital in highlighting differences in factors which increase or decrease utilizing skilled care, but at the same time, these findings tell us very little about the effect of utilizing either professional care or TBAs on any given maternal health outcome. There is need to understand the effect of this choice on maternal outcomes such as under-five mortality. Thus chapter 6 solely focuses on addressing this question. 


\section{Limitations}

One of the limitations to this chapter is that the HIV status of some women who did not consent to having their blood tested for HIV was unclear and therefore we had to exclude these women from our sample. This means that the final sample was reduced in size and this may have affected the representativeness of the sample. Further, like in most studies that rely on household surveys, we acknowledge that the quality of the data used in this study depends on the women's ability to correctly recall events during maternity. This means that there is a possibility of recall bias. That notwithstanding, we believe this chapter provides useful insights and grounds for a more careful evaluation of factors associate with choice of antenatal, delivery and postnatal health service between HIV positive and HIV negative women.

\subsection{Conclusion}

There seems to be some similarity in factors which affect choice of care during antenatal, at birth and postnatal periods between HIV positive and HIV negative women. Being older, having more children, being highly educated, wealthier, having caesarean birth and residing in urban areas increases the probability of utilizing professional care in both HIV positive and HIV negative women. Further, we showed that although the probability of utilizing professional care for HIV positive appears to be slightly higher than those who are HIV negative, the difference is relatively small. This suggests that there is still a large number of HIV positive women who do not have access to PMTCT services. That notwithstanding, we also argue that although institutional care is desirable and an ideal solution for HIV positive women, insisting on exclusive institutional care (which is ideal) while ignoring the many challenges and barriers that exist within professional care in Zambia is counterproductive. 


\section{Chapter 6}

Professional care or TBAs? The impact of choice of care by mothers on under-five mortality of their children

\section{This chapter draws upon:}

Muzyamba, C., Groot, W., Rud, I., Tomini, S.M, \& Pavlova, M (2018) Professional delivery care or traditional birth attendants? The impact of choice of care by mothers on under-five mortality of their children; BMC Tropical medicine and health 46 (8). 


\begin{abstract}
Because of the high under-five mortality rate, the government in Zambia has adopted the WHO policy on child delivery which insists on professional maternal care. Zambia has consequently discouraged use of TBAs in preference for professional care. This is to ensure timely mitigation of any pregnancy related complication, and to promote PMTCT, which are both supposed to reduce the child's chances of dying before the child is five years old. However, there are scholars who criticize this policy by arguing that although built on good intentions, the policy to ban TBAs is out of touch with local reality in Zambia, and contributes to high under-five mortality rates in the country. There is lack of evidence to legitimize either of the two positions, nor how the outcome differs between women with HIV and those without. Thus the aim of this chapter is to investigate the effect of using professional maternal care or TBA care (during antenatal, delivery and postnatal) on under-five mortality. We also compare these outcomes between HIV positive and HIV negative women.
\end{abstract}

Propensity Score Matching is used to investigate the effect of utilization of professional care or TBA during antenatal, childbirth and postnatal on under-five mortality. This method allows us to estimate the Average Treatment Effect on the Treated (ATT).

The results show that the use of professional care (as opposed to TBAs) in all three stages of maternal care increases the probability of children surviving beyond five years old. However, although there is a positive impact when mothers choose professional care over TBAs, the differences at all three points of maternal care are small.

Professional care is desirable and appears to be an ideal solution for reducing under-five mortality of children. However, completely excluding TBAs and insisting only on professional care when the health facilities in Zambia, especially in rural areas, continue to lack adequate trained personnel, drugs, and equipment seems counterproductive. Our results indicate an opportunity for improving maternal care by incorporating, regulating and making use of TBAs in a complementary manner. It seems plausible that integrating TBAs in the response unit rather than excluding them may make it easier to mitigate their shortcomings, amplify their potential benefits, regulate, and monitor them in a manner that complements institutional care. 


\subsection{Background}

Following the western-influenced evidence-based biomedical approach and the WHO policy on child delivery which insists on skilled delivery, most countries in SSA have moved to exclude TBAs in preference for institutional care (Sialubanje, et al., 2015). Nowhere else is this more evident than in Zambia where TBAs were officially excluded from the line of care in 2010 (Sialubanje, et al., 2015; Cheelo, et al., 2016).

Proponents of institutional-care argue that opportunistic infections such as malaria, tuberculosis, and delicate complications that mothers face during antenatal, child birth and postnatal periods require the attention of trained personnel, especially for women living with HIV. This is in order to ensure PMTCT (Chi, et al., 2013). Scholars from this school of thought postulate that the low utilization of skilled attendants in Zambia has led to unacceptably high under-five mortality (Vallely, et al., 2005; Harrison, 2011). Evidence from Zambia indicates that children born from women living with HIV are more likely to die before reaching the age of five than those born from HIV negative mothers (Gartland, et al., 2013; Gill, 2011; Vallely, et al., 2005). As an antidote to this predicament, proponents of institutional care have been calling for mandatory skilled attendance during antenatal, childbirth and postnatal periods especially for women living with HIV (Lukonga \& Michelo, 2015). This is in order to ensure consistent uptake of antiretroviral treatment and caesarean births, which are both supposed to reduce the child's chances of dying before reaching age five.

There are however other scholars who criticize the Zambian government's policy on TBAs by arguing that although built on good intentions, the policy to exclude TBAs is out of touch with reality in Zambia, and contributes to high under-five mortality rates in the country (Ana, 2011; Cheelo, et al., 2016). Obliterating TBAs who in most cases are the only feasible source of maternity care in preference for ideally better trained but unavailable professionals is disingenuous (Ana, 2011). These scholars intimate that the Zambian health system is too weak to sustain the government's policy of strict institutional-care for women. For example, Lukonga and Michelo (2015) posit that Zambia has poorly-equipped and overcrowded health institutions which lack sufficient numbers of technically skilled personnel. This makes the much-talked about 'health institutions' ideal but not practical. A combination of all these shortcomings compromises the care for pregnant women, and subsequently the survival of their children beyond the age of five (Gill, 
2011). This is why despite the government directive to exclude TBAs and encourage professional care, many women in Zambia have continued to utilize TBAs (Bolu, et al., 2007; Stekelenburg, et al., 2004; Banda, 2015; Cheelo, et al., 2016).

Further, despite the forgoing two conflicting positions, there is a lack of evidence to legitimize either of the two positions (Kendall \& Langer, 2015; Lukonga \& Michelo, 2015). It is not yet clear whether in the Zambian case utilization of skilled professionals as opposed to TBAs during the antenatal, childbirth and postnatal period significantly reduces under-five mortality (Kendall, et al., 2014). It is also not yet known if on the basis of type of care, the resulting under-five mortality outcomes are similar for women with HIV and those who are HIV negative. There are no studies that specifically focus on compering the differences in outcomes on the basis of utilizing skilled care or TBAs during the continuum of maternal care for women with HIV and those without HIV (Kendall, et al., 2014; Chi, et al., 2013).

The expectation however is that in both HIV negative women and women with HIV, skilled care along the continuum of maternal care would reduce the chances of under-five mortality (WHO, 2015). It is expected that the impact will be higher for women with HIV (WHO, 2015). This is because skilled care allows women with HIV (who are more vulnerable) to access life-saving antiretroviral treatment, cesarean birth and continuation of antiretroviral treatment which promote PMTCT and ultimately reduce under-five mortality (Avert, 2016). However, the extent to which this is evident in Zambia is still unclear (Sialubanje, et al., 2015). It is vital to provide evidence on the causal nature of this relationship and clearly demonstrate how in the context of Zambia, utilization of skilled attendants affects under-five mortality for women with HIV and how this differs for HIV negative women. This delineation will serve as a first step towards the formulation of contextspecific and effective policy to reduce under-five mortality in Zambia (Kendall \& Langer, 2015). Thus, the aim of this chapter is to investigate and compare the effect of utilization of professional maternal care or TBA care during the antenatal, delivery and postnatal period on under-five mortality in women living with HIV and in HIV negative women. 


\subsection{Methods}

We used the 2013-2014 ZDHS. The ZDHS includes data on women who are aged between 15 and 49 years. The data contained in the ZDHS include demographic and health indicators. The sample design in the 2013-2014 ZDHS is a two-stage stratified cluster sample design. During the first sampling stage, a total of 722 Enumeration Areas (EAs) (which includes 305 in urban areas and 417 in rural areas) were selected from Zambia's 10 provinces. This was done by a stratification technique in which 10 provinces were divided into urban and rural areas giving rise to 20 sampling strata. In the second stage, a sampling frame containing a complete list of households was drawn, upon which a total of 25 households were selected for enumeration in each EA (ZDHS, 2014).

Regarding HIV test results, the HIV data were obtained by collecting blood samples during interviews from consenting participants which was later tested for HIV. The HIV data were however not publicly available. The data were only availed to us after obtaining ethical clearance from the Zambia ethics board, the Ministry of Health of Zambia and the ZDHS team. This was followed by signing of a confidentiality form to treat the data with strict confidentiality. We then linked the HIV data to the rest of the ZDHS data based on unique IDs as instructed and recommended by the ZDHS team.

From the overall ZDHS data on all women (aged 15 to 49), we selected a sub-sample of women who had stated that they had given at least one birth in the last 5 years preceding the survey and were either HIV positive or negative. Women whose HIV status were not determined or did not consent in taking part in the HIV test were not included in our final sample. However, before dropping the group of respondents who had an undetermined HIV status, we provide a summary of statistics showing how the three groups (HIV positive, HIV negative and HIV-Undetermined) compare with each other (see table 6.1). The third group was dropped because the focus of this chapter (and the entire dissertation) was on respondents whose HIV status was determined. This approach allowed us to accurately see the impact of professional care (or TBA care) on under-five mortality between and see the difference between women with HIV and those without HIV. A summary of the characteristics of the data is provided in table 6.1 below. We made use of anova and chi-square tests to summarize the data. 
Table 6.1 Summary of characteristics (differences and similarities) between HIV positive, HIV negative and HIV-undetermined women aged 15-49 who gave birth in the last 5 years

\begin{tabular}{|c|c|c|c|c|c|c|}
\hline \multicolumn{7}{|c|}{ Anova tests } \\
\hline & & $\begin{array}{l}\text { HIV- } \\
\mathrm{N}=10,112 \\
\mathrm{M}(\mathrm{SD})\end{array}$ & $\begin{array}{l}\text { HIV+ } \\
N=2,113 \\
M(S D)\end{array}$ & $\begin{array}{l}\text { Undetermined } \\
\mathrm{N}=1,494 \\
\mathrm{M}(\mathrm{SD})\end{array}$ & $\mathbf{F}$ & $\begin{array}{l}\text { Posthoc test - } \\
\text { Tukey test }\end{array}$ \\
\hline Age & & $\begin{array}{l}\mathbf{2 8 . 0} \\
(9.34)\end{array}$ & $\begin{array}{l}28.9 \\
(9.32)\end{array}$ & $\begin{array}{l}27.9 \\
(8.53)\end{array}$ & $106.16^{* * *}$ & $\begin{array}{l}\text { HIV+ vs HIV_*** } \\
\text { Und' vs HIV-*** } \\
\text { Und' vs HIV+*** }\end{array}$ \\
\hline number of children & & $\begin{array}{l}\mathbf{5 . 9} \\
(2.76)\end{array}$ & $\begin{array}{l}4.8 \\
(2.79)\end{array}$ & $\begin{array}{l}5.2 \\
(2.67)\end{array}$ & $32.08 * * *$ & $\begin{array}{l}\text { HIV+ vs HIV-*** } \\
\text { Und' vs HIV_*** } \\
\text { Und' vs HIV+*** }\end{array}$ \\
\hline number of years in $\mathrm{fe}$ & mal education & $\begin{array}{l}7.8 \\
(2.12)\end{array}$ & $\begin{array}{l}7.7 \\
(2.09)\end{array}$ & $\begin{array}{l}7.7 \\
(2.05)\end{array}$ & $3.67 * *$ & $\begin{array}{l}\text { HIV+ vs HIV-*** } \\
\text { Und' vs HIV_*** } \\
\text { Und' vs HIV+*** }\end{array}$ \\
\hline \multicolumn{7}{|c|}{ Chi-square tests } \\
\hline & & HIV- & HIV+ & Undetermined & \multirow{2}{*}{\multicolumn{2}{|c|}{ Pearson chi2(2) }} \\
\hline & & $(\%)$ & $(\%)$ & $(\%)$ & & \\
\hline \multirow[t]{2}{*}{ Area of residence } & Rural & $5,359 \quad(53)$ & $1,098 \quad(51)$ & $\begin{array}{ll}777 & (52) \\
\end{array}$ & \multirow{2}{*}{\multicolumn{2}{|c|}{$252.56^{* * *}$}} \\
\hline & Urban & $4,752 \quad(47)$ & $1,098 \quad(49)$ & $\begin{array}{ll}717 & (48) \\
\end{array}$ & & \\
\hline \multirow[t]{5}{*}{ Wealth index } & Poorest & $1,742(17)$ & $374 \quad(18)$ & $254 \quad(17)$ & \multirow{5}{*}{\multicolumn{2}{|c|}{$483.34 * * *$}} \\
\hline & Poorer & $1,866 \quad(19)$ & $364 \quad(17)$ & $284 \quad(19)$ & & \\
\hline & Middle & $2,154 \quad(21)$ & $464 \quad(22)$ & $(22)$ & & \\
\hline & Richer & $2,053 \quad(21)$ & $467 \quad(21)$ & $299 \quad(20)$ & & \\
\hline & Richest & $2,225 \quad(22)$ & $468 \quad(22)$ & $330 \quad(22)$ & & \\
\hline \multirow[t]{4}{*}{ Religion } & Catholic & $1,792 \quad(18)$ & $369 \quad(18)$ & $(19)$ & \multirow{4}{*}{\multicolumn{2}{|c|}{5.21}} \\
\hline & Protestant & $8,209 \quad(81)$ & $1,722 \quad(82)$ & $1,195 \quad(80)$ & & \\
\hline & Muslim & $50 \quad(0.5)$ & $10 \quad(0.5)$ & $\begin{array}{ll}8 & (0.5) \\
\end{array}$ & & \\
\hline & other & $(0.6)$ & $(0.6)$ & $(0.5)$ & & \\
\hline \multirow[t]{2}{*}{ Health insurance } & No & $9,808 \quad(97)$ & $2,066(98)$ & $1,449 \quad(97)$ & \multirow{2}{*}{\multicolumn{2}{|c|}{$17.15^{* * *}$}} \\
\hline & Yes & $303 \quad(3)$ & $46 \quad(2)$ & $45 \quad(3)$ & & \\
\hline \multirow[t]{2}{*}{ Birth by caesarean } & No & $9,576 \quad(95)$ & $1,427 \quad(67)$ & $1,359 \quad(91)$ & \multirow{2}{*}{\multicolumn{2}{|c|}{$16.20^{* * *}$}} \\
\hline & Yes & $536 \quad(5)$ & $686 \quad(33)$ & $134 \quad(9)$ & & \\
\hline \multirow{2}{*}{$\begin{array}{l}\text { Distance to health } \\
\text { facilities }\end{array}$} & Big problem & $4,348 \quad(44)$ & $795 \quad(38)$ & $598 \quad(40)$ & \multirow{2}{*}{\multicolumn{2}{|c|}{$86.88^{* * *}$}} \\
\hline & Not a big problem & $5,764 \quad(56)$ & $1,318 \quad(62)$ & $896 \quad(60)$ & & \\
\hline \multirow{2}{*}{$\begin{array}{l}\text { Drug availability at } \\
\text { health facility }\end{array}$} & Big problem & $4,142 \quad(41)$ & $586 \quad(28)$ & $\begin{array}{ll}478 \quad(32) \\
\end{array}$ & \multirow{2}{*}{\multicolumn{2}{|c|}{1.33}} \\
\hline & Not a big problem & $5,970 \quad(59)$ & $1,527 \quad(72)$ & $1,016 \quad(68)$ & & \\
\hline \multirow{2}{*}{$\begin{array}{l}\text { Attitude of workers } \\
\text { in health facility }\end{array}$} & Big problem & $3,369 \quad(33)$ & $549 \quad(26)$ & $433 \quad(29)$ & \multirow{2}{*}{\multicolumn{2}{|c|}{$44.67 * * *$}} \\
\hline & Not a big problem & $6,743 \quad(77)$ & $1,564 \quad(74)$ & $1,061 \quad(71)$ & & \\
\hline \multirow{2}{*}{$\begin{array}{l}\text { Choice of care } \\
\text { antenatal }\end{array}$} & TBA & $2,375 \quad(24)$ & $486 \quad(23)$ & $314 \quad(21)$ & \multirow{2}{*}{\multicolumn{2}{|c|}{$54.21 * * *$}} \\
\hline & Health professional & $\begin{array}{ll}7,737 & (76) \\
\end{array}$ & $1,527 \quad(77)$ & $1,180 \quad(79)$ & & \\
\hline \multirow{2}{*}{$\begin{array}{l}\text { Choice of care at } \\
\text { birth }\end{array}$} & TBA & $2,124 \quad(21)$ & $448 \quad(21)$ & $313 \quad(21)$ & \multirow{2}{*}{\multicolumn{2}{|c|}{2.87}} \\
\hline & Health professional & $7,989 \quad(79)$ & $1,665 \quad(79)$ & $1,181 \quad(79)$ & & \\
\hline \multirow{2}{*}{$\begin{array}{l}\text { Choice of care at } \\
\text { birth }\end{array}$} & TBA & $2,395 \quad(24)$ & $507 \quad(24)$ & $433 \quad(22)$ & $67.36^{* * *}$ & \\
\hline & Health professional & $7,718 \quad(76)$ & $1,606 \quad(76)$ & $1,061 \quad(78)$ & & \\
\hline Child is alive & Yes & $9,809 \quad(97)$ & $2,049 \quad(97)$ & $1,434 \quad(96)$ & 1.02 & \\
\hline & No & $303 \quad(3)$ & $64 \quad(3)$ & $(4)$ & & \\
\hline
\end{tabular}

${ }^{* * *} \mathrm{p}<0.01,{ }^{* *} \mathrm{p}<0.05,{ }^{*} \mathrm{p}<0.10$. Reported F-values are based on Anova tests for continuous variables and chi-squares for proportions/categorical variables. 
Propensity Score Matching (PMS) was applied to investigate the effect of the use of professional care or TBA during the antenatal, childbirth and postnatal period on under-five mortality. This method allows us to calculate the Average Treatment Effect on the Treated (ATT). We do this at three different stages (antenatal, childbirth, and postnatal) for both women with HIV and HIV negative women giving us six different PSM investigations. More specifically, we investigated: (a) the effect of using either professional care or TBAs during antenatal among women with HIV and HIV negative women on under-five mortality; (b) the effect of using either professional care or TBAs during childbirth among women with HIV and HIV negative women on under-five mortality; (c) the effect of using either professional care or TBAs during postnatal among women with HIV and HIV negative women on under-five mortality.

The variables used for matching include: age at the most recent birth of the woman, mother's number of years in formal education, total number of children, area of residence, religion, household wealth, birth by caesarean, access to health insurance, distance to health facility, and attitude of health workers. The selection of variables was guided by theory and consensus in extant literature regarding what factors are likely to influence women to access professional care (Ansari, et al., 2003; Sahlua, et al., 2014; Bolu, et al., 2007).

We generated the propensity scores by using STATA. This means we used PSM to enable us to statistically create a control group (women with HIV/ HIV negative women who utilize TBAs) by matching the observed characteristics of the treated participants (women with HIV/ HIV negative women who utilize skilled attendants) to the control group. This is done on the basis of similar values of the propensity score (Rosenbaum, 2002). Heckman et al. (1998) defined PSM as the probability of selection into the treated group; which in this case means the probability of utilizing professional care. It is also important to note that the "unbiased inference" which arises from propensity score matching, is based on the assumption that the potential outcomes are independent of treatment assignment conditional on observable characteristics (Caliendo, et al., 2008). Another important condition is that there must exist a "common-support" region in the propensity score distributions comprising of participants from both the treatment and control groups (Caliendo, et al., 2008). 
To estimate the ATT, we used the Nearest Neighbor Matching technique. The nearest neighbor matching method works by matching individuals in the control to the treated group and then discards individuals who are not selected as matches (Rosenbaum, 2002). By using this technique, the individual from the comparison group is selected which then acts as a matching partner for the closest treated partner in terms of the propensity score (Khanker, et al., 2010; DiPrete \& Gangl, 2004). We make use of the 1:1 nearest neighbor matching technique which works by selecting for each individual in the treated $i$, the control individual with the smallest distance from the individual $i$. The disadvantage of 1:1 Nearest Neighbor Matching technique is that it discards a large number of observations which may reduce statistical power (Huber, et al., 2012).

The reliability of the estimated effect of either utilizing professional care or TBAs on under-five mortality when using PSM depends on selection of observables (Caliendo, et al., 2008). We thus checked to ensure that the common support assumption was satisfied. This was done by inspecting the propensity score distribution (Rosenbaum \& Rubin, 1983). For the balancing test, several iterations of estimation of the propensity score were carried out in which variables were recoded to have satisfied the balancing property (Garrido, et al., 2014).

For robustness, we compare our ATT results obtained from the nearest neighbor matching method with two other matching techniques to ensure that our findings are consistent; namely Kernel Matching and Stratification Matching (Khanker, et al., 2010). The Kernel matching uses weighted average of the individuals in the control group to construct a counterfactual (Caliendo, et al., 2008). Whereas Stratification matching works by partitioning the common support into different strata and after which impact is computed in each of those two strata (Khanker, et al., 2010).

Hidden bias and Sensitivity Test

In order to see if there is bias resulting from unobservables, we conducted the Altonji test (the procedure is explained in chapter 5 of this dissertation) (Caliendo, et al., 2008). 


\subsection{Results}

In order to investigate and compare the effect of the use of professional maternal care or TBA care during the antenatal, delivery and postnatal period on under-five mortality in women living with HIV and in HIV negative women, we used PSM. As recommended (Khanker, et al., 2010), the three steps of propensity score matching estimation were followed. Firstly, we ran probit models for the three stages of maternal care (antenatal, birth and postnatal) in order to estimate the propensity score. After this, the estimated propensity scores were used to match a group of individuals who utilized professional care but were comparable to those that utilized TBAs in terms of propensity scores generated in the first step. To assess the quality of our matching process, see appendix N.

The final step was to compare the under-five mortality outcomes of professional care and TBAutilizers between women with HIV and HIV negative women at the three different stages of maternal care, a process which is also known as ATT. By checking the ATT results in table 6.2, we can see the effect of the mothers choice of care between professional and TBA care on the survival of the child beyond five years.

Table 6:2 Average Treatment Effect on the Treated (ATT) Results

\begin{tabular}{|l|l|l|l|l|l|l|}
\hline $\begin{array}{l}\text { Maternal } \\
\text { Health } \\
\text { Stage }\end{array}$ & \multicolumn{2}{|l|}{$\begin{array}{l}\text { Survival rate } \\
\text { Treated }\end{array}$} & \multicolumn{2}{l|}{$\begin{array}{l}\text { Survival rate } \\
\text { Controls }\end{array}$} & \multicolumn{2}{l|}{$\begin{array}{l}\text { ATT } \\
\text { (percentage point increase in the probability of a child } \\
\text { surviving beyond 5 years) }\end{array}$} \\
\hline & HIV+ & HIV- & HIV+ & HIV- & HIV+ & HIV- \\
\hline Antenatal & .970 & .971 & .965 & .964 & $\mathbf{. 0 0 5 3 * * *}$ & $\mathbf{. 0 0 7 8 * * *}$ \\
\hline At birth & .972 & .981 & .964 & .979 & $\mathbf{. 0 0 7 9 * * *}$ & $\mathbf{. 0 0 1 1 * * *}$ \\
\hline Postnatal & .972 & .970 & .970 & .967 & $\mathbf{. 0 0 2 1 * * *}$ & $\mathbf{. 0 0 3 4 * * *}$ \\
\hline
\end{tabular}

In general, the results in table 6.2 show that utilizing professional care (as opposed to TBAs) in all three stages of maternal care for both women with HIV and HIV negative women slightly increases the probability of their children surviving beyond five years old. 
For the specific stages in women with HIV; uptake of professional antenatal care (as opposed to TBAs) by women with HIV increased the probability of the child surviving beyond age five by 0.53 percentage points (p.p) representing a survival rate of $97.0 \%$ for those who used professional care and $96.5 \%$ for those who used TBAs. Similarly, the uptake of professional care during childbirth (as opposed to TBAs) by women with HIV increased the probability of the child surviving beyond age five by 0.79 p.p, representing a survival rate of $97.2 \%$ for professional care users and $96.4 \%$ for TBA users. At postnatal, the probability increases by 0.21 p.p. representing a survival rate of $97.2 \%$ for professional care utilizers and $97.0 \%$ for TBA-utilizers.

Similarly, for HIV negative women; uptake of professional care (as opposed to TBAs) during antenatal, at birth and postnatal period slightly increased the probability of the child surviving beyond age five. For example, the probability of a child surviving beyond age five increased by 0.78 p.p as a result of using professional care representing a survival rate of $97.1 \%$ for professional care utilizers and $96.4 \%$ for TBA utilizers. At birth, the uptake of professional care for HIV-negative women increased the probability of the child surviving beyond age five by 0.11 p.p representing a survival rate of $98.1 \%$ for professional care utilizers and $97.9 \%$ for TBA utilizers. During postnatal, it increased by 0.34p.p representing a survival rate of $97.0 \%$ for professional care utilizers and $96.7 \%$ for TBA utilizers.

Robustness checks for the ATT were done by the use of two alternative matching techniques; namely, Kernel Matching and Stratification Matching (see appendix O). Both of the matching techniques produced similar ATT results in direction and magnitude for all the three stages. We further carried out the Altonji test to see if there was any bias resulting from unobservables; the Altonji sensitivity test indicated that our results were robust to selection on unobservables (see appendix $P$ ).

\subsection{Discussion}

The aim of this chapter was to investigate the effect of utilization of professional maternal care or TBA-care during antenatal, delivery and postnatal period on under-five mortality for women with HIV and those who are HIV negative. 
Our findings highlight the fact that, in general, children born from mothers who utilize professional care have a slightly higher probability of surviving beyond the age of five regardless of the HIV status of the mother compared to mothers who use TBAs. However, despite these positive results in support of professional care, it should be noted that these differences were small. From the forgoing we make the following two important conclusions: (a) for both HIV negative women and those living with HIV, professional care at all the three stages of care leads to slightly higher probability of their children to survive beyond age five; (b) although professional care appears to produce comparatively higher survival rates, the difference between those who utilize professional care and those who utilize TBAs is relatively small.

The slight reduction in probability of under-five mortality resulting from professional care stands out as one of the most important findings of this chapter, especially considering the fact that in the recent past, there has been an increased focus on the need to promote professional care during antenatal, at birth and postnatal period, from the Zambian government and the WHO (WHO, 2013; Cheelo, et al., 2016). Other studies have emphasized the importance of professional care as a means of reducing under-five mortality (Avert, 2016; Chi, et al., 2013). In this regard, professional care is credited for helping to mitigate pregnancy-related complications, particularly pre-eclampsia, and also specifically for mothers with HIV, it helps in the promotion of PMTCT (Lincetto, et al., 2010; Choguya, 2014). The results have also demonstrated that professional care at all three stages is a practical platform through which any potential complications arising during birth can be effectively handled; most importantly for women living with HIV where cesarean birth, a preserve of professional care is an indispensable procedure in the promotion of PMTCT. This is why the WHO (2013) and subsequently the government of Zambia disapproves of TBAs in preference for professional caregivers with the anticipation that professional caregivers could significantly reduce the probability of dying before age five (Lincetto, et al., 2010).

However, our findings indicate that in both women with HIV and those without HIV, professional maternal care only led to a slight improvement in probability of surviving beyond age five. Our findings are consistent with a growing body of evidence emanating from Zambia which challenges the WHO's notion of change anchored on the assumption that professional care automatically and significantly leads to high reduction in under-five mortality (Kyei, et al., 2012; Ana, 2011; Banda, 2015). Just as other scholars have recently observed, the increased utilization of professional 
maternal care has not significantly reduced under-five mortality in Zambia regardless of HIV status. This could, as other scholars have shown, be the result of poor standards of care under professional care in Zambia epitomized by inadequate medical supplies, equipment and staff (Gill, 2011; Kyei, et al., 2012; Cheelo, et al., 2016). We have shown that in the case of Zambia, there is a small difference in under-five mortality between professional care utilizers and TBA-utilizers for both HIV negative and women living with HIV. It was also evident that the effect of professional care does not differ much between HIV negative women and those living with HIV.

Given these findings, important questions worth asking are: (a) seeing that in Zambia, there seems to be only small differences in outcomes between professional care utilizers and TBA-utilizers; is it justifiable to officially exclude TBAs (who are readily available) from the line of care in preference for health professionals (who are not readily available, especially in rural areas); (b) how good is the quality of care in these health institutions in Zambia?; (c) and similarly, how good is the care under TBAs?

Although professional care produces slightly better outcomes than TBAs, there is a lack of adequate health personnel in Zambia (Banda, 2015). This observation is in line with what other studies from Zambia have continued to highlight, which is that most professional maternal care stations in Zambia are crippled with a shortage of qualified medical personnel and medical equipment, shortage of life-saving antiretroviral drugs, overcrowding, poor infrastructure especially in rural parts of Zambia (chileshe, 2014; Gartland, et al., 2013; Sialubanje, et al., 2015; Stekelenburg, et al., 2004). Our findings from chapter 3, 4 and 5 also emphasize the lack of adequate medication, personnel and equipment in Zambian health facilities. Further, whereas it appears logical to recommend improvement in the availability and quality of care in Zambia, such ideal recommendations are frequently not achievable due to the high costs involved in implementing them. The government in Zambia has been reluctant, and to some extent financially-incapable of implementing these ideal yet costly recommendations (Gartland, et al., 2013; Gill, 2011; Ministry-of-Health, 2013). This finding is in line with other similar studies from within the region (Gartland, et al., 2013; O'Gorman, et al., 2010). In these studies, public health scholars have highlighted government's inability to sufficiently fund the health sector in countries like Zambia and Malawi. This has prompted scholars to suggest other nonconventional ways of strengthening the health system such as "task-shifting". Similarly, given the small differences between professional care and TBAs in terms of probability of under-five mortality in our results, it seems legitimate to explore ways through which TBAs can be used to 
complement the weak health system in Zambia. From chapter 2, 3, 4 and 5 of this dissertation including other studies within SSA (Ana, 2011; Bergstrom \& Goodburn, 2001) it seems that the efforts of TBAs have potential value in boosting the maternal health response in Zambia. The decision to exclude them seems counterproductive especially considering that they are still being relied upon (albeit illegally) amidst an inefficient health system. Excluding them makes the chances of mitigating their shortcomings and amplifying their benefits impossible. In a country like Zambia which is experiencing a critical shortage of professional health workers, relying on already established traditional and indigenous solutions such as TBAs may be profitable. This will ensure improved cooperation, access to care and coordination. TBAs may also be trained, regulated and given suitable functions within the line of maternal care. This might help complement professional attendants (who are in most cases inadequate or unavailable).

Limitations

A dominant limitation in this chapter, like in many other studies that rely on household surveys, is the problem of recall bias. The quality of the survey normally depends on the respondent's ability to accurately recall events, which in some cases is very difficult to assure, and to deal with. Secondly, some women who did not consent to have their HIV status determined were excluded from the sample which might have affected the representative value of the sample. That notwithstanding, our findings provide useful insights in understanding the impact of professional care on under-five mortality of children born to HIV positive mothers. However, in order to legitimize our findings, we recommend that more similar studies must be conducted to validate the generalizability of our findings.

\subsection{Conclusion}

In this chapter, we have demonstrated that in general, children born to mothers who utilize professional care have a slightly higher probability of surviving beyond the age of five, regardless of 
the HIV status of the mother. However, although there is a positive impact when mothers choose professional care over TBAs, the difference at all the three points of maternal care is small.

Given our findings which show small differences in under-five mortality outcomes between utilizers of professional care and utilizers of TBAs, it has become necessary to question the government's logic of completely excluding TBAs (who despite being outlawed are still being used). The idea of completely excluding TBAs in the line of care in Zambia presents a lost opportunity for a health system that lacks skilled personnel, equipment and is highly inaccessible to the majority of the rural population. The current set up is counterproductive as it results in a loss of potential benefits of TBAs whose efforts produce comparatively similar results with professionals (despite their shortcomings). Indeed, good quality professional care is desirable and an ideal solution for reducing under-five mortality in children, but insisting only on professional care when the health facilities in Zambia especially in rural areas continue to lack adequate trained personnel, drugs, and equipment seems counterproductive. Our results indicate an opportunity for improving maternal care by incorporating, regulating and making use of TBAs. It thus seems plausible that carefully integrating TBAs in the response unit rather than officially excluding them would make it easier to mitigate their shortcomings, amplify their potential benefits, regulate, and monitor them in a manner that complements institutional care (since the two are not mutually exclusive). 


\section{Chapter 7}

General discussion 


\subsection{Background}

The main aim of this dissertation was to provide insights on the role of community mobilization in the promotion of maternal health in women with HIV in Zambia. Recently, studies have shown that women living with HIV are more likely to experience negative maternal health outcomes than those without HIV (Kendall \& Danel, 2004). Gaps in knowledge still remain regarding how HIV positive women in resource-poor settings dominated by inefficient health systems, rely on community mobilization in handling their maternal care burden and the consequences thereof. In order to improve maternal health outcomes in Zambia and across SSA in general, more attention must be paid on how the most vulnerable women make sense and use of available community resources in the face of inefficient and sometimes non-existent health systems. However, to date, this has issue remained generally unexplored across Zambia and SSA in general.

As a first step in addressing this question, we have conducted a thorough assessment and exploration of the available evidence on the role of community mobilization on maternal health outcomes of women living with HIV in SSA (chapter 2). This was done through a systematic review. The systematic review demonstrates that many gaps remain in understanding the effect of community mobilization on maternal outcomes of women with HIV. It also shows that outcomes differ between women with HIV and those without HIV. This reflects a lack of focus on the uniqueness that characterizes women living with HIV in the existing literature. On the basis of the evidence arising from the systematic review, in chapter 3, we qualitatively investigate the role of community mobilization in women living with HIV in Mfuwe, Zambia. In this regard, the investigation demonstrates that women living with HIV in Zambia rely heavily on community mobilization (peer support, TBAs and community involvement) in promoting their health. While there is a relative agreement on the usefulness of the other two components of community mobilization (peer support and community involvement), TBAs present a unique and controversial position in the Zambian maternal care system, especially for women living with HIV thereby raising several questions. For example, given the fact that women with HIV need access to antiretroviral treatment and cesarean births in order to promote PMTCT, of what use are TBAs? Given that TBAs have culturally been relied upon for generations in Zambia, what has been their effect on maternal health outcomes especially for women with HIV, and why do women choose to use them over skilled attendants? The following three chapters (4, 5 and 6 ) focus on addressing these 
questions. Specifically in chapter 4, we investigate the usefulness of TBAs to women living with HIV; and in chapter 5 we investigate and compare factors affecting the choice of care (TBAs or professional care service) between HIV negative women and women living with HIV. The results here indicate that the main reasons why women with HIV choose to utilize TBAs instead of professional care include unavailability of drugs and equipment in health facilities, high cost in facilities, negative attitude from staff in facilities, and long distance to health facilities. In Chapter 6, we focus on investigating and comparing the effect of choice of care (TBAs or professional care service) on under-five mortality between HIV negative and HIV positive women. In this regard, the dissertation has shown that in so far as under-five mortality is concerned, when compared to TBAs, professional care only slightly increases the probability of a child surviving beyond age five. The margin is very small indicating that the impact of professional care is not very different from that of TBAs in Zambia. This trend is also similar between women with and without HIV.

In this final chapter of the dissertation, we present and discuss the main findings of the dissertation centered on four statements.

\subsection{Discussion of statements}

Statement 1: In the face of poorly-resourced governments and inefficient health systems, women living with HIV in Zambia rely on community mobilization (support from peers, TBAs and community-led and collaborative initiatives) to improve maternal health outcomes.

In this dissertation, we have shown that local communities are not conglomerates of passive citizens lacking agency and strategies; they are in fact a hub of useful contextual-resources and local wisdom necessary for the enhancement of maternal health of women with HIV (chapter 2, 3, 4 and 6). This is consistent with evidence emanating from other resource-poor settings within SSA (Doherty \& Coetzee, 2005; Mbiydzenyuy, 2012). Women in Zambia (especially those in rural areas) have lived in areas where technologically-advanced health systems are frequently unavailable. Thus, relying on community strengths is in many cases the only remaining option. Other studies acknowledge that most rural areas within SSA have over the years relied on culturally-available resources in dealing 
with different health challenges (Marcos, et al., 2012; Schneider, et al., 2008). The dissertation has stressed the importance of community resources in addressing local challenges faced by women with HIV in asserting their maternal health care needs (chapter 2, 3, 4, 5 and 6). Local communities demonstrate that even though they invariably lack proper health centers, their survival over generations has been dependent on social networks, reliance on locally-available resources such as TBAs and collective action. Relying on these resources in the face of weak health institutions made access to much-need care possible (chapter 2, 3 and 4). This argument is represented not as a critique to highly-functional and accessible professional care, but rather as a confirmation that local people are not passive victims of failed health systems. In chapter 5 , we demonstrated that barriers relating to cost prevented most women from accessing professional care. Communities are aware of the importance of professional care, but their attachment to community resources (in the absence of professional care) reflects the need to develop useful local alternative strategies nonetheless (chapter 6). Similar evidence was demonstrated by other researches in Zimbabwe and South Africa (Mukumbura, 2000; Schneider, et al., 2008).

The Zambian case in particular reveals that in promoting maternal care of women with HIV, communities rely heavily on peer support in the form of economic, psychological, nutritional, and logistical support. TBAs also occupy a substantial role in maternal health response unit for women with HIV in the country (Chapter 5 and 6). Zambian communities also demonstrate through the 'Zambualance' project and the waiting shelter projects that communities have useful yet lessrecognized strategies that are equally important for their survival. The problem however, is that these strategies have been generally ignored or obscured by highly acclaimed evidence-based strategies. In most cases, local interventions are disregarded when researchers pay little attention to local contexts and people's own psycho-social experiences that shape maternal health opportunities in resource poor settings. This practice has been observed elsewhere within SSA in which local people's knowledge has gone unrecognized in public health efforts (Doherty \& Coetzee, 2005; Mbiydzenyuy, 2012; Schneider, et al., 2008; Lehmann, et al., 2009). In this dissertation, we demonstrate how women living with HIV in Mfuwe, Zambia through community mobilization rely on culturally-appropriate and contextually-feasible practices to shape their possibilities for success in dealing with maternal health challenges. In the absence of an easily-accessible well-functioning health system that could provide high quality care, women in Zambia resort to locally-available options despite the many shortcomings associated with this kind of care. 
Just as other studies have previously shown, local knowledge and practices are not unquestionably always good for health (Doherty \& Coetzee, 2005; Kidane \& Morrow, 2000). This dissertation does show that apart from having several benefits, local practices have limitations which may be harmful for maternal health of women with HIV. Certain harmful practices and norms can easily be reinforced within local cultural strategies such as peer-support (chapter 3). The assumption that anything local is unequivocally good for maternal health for women with HIV is disingenuous. In this dissertation, we have demonstrated that TBAs lack advanced skills, equipment and drugs to handle several complications that could arise during pregnancy (chapter 3, 4, 5 and 6). Another aspect of care where TBAs are lacking is the correct detection of CD4-count including correctly determining which type, and dosage of ARVs to be administered at a given point in time. This knowledge is important for the promotion of PMTCT; however, TBAs lack the technical knowhow of doing this. This raises several questions regarding how useful TBAs are to women with HIV including which services they can actually provide (chapter 4, 5 and 6). This trend can be particularly harmful to women with HIV, especially if the TBAs operate on the 'black market' without any regulations from authorities. It remains evident however that several women still utilize services of TBAs (mostly out of necessity) despite TBAs being outlawed. This means that the act of outlawing and ignoring TBAs makes any possibilities of identifying their shortcomings and subsequently minimizing them impossible. It is thus clear that decriminalizing TBAs could present an opportunity to properly regulate them. This is similar to what Dambisya and Matinhure (2005) show; which is that apart from possessing several advantages, community responses to health of women with HIV in Africa do have some shortcomings (Doherty \& Coetzee, 2005). They are not in themselves an unmixed blessing, but ignoring them essentially makes it difficult to regulate and improve on them.

Research and policy implications

Findings from this dissertation speak against the practice of formulating international maternal health policies which are oblivious to local solutions. The dissertation distances itself from traditional international maternal health policies that are based on the assumption that local people are passive beneficiaries or victims of existing health systems. Different communities have varying ways of responding to maternal health needs of women with HIV. Given the weak health systems that persist in resource poor settings, maternal health policy must focus on meaningfully taking account of locally-available strategies. Maternal health policies at different levels should therefore 
account for the different ways specific resource-poor communities make sense of their traditionallyavailable resources and how they appropriate them in ways that enable them deal with maternal health challenges in women with HIV.

Within local communities, specific interaction of traditions, risks and available-resources need careful interrogation, understanding and appropriation. Maternal health policy would benefit from an enhanced understanding regarding the interaction of these factors at a local level. Therefore, future studies must focus on investigating different social psychological processes that motivate local people to develop agency to identify, utilize and normalize local maternal health strategies aimed at women with HIV, and how these strategies promote or inhibit maternal health in context-specific ways. In general, different cultures possess helpful cultural resources which are not incontestable goods in themselves. We have shown that some of these local practices while increasing access to treatment and support, may at the same time sustain and reinforce stigma, discrimination, patriarchy etc. all of which can inhibit maternal health of women with HIV. Therefore, policies and future studies on maternal health of women with HIV must pay attention on the specific causal links between local strategies and specific maternal health outcomes in order to maximize their benefits and limit their costs

Statement 2: As a response to maternal health needs of women with HIV in Zambia, community-strategies are characterized as "useful and effective" by local people and in some cases they produce under-five mortality results that are not all that different from those of professional care.

As we have shown in chapter 3 and 4 , local people characterize community responses as useful in providing maternal care to women living with HIV. There seems to be consensus among local people on the fact that local strategies have some limitations in exclusively delivering care to women with HIV. The assumption that local people are unware of the shortcomings of local responses is misplaced (Easterly, 2014). Their reliance on local strategies is imbedded in several social and structural barriers (cost, long distance to facility, lack of adequate personnel and drugs in facilities etc.) and not as a symbolic devotion to culture. This observation is consistent with a strand of literature coming from different countries within SSA; in which local people assert their preference for local responses despite being aware of the challenges that come with it (Lehmann, et al., 2009; Dambisya \& Matinhure, 2012; Schneider, et al., 2008). This is because of the complex social and 
structural interactions that continue to govern communities within Africa. This is why scholars are suggesting that indigenous strategies should be judged not merely on the basis of their professed limitations, but rather on how and why they are used in different contexts and the effects thereof. A context-specific and nuanced understanding of why despite shortcomings people still stick to local responses is warranted.

Local people and particularly women living with HIV in Zambia situate and utilize local responses in a manner that helps them practically lessen rather than perpetuate the burden of maternal complications. They remain loyal to practically feasible and locally-available solutions (albeit their limitations) rather than putting their faith in attractive yet unavailable solutions (in the form of efficiently operational facilities). Peer-support for example serves as a crucial platform for enhancing collective action in bringing about much needed social, psychological, emotional, logistical, nutritional and economical supportive services to women living with HIV during maternity (chapter 2, 3 and 4). It also allows for social spaces that help deal with stigma and discrimination that women with HIV suffer from. Relying on networks from peers faced with similar challenges helps build alliances that help deal with common challenges. Similar results in peer support have been observed in Tanzania, Zimbabwe and Uganda in enhancing care for people living with HIV (Dambisya \& Matinhure, 2012; Mukumbura, 2000; Mdege, et al., 2013). Community-involvement on the other hand is unequivocally characterized as useful in bridging gaps left by a highly inefficient health system, without which women with HIV are left uncared for in Zambia. Horizontal collaboration is useful in addressing challenges that characterize the Zambian health response to maternal health needs of women with HIV. Particularly, establishment and use of the "Zambambulance" initiative and the 'waiting shelter' initiative help promote access to care in health institutions for women with HIV. Many such initiatives are reported elsewhere in Africa and they have been proved to be useful in filling the gap left by dysfunctional health systems (Mdege, et al., 2013). Chapter 3, 4, 5 and 6 demonstrate in different ways how TBAs are useful in handling maternal care of women with HIV, and at the same time, these chapters highlighted several limitations associated with TBAs. TBAs lack technical skills, equipment and drugs to handle complications related to pregnancy. As demonstrated in chapter 3 and 4, TBAs seem to be aware of the need for caesarean birth and uptake of antiretroviral therapy in order to promote PMTCT; given their limited skills, TBAs functions are mostly limited to providing "soft-services" (treatment-adherence-support, provision of maternal health information, logistical support, referral to facilities, challenging stigma, nutritional and referral 
services to facilities discrimination and patriarchy, etc.). As confirmed by other studies, this practice is similar to other countries within the region (Kidane \& Morrow, 2000; Doherty \& Coetzee, 2005; Mbiydzenyuy, 2012). Both women and TBAs themselves are aware of the limitations that TBAs present (lack of surgical skills and equipment) to handle complications and promote PMTCT, however, TBAs are relied upon due to lack of access to high quality professional care. Further, as demonstrated in chapter 6, TBAs and skilled care givers in Zambia have comparable effects in so far as under-five mortality is concerned in both HIV positive and negative women. This dissertation and many other studies (Mbiydzenyuy, 2012; Doherty \& Coetzee, 2005; Dehne, et al., 1995) have shown that the policy to outlaw or ignore TBAs on grounds that they produce significantly worse outcomes is misplaced in the absence of good quality professional care.

Research and policy implications

The key message for policy here is that maternal health policy in Zambia should take into account local people's characterization of indigenous strategies and the effects of these strategies. The assumption that 'indigenous strategies are useless and always ineffective' needs revisiting. We have demonstrated in chapter 3, 4, 5 and 6 that local people in Zambia categorically characterize local strategies as useful, and the effect of some of the local strategies is comparable to skilled care. This reflects the fact that taking into account local worldviews and context-specific realities is crucial in handling maternal health challenges especially in women with HIV in resource poor settings.

There are gaps however in our understanding why despite local people characterizing local strategies as useful, accessible and as effective as professional care does the local policy on maternal health in Zambia ignores them. Therefore, future studies must focus on investigating the social barriers which prevent indigenous responses from being mainstreamed into the maternal health response policy in Zambia. Further research should also provide understanding on how to best respond to these barriers in a contextually-useful way. Delineating this is the first step towards achieving integration of indigenous responses. Failure to take account of local worldviews and carefully responding to them presents a risk of reinforcing the unhelpful act of ignoring local feasible options in the process of aspiring for the impossible. 


\section{Statement 3: Ignoring or excluding components of community mobilization in maternal health care of women with HIV obliterates the opportunity to maximize their benefits and minimize their costs. It is effectively a 'lose-lose' situation}

A plethora of research has demonstrated that the dominance and universalization of the biomedical approach (evidence-based medicines) has done very little to address maternal health challenges in resource poor settings (Campbell \& Cornish, 2012; Campbell, et al., 2013; Catling, et al., 2015; Dehne, et al., 1995; Balogun \& Odeyemi, 2010). Traditionally, the general response to maternal health challenges has been the application of this approach which normally focuses on modernizing and improving quality of care through the provision of drugs, advanced equipment and skilled personnel, improved infrastructure etc. This is especially emphasized for women with HIV. The biomedical approach has become the gold-standard (Campbell \& Gibbs, 2009; Dambisya \& Matinhure, 2012). In some instances, this has led to local strategies being ignored or forbidden even when good quality care is not available to replace it. In maternal care of women with HIV in Zambia, chapter 3, 4, 5 and 6 of this dissertation argued that the policy to eradicate local strategies (such as TBAs) is sometimes out of touch with reality and counterproductive. Practical maternalhealth-enhancing opportunities are consistently lost. Findings from this dissertation (chapter 2, 3, 4, 5 and 6) are in consonance with a growing strand of literature (Campbell \& Graham, 2006 ; Dambisya \& Matinhure, 2012) which postulates that despite sustained insistence of these global strategies in low-income countries, the reality has been that these seemingly attractive yet costly strategies are never sustainably implemented, nor has their insistence significantly reduced negative maternal health outcomes. This is why without careful inspection, these strategies continue to appear coherent and logical from the international policy perspective, but they remain completely blunt instruments in the face of the complexities of poor countries. Building more efficient hospitals, increasing the numbers of skilled workers, and modernizing infrastructure are attractive and useful to HIV positive women, but poor governments have consistently struggled to achieve these goals. The continued quest to achieve these unattainable goals in the case of Zambia appears to be 'a wild goose-chase'.

The dominant evidence-based response to maternal health based on "globality" (effectively a topdown approach) exclusively and invariably romanticizes medical experts' perspectives while delegitimizing local wisdom, worldviews, and ways of doing and being. The dissertation, consistent with other studies from SSA (Mbiydzenyuy, 2012; Schneider, et al., 2008) illustrates how the 
maternal- health-related experiences and worldviews of grassroots communities (local strategies, knowledge and interests) are subordinated to the imperatives of internationally acclaimed evidencebased models much to the detriment of women with HIV.

It is apparent that 'high quality' evidence approaches have become the gold standard in international maternal health policy and in the process; stakeholders have overlooked how these interventions work out in different contexts around the world. Within this context (where local realities and strategies are sometimes ignored), the findings of this dissertation highlight the fact that potential benefits of local strategies (TBAs, peer support etc.) can be useful. Attempts to implement evidencebased strategies similar to those of advanced counties have kept the attention of resource poor countries on unachievable targets while losing out on available, practical and feasible alternatives. The trend is similar with findings from similar studies in Malawi (Mannel, 2010; Colbourn, et al., 2013).

Research and policy implications

'Wholesale' transposition of global initiatives in local settings in SSA in maternal health policy should be looked at critically. In this sense, future policies need to depart from top-down global prescriptions which do not take into account localized-realties. The idea that because it worked there it must therefore work here' is pervasive in the fight for better maternal health outcomes for women with HIV in SSA. Policies on maternal health should take into account the contrasting outcomes and characterization of popular global maternal health initiatives between wealthier and resource poor settings. Rather than establishing the biomedical approach as an incontestable good for all contexts, it is important to interrogate its suitability for different contexts especially in resource poor settings. Maternal health policy at an international level needs to be detached from a decontextualized one size-fits-all approach by focusing on ways global efforts can be appropriated into local contexts much to the benefit of HIV positive women. Uncritical adherence and mechanical-rule-following of established global standards may sometimes deny the women it is meant to serve the much-needed care.

More research however needs to be done in order to clearly demonstrate what social factors lead to the persistence of the one-size-fits all application of maternal health strategy. Specifically to find out 
what sustains and reinforces it. In order to promote maternal health of women with HIV in resource poor settings, it is vital that future research investigates: (a) what social factors sustain and perpetuate the act of universalization of global initiatives; (b) how global initiatives overshadow local initiatives; and (c) what impact this has on the maternal health of women with HIV in SSA.

\section{Statement 4: Community mobilization offers space for engagement between externally imposed interventions and local people in a manner that allows for improved maternal care and outcomes in women with HIV in resource-poor settings.}

This dissertation has offered insights on how local and global maternal health responses interact in Zambia. It has demonstrated ways in which local interventions, community agency, local resources are appropriated in order to provide survival and coping strategies in the face of inefficient health systems. It further highlighted how de-contextualized evidence-based biomedical rationalities disadvantage the people they are meant to serve. We have also argued that the struggle for 'exclusivity' between the local and global has disadvantaged women living with HIV. Insisting on one over the other on the basis of evidence (in the case of global strategies) or lack of alternative (in the case of local strategies) leaves women with unavailable and less-effective possibilities. Improving maternal health of women with HIV requires a combination of efforts from both local and global dichotomies in a manner that makes the services available and effective in a context-specific way (chapter 2,3,4,5 and 6).

We have argued throughout the dissertation that community mobilization provides space for local and global engagement in a manner that increases access to quality care, maximizes benefits and minimizes shortcomings on both local and global responses. Our findings are in line with other studies which show that both local and global strategies have useful elements and shortcomings; the two are also not mutually exclusive, meaning that they can complement rather than replace each other (Campbell \& Cornish, 2010; Catling, et al., 2015). Women living with HIV require quality care throughout pregnancy and different elements within the community and within health centers can help each other in achieving this goal. However, this is only possible when there is proper communication and coordination between the two. Community mobilization allows for meaningful non-tokenistic community involvement, peer-support and use of local expertise in the process of fostering cooperation between evidence-based and indigenous strategies. It allows for cooperation between globally acclaimed experts and indigenous experts (those who have expertise through 
experience in a given complex context) much to the benefit of local people. This approach as argued elsewhere provides much-needed maternal care to women with HIV in a contextually-useful manner.

The dissertation has demonstrated that by relying on peer support (economic, psychological and logistical support), TBAs (through provision of soft services), and community involvement (Zambulance, waiting shelters) there is an increase in access and quality of care to women with HIV. Community mobilization thus entails allowing local and global strategies to work together in manner that benefits the context (Campbell \& Jovchelovitch, 2000; Marcos, et al., 2012). Obscuring or ignoring one of the two sides, works against the aims of promoting maternal health in women with HIV. In agreement with Sialubanje (2015), we posit that responding to maternal health needs in Zambia requires cooperation between professional care and the community (Sialubanje, et al., 2015). Open recognition and dialogue between local and global allows for partnership and strengthening of maternal health response in a manner that is regulated, harmless, feasible, contextually-suitable and beneficial. Community mobilization thus offers this opportunity.

Research and policy implications

Maternal health policy would benefit from community mobilization which offers space for engagement between local and global in a context-specific way. There is more to benefit from sustained and careful engagement of local and global initiatives via community mobilization. Such engagement must separately pay attention to different struggles and successes of local and global efforts in the process of promoting maternal care for women with HIV.

More studies and further triangulation of our findings still need to be done in order to concretely establish ways through which this engagement can be made most successful. Future studies should therefore focus on investigating specific ways through which global-local interaction are achieved, and how this interaction leads to improved maternal health outcomes in women with HIV. Studies should focus on opening up new ways of thinking around local-global initiatives in a manner that enhances the maternal health of women with HIV. There is a need to focus on providing sophisticated understanding on how nuanced global-local struggles and connectedness are constituted and how they influence maternal health outcomes for women with HIV. It is important these investigations provide more understanding on how to ensure non-tokenistic involvement of 
local expertise (those who have expertise through e.g. users and survivors) and ensuring that they are not overshadowed by more powerful and appealing global efforts in this partnership.

\subsection{Concluding remarks}

Maternal health care for women living with HIV still remains a big challenge in most parts of SSA, and in particular, Zambia. The provision of good quality professional maternal health care remains central in addressing the many challenges faced by women living with HIV. This dissertation has however demonstrated that due to several structural constraints in Zambia, this ideal solution has remained unattainable. Thus by relying on community mobilization, HIV positive women have continued to make use of contextually-feasible options to shape their possibilities for success in dealing with maternal health challenges. In particular, relying on peer support, collaboration and use of indigenous resources such as TBAs has helped shape opportunities for survival in the face if inefficient health systems. These local solutions which are sometimes the only available options are not in themselves unmixed blessings, they do contain several shortcomings. However, outlawing or ignoring them takes away the possibility of maximizing their potential benefits and minimizing their costs. The dissertation also demonstrated that indigenous and evidence-based solutions are not necessarily mutually exclusive; they are in many ways complementary. This is why we posit that responding to maternal health needs of women with HIV in Zambia requires cooperation between

professional care and the community. This will allow for partnership-building and strengthening of maternal health response in a manner that is regulated, feasible, contextually-suitable and beneficial to women with HIV. 


\section{Bibliography}

Aantjes, C., Quinlan, T. \& Bunders, J., 2016. Towards universal health coverage in Zambia: impediments and opportunities. Development in Practice, 5(1995 - Issue 2).

Abdool-Karim, Q., AbouZhar, C. \& Dehne, K., 2010. HIV and maternal mortality: turning the tide. Lancet, Volume 375, p. 1948-1949.

Ackerman, G. L. \& Kiragu, K., 2012. Lessons learnt from promising practices in community engagement for the elimination of new HIV infections in children by 2015 and keeping their mothers alive: summary of a desk review. journal of the International AIDS Society, 15(12).

Akpala, C., 1994. An evaluation of the knowledge and practices of trained traditional birth attendants in Bodinga, Sokoto State, Nigeria. The American Journal of Tropical Medicine and Hygiene, 97(1), pp. 46-50.

Altman, L., Kuhlmann, A. K. S. \& Galavotti, C., 2015. Understanding the black box: A systematic review ofthe measurement of the community mobilization process in evaluations of interventions targeting sexual, reproductive, and maternal health. Evaluation and Program Planning, Volume 49, pp. 86-97.

Ana, J., 2011. Are traditional birth attendants good for improving maternal and perinatal health? Yes. British Medical Journal, Volume 342.

Andersen, R., 1995. Revisiting the behavioral model and access to medical care: does it matter?. Journal of Health and Social Behaviour, 36(1), p. 1-10.

Ansari, Z. et al., 2003. A public health model of the social determinants of health. Journal of Preventive Medicine , 48(4), pp. 242-51..

Avert, 2016. PREVENTION OF MOTHER-TO-CHILD TRANSMISSION (PMTCT) OF HIV, London : AVERT .

Balogun, M. \& Odeyemi, K., 2010. Knowledge and practice of prevention of mother-to-child transmission of HIV among traditional birth attendants in Lagos State, Nigeria. The Pan African Medical Journal, 5(7).

Banda, P. C., 2015. Status of Maternal Mortality in Zambia: Use of Routine Data. African Population Studies, 29(2).

Bartle, P., 2007. What is community? A Sociological Perspective, Vancouver: Vancouver Community Network.

Bergstrom, S. \& Goodburn, E., 2001. The role of traditional birth attendants in the reduction of maternal mortality. Safe motherhood strategies: a review of the evidence, p. 451.

Bolu, O. et al., 2007. Utility of antenatal HIV surveillance data to evaluate prevention of mother-to-child HIV transmission programs in resource-limited settings. American Journal of Obstetric Gynecology, Volume 197, pp. 17-25. 
Bourdieu, P., 1986. The forms of capital. In: Richardson J. G., editor. Handbook of theory and research sociology of education for the. New York: Greenwood Press.

Braun, V. \& Clarke, V., 2006. Using thematic analysis in psychology. Qualitative research in psycholog, 3(2), p. 77-101.

Burgess, R. \& Campbell, C., 2014. Contextualising women's mental distress and coping strategies in the time of AIDS: a rural South African case study. Transcultural Psychiatry.

Caliendo, M., Bonn, I. \& Kopeinig, S., 2008. Some Practical guidance on how to implement propensity score matching. University of Cologne.

Calvert, C. \& Ronsmans, C., 2013. The contribution of HIV to pregnancy-related mortality: a systematic review and meta-analysis. AIDS, Volume 27, p. 1631-163.

Campbell, C., 2014. Community mobilisation in the 21st century: Updating our theory of social change?. Journal of Health Psychology, 19(1), pp. 46-59.

Campbell, C. \& Cornish, F., 2010. Towards a "fourth generation" of approaches to HIV/AIDS management: creating contexts for effective community mobilisation. AIDS care, 22(1), p. 569-79.

Campbell, C. \& Cornish, F., 2012. How can community health programmes build enabling environments for transformative communication? Experiences from India and South Africa. AIDS and Behavior, 16(4), p. 847-857.

Campbell, C. et al., 2015. Conceptualising schools as a source of social capital for HIV affected children in southern Africa. LSE research Online, pp. 1-25.

Campbell, C. \& Gibbs, A., 2009. Stigma, gender and HIV: case studies of intersectionality.. In: Gender and HIV/AIDS: critical perspectives from the developing world. Surrey : Ashgate , pp. 29-46.

Campbell, C. \& Jovchelovitch, S., 2000. Health, community and development :towards a social psychology of participation. Journal of community and applied social psychology, Volume 10, pp. 255270.

Campbell, C. \& Mzaidume, Y., 2002 . How can HIV be prevented in South Africa? A social perspective. BMJ, Volume 324, pp. 229-232.

Campbell, C. et al., 2013. Social capital and HIV competent communities: the role of community groups in managing HIV/AIDS in rural Zimbabwe. AIDS Care, 25(1), pp. 114-122.

Campbell, C., Wood, R. \& Kelly, M., 1999. Social capital and health, london: Health Education Authority.

Campbell, H. S., Phaneuf, M. R. \& Deane, K., 2004. Cancer peer support programs-do they work?.

Patient Education and Counseling, Volume 55, p. 3-15. 
Campbell, O. M. \& Graham, W. J., 2006 . Strategies for reducing maternal mortality: getting on with what works. The Lacent, 368(9543), p. 1284-1299.

Catling, C. et al., 2015. Group versus conventional antenatal care for pregnant women. Cochrane, Volume 2.

CDC, 2017. Fact-sheet, Zambia, Lusaka: Center for Disease Control and Prevention (CDC) .

Chama-Chiliba, C. M., 2014. Assessing Regional Variations in the Effect of the Removal of User Fees on Institutional Deliveries in Rural Zambia, Pretoria : Department of Economics, University of Pretoria.

Cheelo, C., Nzala, S. \& Zulu, J. M., 2016. Banning traditional birth attendants from conducting deliveries: experiences and effects of the ban in a rural district of Kazungula in Zambia. BMC Pregnancy Childbirth, 16(323).

Chi, B. H., Bolton-Moore, M. C. \& Holmes, C. B., 2013. Prevention of mother-to-child HIV transmission within the continuum of maternal, newborn, and child health services. Current Opinion in HIV and AIDS, 8(5), p. 498-503.

chileshe, M., 2014. ARV TREATMENT IN ZAMBIA: current issues, Lusaka: Institute of Economic and Social Research, University of Zambia .

Chisi, D., 2018. introduction of Health Insurance Bill vital, Luska: times of Zambia.

Chitah, B. M. \& Jonsson, D., 2015. Universal Health Coverage-Zambia, Lusaka: Global Network for Health Equity (GNHE).

CHMI, 2015. Zambulance, Lusaka: Center for Health Market Innovations.

Choguya, N. Z., 2014. Traditional Birth Attendants and Policy Ambivalence in Zimbabwe. Journal of Anthropology.

Colbourn, T. et al., 2013. Effects of quality improvement in health facilities and community mobilization through women's groups on maternal, neonatal and perinatal mortality in three districts of Malawi: MaiKhanda, a cluster randomized controlled effectiveness trial. International Health , 5(3), pp. 180-195.

Cornish, F., Priego-Hernandez, J., Campbell, C. \& Mburu, G., 2014. The impact of Community Mobilisation on HIV Prevention in Middle and Low Income Countries: A Systematic Review and Critique. AIDS Behav, Volume 18, p. 2110-2134.

Crowe, M., Utley, A., Costello \& Pagel, C., 2012. How many births in sub-Saharan Africa and South Asia will not be attended by a skilled birth attendant between 2011 and 2015?. BMC Pregnancy and Childbirth, 12(4).

CSO, C.-S.-O.et al., 2009. 2007 Zambia demographic and health survey, Lusaka: CSO and Macro International. 
Dambisya, Y. \& Matinhure, S., 2012. Policy and programmatic implications of task shifting in Uganda: a case study. BMC Health Services, 12(61).

Dehne, K., Wacker, J. \& Cowley, J., 1995. Training birth attendants in the Sahel.. World Health Forum, 16(4), pp. 415-9.

DiPrete, T. \& Gangl, M., 2004. Assessing bias in the estimation of causal effects: Rosenbaum bounds on matching estimators and instrumental variables estimation with imperfect instruments. Sociological methodology, 34(1), pp. 271-310..

Doherty, T. \& Coetzee, M., 2005. Community health workers and professional nurses: defining the roles and understanding the relationships. Journal of Public Health, 22(4), pp. 360-5.

Easterly, W., 2014. The Tyranny of Experts. New York: Basic Books.

Fagan, T. \& Zeng., W., 2015. Sustainable HIV Financing in Zambia: Baseline Analysis and Prospects for New Domestic Resource Mobilization, Washington : Health Policy Project.

Family-Care-International, 2013. Mapping Maternal Health Advocacy- A case study of Zambia, s.I.: Global Health Insights.

Foucault, M., 1977. Discipline and Punish: The Birth of the Prison. London : Pengiun .

Foucault, M., 1977. Politics Philosophy Culture. s.I.:Palgrave Macmillan.

Freedom-to-create, 2016. Policy Report on the Healthcare Financing System in Zambia, Lusaka:

Freedom-to-create.

Freire, P., 1970. Pedagogy of the Oppressed. London : Penguin .

Freire, P., 1973. Education for Critical Consciousness. New York: Continuum Press.

Garrido, M. M. et al., 2014. Methods for Constructing and Assessing Propensity Scores. Health Services Research, 49(5), p. 1701-1720.

Gartland, M. G. et al., 2013. Field effectiveness of combination antiretroviral prophylaxis for the prevention of mother-to-child HIV transmission in rural Zambia. AIDS, 27(8).

Gawande, A. A., Fisher, E. S., Gruber, J. \& Rosenthal, M. B., 2009. The Cost of Health Care - Highlights from a Discussion about Economics and Reform. New England Journal of Medicine, Volume 361, pp. 1421-1423.

Gill, C. J., 2011. Effect of training traditional birth attendants on neonatal mortality (Lufwanyama Neonatal Survival Project): randomised controlled study. BMJ Global Health Journal .

Graham, W. \& Varghese, B., 2012. Quality, quality, quality: gaps in the continuum of care. Lancet, Volume 379, pp. 5-6. 
Green-top-Guideline-No-39, 2010. Management of HIV in Pregnancy, London: Royal College of Obstetricians and Gynaecologists.

Gulliford, M. et al., 2002. What does 'access to health care' mean?. Journal of Health Service Research Policy, 7(3), pp. 186-8.

Gupta, K. S. \& Rokade, V., 2016. Importance of Quality in Health Care Sector: A Review. Journal of Health Management, 18(1), p. 84-94.

Hanson, C., 2013. The Epidemiology of Maternal Mortality in Southern Tanzania, London : London School of Hygiene and Tropical Medicine.

Harpham, T., Silva, M. J. D. \& Tuan, T., 2006. Maternal social capital and child health in Vietnam. J Epidemiol Community Health, Volume 60, pp. 865-871.

Harrison, K., 2011. Are traditional birth attendants good for improving maternal and perinatal health? No. British Medical Journal, Volume 342.

Heckman, J., 1976. The common structure of statistical models of truncation, sample selection and limited dependent variables. Ann Econ Soc Measure, Volume 5, p. 475-492.

Hodder, I., 1994. The contextual analysis of symbolic meanings. In: SM Pearce, ed. Interpreting Objects and Collections. London : Routledge, p. 12-13.

Hooijmans, C. R. \& Ritskes-Hoitinga, M., 2013. Progress in Using Systematic Reviews of Animal Studies to Improve Translational Research. PlosOne.

Howard-Grabman, L., Storti, C., Hummer, P. \& Pooler, B., 2007. Demystifying community mobilisation: an effective strategy to improve maternal and newborn health, Geneva: USAID.

Huber, M., Lechner, M. \& Steinmayr, A., 2012. RADIUSMATCH: Stata module to perform distanceweighted radius matching with bias adjustment. Boston: ideas.

Hussey, P. S. et al., 2009. A Systematic Review of Health Care Efficiency Measures. Health Service Research, 44(3), p. 784-805.

Ibrahim, S. et al., 1992. The role of the village midwife in detection of high risk pregnancies and newborns. International Journal of Gynecology \& Obstetrics, 39(2), pp. 117-22.

Jayachandran, V., Sahu, D., Rajaram, S. \& Pedersen, B., 2015. Does HIV Status Affect Utilization of Maternal Care Services among Women in India: An Analysis of NFHS 2005-2006. World Journal of AIDS, Volume 5, pp. 105-112.

Jovchelovitch, S., 2000. Socia representations, public life and socia! construction. In Social Representations: Introductions and Explorations. Oxford : Blackwell Publishers. 
Jovchelovitch, S., 2012. Subterranean Sociabilities: Identity, Culture and Resistance in the Favelas of Rio de Janeiro, São Paulo: UNESCO.

Kaayaa, S. F. et al., 2013. Randomized controlled trial evaluating the effect of an interactive group counseling intervention for HIV-positive women on prenatal depression and disclosure of HIV status. AIDS Care: Psychological and Socio-medical Aspects of AIDS/HIV, 25(7).

Kayombo, E., 2013. Impact of training traditional birth attendants on maternal mortality and morbidity in Sub-Saharan Africa. Tanzanian journal of health research.

Kelly, G., Mulgan, G. \& Muers, S., 2012. Creating Public Value: An analytical framework for public service reform, London: Strategy Unit, Cabinet Office.

Kendall, T. et al., 2014. Eliminating Preventable HIV-Related Maternal Mortality in Sub-Saharan Africa: What Do We Need to Know?. J Acquir Immune Defic Syndr, 1(64), p. 250-258.

Kendall, T. \& Danel, I., 2004. Research and Evaluation Agenda for HIV and Maternal Health in SubSaharan Africa. Women and Health Initiative Working Paper No. 1, Boston: Women and Health Initiative, Harvard School of Public Health.

Kendall, T. \& Langer, A., 2015. Critical maternal health knowledge gaps in low- and middle-income countries for the post-2015 era. Reproductive Health, pp. 1-4.

Khanker, S. R., Koowal, G. B. \& Samad, H. A., 2010. Handbook on impact evaluation, quantitative methhods. s.I.:World bank .

Kidane, G. \& Morrow, R., 2000. Teaching mothers to provide home treatment of malaria in Tigray, Ethiopia: a randomised trial. Lancet, 356(9229), pp. 550-55.

Kim-Ju, G. et al., 2008. Community Mobilization and Its Application to Youth Violence Prevention. American Journal of Preventive Medicine, 34(3), p. S5-S12.

Kuhn, L. et al., 2010. Potential impact of new World Health Organization criteria for antiretroviral treatment for prevention of mother-to-child HIV transmission. AIDS, 24(9), p. 1374-1377.

Kyei, N. N. A., Chansa, C. \& Gabrysch, S., 2012. Quality of antenatal care in Zambia: a national assessment. BMC Pregnancy and Childbirth.

Lassi, Z. S., Das, J. K., Salam, R. A. \& Bhutta, Z. A., 2014. Evidence from community level inputs to improve quality of care for maternal and newborn health: interventions and findings. Reproductive Health, 11(2).

Lehmann, U., Van Damme, W., Barten, F. \& Sanders, D., 2009. Task shifting: the answer to the human resources crisis in Africa?. HumanResources for Health, 7(49). 
Lewycka, S. et al., 2013. Effect of women's groups and volunteer peer counselling on rates of mortality, morbidity, and health behaviours in mothers and children in rural Malawi (MaiMwana): a factorial, cluster-randomised controlled trial. lancet, Volume 381, pp. 1721-35.

Lincetto, O., Mothebesoane-Anoh, S., Gomez, P. \& Munjanja, S., 2010. Antenatal Care. WHO.

Lindegren, M., Kennedy, C. \& Bain-Brickley, D., 2012. Integration of HIV/AIDS services with maternal, neonatal and child health, nutrition, and family planning services, s.l.: Cochrane Database Systematic Review.

Lippmann, Q. et al., 2012. Exploring the feasibility of engaging Traditional Birth Attendants in a prevention of mother to child HIV transmission program in Lilongwe, Malawi. Malawi Medical Journal, 24(4), pp. 79-80.

Lippman, S. A. et al., 2013. Conceptualizing Community Mobilization for HIV Prevention: Implications for HIV Prevention Programming in the African Context. PLOSE ONE.

Lukonga, E. \& Michelo, C., 2015. Factors associated with neonatal mortality in the general population: evidence from the 2007 Zambia Demographic and Health Survey (ZDHS); a cross sectional study. The pan african medical journal, Volume 2064.

Lusaka-times, 2017. Social Health Insurance in Zambia: Getting the bolt and nut right with Health Economics, Lusaka: Lusaka Times.

MacQueen, K., McClellan, E. \& Metzger, D., 2001. What is community? An evidence-based definition for participatory public health. Am. J. Public Health, Volume 1, p. 1929-1938.

Mahdon, M., 2006. Public value and health, London: The Work Foundation project.

Mannel, I. J., 2010. Gender mainstreaming practice: considerations for HIV/AIDS community organisations. AIDS care, 22(2), pp. 1613-1619.

Mant, J., 2001. Process versus Outcome indicators in the assesment of quality health care. International Journal of Quality in Health Care, 13(6), pp. 475-480.

Marcos, Y., Phelps, B. \& G, B., 2012. Community strategies that improve care and retention along the prevention of mother-to-child transmission of HIV cascade: a review. Journal of the International AIDS Society, 15(2).

Marston, C., Renedo, A., McGowan, C. R. \& Portela, A., 2013. Effects of Community Participation on Improving Uptake of Skilled Care for Maternal and Newborn Health: A Systematic Review. PloSOne, 8(2).

Mbiydzenyuy, N. E., 2012. Traditional Birth Attendants: Filling the blank space, Yaunde: Maternal and Child Aid Cameroon.

McKenzie, J., Neiger, B. \& Thackeray, R., 2013. Planning, Implementing \& Evaluationg Health Promotion Program. 6 ed. Boston: Pearson Education. 
Mdege, N., Chindove, S. \& Ali, S., 2013. The effectiveness and cost implications of task-shifting in the delivery of antiretroviral therapy to HIV-infected patient:a systematic review. Health Policy \& Planning, 2B(3), pp. 223-36.

MERCY-CORPS, 2009. COMMUNITY MOBILIZATION Approach, Portland: MERCY-CORPS.

Ministry-of-Health, 2013. Roadmap for Accelerating Reduction of Maternal,Newborn and Child Mortality, 2013-2016, Lusaka: Ministry of Health.

MoH, 2014. Eastern Province Bulletin, Lusaka: MoH.

Morris, A. \& Herring, C., 1984. Theory and research of social movements . In: Political Behavior Annual. New York: Westview Press, pp. 167-327.

Moscovici, S., 1993. The Invention of Society: Psychological explanations for social phenomena. Cambridge: Polity Press.

Mphuka, C. \& Kaonga, O., 2017. Economic growth, inequality and poverty: Estimating the growth elasticity of poverty in Zambia, Lusaka: IGC.

Mujenja, F., 2014. The Employment Status of Zambians: Official Definitions versus Citizen Perceptions, Lusaka: Afrobarometer Briefing Paper No. 135.

Mukumbura, R., 2000. Zimbabwe: more people turn to traditional medicine,. Africanews,, Volume 54, pp. 1-3.

Muzyamba, C., Broaddus, E. \& Campbell, C., 2015. "You cannot eat rights": a qualitative study of views by Zambian HIV-vulnerable women, youth and MSM on human rights as public health tools. BMC International Health and Human Rights, 15(26).

Mwai, G. W. et al., 2013. Role and outcomes of community health workers in HIV care in sub-Saharan Africa: a systematic review. Journal of the International AIDS Society, Volume 16, pp. 185-86.

Mwansa, A., 2017. National Health Insurance (NHI) Bill-Zambia, Lusaka: Of of the Solicitor-General.

Nahar, T. et al., 2012. Scaling up community mobilisation through women's groups for maternal and neonatal health: experiences from rural Bangladesh. BMC Pregnancy Childbirth, 12(5).

Ngozo, C., 2011. Malawi: uncertainty over role for traditional birth attendants. Global Issues.

Nhamo, M., Campbell, C. \& Gregson, S., 2010. bstacles to local-level AIDS competence in rural Zimbabwe: Putting HIV prevention in context. AIDS Care, 22(2), p. 1662-1669.

O'Gorman, D. A., Nyirenda, L. J. \& Theobald, S. J., 2010. Prevention of mother-to-child transmission of HIV infection: Views and perceptions about swallowing nevirapine in rural Lilongwe, Malaw. BMC Public Health 2, 10(34). 
Perez, F. et al., 2008. Participation of traditional birth attendants in prevention of mother-to-child transmission of HIV services in two rural districts in Zimbabwe: a feasibility study. BMC Public Health, 401(8).

PRISMA, 2015. Transparent reporting of systematic reviews and meta analysis. Oxford: Oxford University Press.

Putnam, R. D., 2000. Bowling alone: The collapse and revival of American community. New York: Simon \& Schuste.

Richter, L. et al., 2014. Pregnant women living with HIV (WLH) supported at clinics by peer WLH: a cluster randomized controlled trial. AIDS Behavior, 18(4), pp. 706-715.

Rifkin, S., 1996. Paradigms lost: Toward a new understanding of community participation in health programs. Acta Tropica, Volume 61, p. 79-92.

Rifkin, S. B., 2014. Examining the links between community participation and health outcomes: a review of the literature. Health Policy and Planning, 29(2).

Rifkin, S. B. \& Pridmore, P., 2001. Partners in Planning: Information, Participation and Empowerment. New York: Macmillan Education.

Rifkin, S. \& Pridmore, P., 2001. Partners in Planning. Oxford : Macmillan.

Rosato, M. et al., 2006. Women's groups' perceptions of maternal health issues in rural Malawi. Lancet, 368(9542), p. 1180-1188.

Rosenbaum, P., 2002. Observational Studies. New York: Springer.

Rosenbaum, P. \& Rubin, D., 1983. The Central Role of the Propensity Score in Observational. Biometrika, 70(1), pp. 41-45.

Rotheram-Borus, M. et al., 2014. A cluster randomized controlled trial evaluating the efficacy of peer mentors to support South African women living with HIV and their infants. PloSe One , 9(1).

RTM, 2015. Education and literacy in Zambia, Petauke: Room To Read.

Sahlua, I., Chanelle J. Howea, b., Clarka, M. A. \& Marshalla, B. D., 2014. HIV status, knowledge of mother-to-child transmission of HIV and antenatal care use among Ethiopian women. Journal of Epidemiology and Global Health, 4(3), p. 177-184.

Schaider, J. et al., 1999. International maternal mortality reduction: outcome of traditional birth attendant education and intervention in Angola. Journal of Medical Systems, 23(2), pp. 99-105.

Schmid, T., Kanenda, O., Ahluwalia, I. \& Kouletio, M., 2001. Transportation for Maternal Emergencies in Tanzania: Empowering Communities Through Participatory Problem Solving. American Journal of Public Health, 91(10), p. 1589-1590. 
Schneider, H., Hlophe, H. \& van Rensburg, D., 179-87. Community health workers and the response to HIV/AIDS in South Africa: tensions and prospects. Health Policy \& Planning , 23(3), p. 2008.

Sebitloane, H. M., Moodley, J. \& Esterhuizen, T. M., 2009. "Prophylactic antibiotics for theprevention of postpartum infectious morbidity in women infected with human immunodeficiency virus: a randomized controlled trial. American Journal Obstetric Gynecology, 198(2), pp. 181-186.

Shamba, D. et al., 2013. Clean home-delivery in rural Southern Tanzania: barriers, influencers, and facilitators. Journal of Health, Population and Nutrition, 31(1), pp. 110-7.

Sialubanje, C., Massar, K., Hamer, D. H. \& Ruiter, R. A., 2015. Reasons for home delivery and use of traditional birth attendants in rural Zambia: a qualitative study. BMC Pregnancy and Childbirth, 15(216).

Sibleycorresponding, L. M. \& Sipe, T. A., 2006. Transition to Skilled Birth Attendance: Is There a Future Role for Trained Traditional Birth Attendants?. Journal of Health, Population and Nutrition, 24(4), p. 472-478.

Stekelenburg, J. et al., 2004. Waiting too long: low use of maternal health services in Kalabo, Zambia. Tropical Medicine \& International Health, Volume 9, pp. 390-8.

Tarekegn, S., Lieberman, L. \& V., G., 2014. Determinants of maternal health service utilization in Ethiopia: analysis of the 2011 Ethiopian Demographic and Health Survey. BMC Pregnancy Childbirt, 4(161).

Taulo, F. et al., 2009. Fertility Intentions of HIV-1 Infected and Uninfected Women in Malawi: A Longitudinal Study. AIDS and Behavior, 13(1), p. 20-27.

The-nation, 2013. Reducing maternal mortality with community involvment, lilongwe: the nation .

Ticconi, C. M. M. M. et al., 2003. Effect of maternal HIV and malaria infection on pregnancy and perinatal outcome in Zimbabwe. Journal of Acquired Immune Deficiency Syndrome, 34(3), pp. 289-294.

Torpey, K. et al., 2010. Increasing the uptake of prevention of mother-to-child transmission of HIV services in a resource-limited setting. BMC health Services Research, 10(29).

Tripathy, P. et al., 2011. Community mobilisation with women's groups facilitated by Accredited Social Health Activists (ASHAs) to improve maternal and newborn health in underserved areas of Jharkhand and Orissa: study protocol for a cluster-randomised controlled trial. Trials, 12(182), pp. 2-12.

UN, 2015. Sustainable development knowledge platform, New York: United Nations.

UNAIDS, 2013. Report on the Global HIV/AIDS Epidemic 2013, Geneva: UNAIDS.

UNAIDS, 2016. Health financing profile-Zambia, Washington DC: UNAIDS.

UNICEF, 2014. Maternal, Newborn, and Child Health, Lusaka: UNICEF. 
United-Nations, 2015. Zambia Country Analysis Summary, Lusaka: UN.

USAID, 2008. MCH program discription - Zambia, New York: USAID.

Vallely, L., Ahmed, Y. \& Murray, S. F., 2005. Postpartum maternal morbidity requiring hospital admission in Lusaka, Zambia - a descriptive study. BMC Pregnancy and Childbirth, 5(1).

van den Broek, N. \& Graham, W., 2009. Quality of care for maternal and newborn health: the neglected agenda. BJOG: An International Journal of Obstetrics \& Gynaecology, 116(1), pp. 18-21.

Wangalwa, G. et al., 2012. Effectiveness of Kenya's Community Health Strategy in delivering communitybased maternal and newborn health care in Busia County, Kenya: non-randomized pre-test post test study. The Pan African Medical Journal, 13(1).

Watson-Thompson, J., Fawcett, S. B. \& Schultz, J. A., 2008. A Framework for Community Mobilization to Promote Healthy Youth Development. American Journal of Preventive Medicine, 34(3), p. S72-S81.

WHO, 1978. Declaration-of-Alma-Ata International Conference on Primary Health Care, Alma-Ata, USSR 1978, Alma-Ata: World Health Organization .

WHO, 2010. People at the Centre of Care.

WHO, 2013. World Health Statistics 2013, Geneva: WHO.

WHO, 2015. Child health and development, Geneva: WHO.

WHO, 2016. Key Country Indicators, Geneva: WHO.

Yamin, A. E., 2013. Applying human rights to maternal health: UN Technical Guidance on rights-based approaches. International Journal of Gynecology \& Obstetrics, 121(2), p. 190-193.

ZDHS, 2007. The Zambia Demographic Health Survey Zambia, Zambia: CSO.

ZDHS, 2014. Zambia Demographic and Health Survey, Lusaka: ZDS/CSO. 


\section{Appendix}

Appendix A: Ethical clearance to conduct study
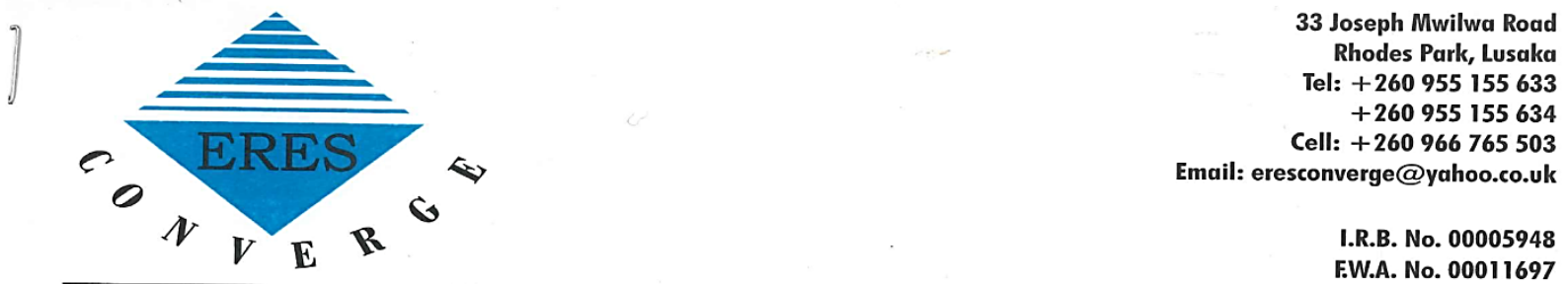

I.R.B. No. 00005948 F.W.A. No. 00011697

$23^{\text {rd }}$ February, 2015

Ref. No. 2016-Feb-003

The Principal Investigator Mr. Mphanza C. Muzyamba 46B Edmond Jasparstrat Maastricht, 6217HR

THE NETHERLANDS.

Dear Mr. Muzyamba,

\section{RE: ANALYZING THE ROLE OF COMMUNITY MOBILIZATION IN PROMOTING MATERNAL HEALTH IN HIV POSITIVE WOMEN IN RURAL ZAMBIA.}

Reference is made to your corrections. The IRB resolved to ethically approve this study and your participation as Principal Investigator for a period of one year.

\begin{tabular}{|l|c|c|}
\hline Review Type & Ordinary & $\begin{array}{c}\text { Approval No. } \\
\mathbf{2 0 1 6 - F e b - 0 0 3}\end{array}$ \\
\hline Approval and Expiry Date & $\begin{array}{c}\text { Approval Date: } \\
23^{\text {rd }} \text { February, 2016 }\end{array}$ & $\begin{array}{c}\text { Expiry Date: } \\
22^{\text {nd }} \text { February, 2017 }\end{array}$ \\
\hline Protocol Version and Date & Version-Nil & $22^{\text {nd }}$ February, 2017 \\
\hline $\begin{array}{l}\text { Information Sheet, } \\
\text { Consent Forms and Dates }\end{array}$ & English. & $22^{\text {nd }}$ February, 2017 \\
\hline Consent form ID and Date & Version-Nil & $22^{\text {nd }}$ February, 2017 \\
\hline Recruitment Materials & Nil & $22^{\text {nd }}$ February, 2017 \\
\hline Other Study Documents & Interview Guides. & $22^{\text {nd }}$ February, 2017 \\
\hline $\begin{array}{l}\text { Number of participants } \\
\text { approved for study }\end{array}$ & - & $22^{\text {nd }}$ February, 2017 \\
\hline
\end{tabular}


Specific conditions will apply to this approval. As Principal Investigator it is your responsibility to ensure that the contents of this letter are adhered to. If these are not adhered to, the approval may be suspended. Should the study be suspended, study sponsors and other regulatory authorities will be informed.

\section{Conditions of Approval}

- No participant may be involved in any study procedure prior to the study approval or after the expiration date.

- All unanticipated or Serious Adverse Events (SAEs) must be reported to the IRB within 5 days.

- All protocol modifications must be IRB approved prior to implementation unless they are intended to reduce risk (but must still be reported for approval). Modifications will include any change of investigator/s or site address.

- All protocol deviations must be reported to the IRB within 5 working days.

- All recruitment materials must be approved by the IRB prior to being used.

- Principal investigators are responsible for initiating Continuing Review proceedings. Documents must be received by the IRB at least 30 days before the expiry date. This is for the purpose of facilitating the review process. Any documents received less than 30 days before expiry will be labelled "late submissions" and will incur a penalty.

- Every 6 (six) months a progress report form supplied by ERES IRB must be filled in and submitted to us.

- ERES Converge IRB does not "stamp" approval letters, consent forms or study documents unless requested for in writing. This is because the approval letter clearly indicates the documents approved by the IRB as well as other elements and conditions of approval.

Should you have any questions regarding anything indicated in this letter, please do not hesitate to get in touch with us at the above indicated address.

On behalf of ERES Converge IRB, we would like to wish you all the success as you carry out your study.

Yours faithfully

ERES CONVERGE IRB

के

55 Dr. E. Munalula-Nkandu

BSc (Hons), MSc, MA Bioethics, PgD R/Ethics, PhD

CHAIRPERSON 
Appendix B: Participant Consent Form

\section{Participant Consent Form}

You have been invited to take part in this research study. Before deciding to participate, it is vital that you understand why this research is being conducted and what it involves. Please take time to read through the following information.

\section{What is this research about?}

The aim of this project is asses what are the pathways for building locally-feasible and useful partnerships between the community and professionals in order to deal with maternal health challenges among women living with HIV. It is important to understand this because it helps understand how to best respond to maternal health challenges among women living with HIV in resource-poor societies.

\section{Who is doing this research?}

The research is being done by C. Muzyamba a PhD fellow at Maastricht University, Netherlands.

\section{Why have you asked me to participate?}

I invite you to participate because I believe that your insights on the maternal health are valuable and will contribute the understanding the how to best build locally-feasible solutions to maternal health challenges of women living with HIV in Zambia .

\section{What will participation involve?}

You will be asked to participate in group discussions/ individual interviews.

\section{What about confidentiality?}

Both the group discussions and the interviews will be recorded and transcribed for further analysis. However, all the names and identity will be handled with strict confidentiality.

If you are willing to participate, then please sign the Consent Form. 


\section{Informed Consent}

Project: Community Mobilization and Maternal Health of Women Living With HIV in Zambia

Researcher: Mphanza C. Muzyamba (Muzyamba@merit.unu.edu)

\section{To be completed by the Research Participant}

Please answer each of the following questions:

Do you feel you have been given sufficient information about the research to enable you to decide whether or not to participate in the research?

Yes No

Have you had an opportunity to ask questions about the research?

Yes No

Do you understand that your participation is voluntary, and that you are free to withdraw at any time, without giving a reason, and without penalty?

Yes No

Are you are willing to take part in the research?

Yes No

Are you aware that the interview/focus group will be audio/video recorded?

Yes No

Will you allow the research team to use anonymized quotes in presentations and publications?

Yes No

Will you allow the anonymized data to be archived, to enable secondary analysis and training future researchers?

Yes No

Participants Name:

Participant's Signature: ___ Date:

If you would like a copy of the research report, please provide your email or postal address 
Appendix C FGD (Group A: Peer Support)

\section{FGD Guide}

Investigating how useful peer- support is to the maternal health of HIV positive women and new mothers in resource poor settings in Zambia?

\section{$\underline{\text { Introduction }}$}

Welcome remarks and thank participants.

Introduce the study and allow them to sign the consent form

\section{Background information}

- How old are you?

- What is your marital status?

- What is your level of education?

Part A. (Peer-Support)

Objective: Investigating how useful HIV peer- support is to the maternal health of HIV positive women and new mothers in resource poor settings in Zambia?

\section{Questions to be answered by women accessing peer-support}

- What kind of support do your receive from your peers?

- How often do you access this support?

- How do these networks of support help you in the identification of maternal health challenges and how are these challenges handled?

- How does peer support help you deal with stigma and discrimination?

- How does peer support allow you to access maternal health services e.g. antenatal, postnatal, PMTCT?

- How does peer-support allow you to adhere to medication?

- How does peer-support allow you to access care during maternity?

- How does peer support help you in organizing and mobilizing resources necessary for your health and the health of your child e.g. income, food, transport, medication etc.?

- How does peer support help allow for the development of critical consciousness of the root causes of the maternal health challenges of HIV positive pregnant women and new mothers?

- Does peer support allow you to challenge any cultural or sexual practices that are health-inhibiting? If so, how?

- Does the peer support help deal with maternal health emergences e.g. sepsis, hemorrhage etc.? if so, how?

- How does peer support allow you to access professional health services?

- Are there any negative experiences you have observed from these peer-support groups? 
Appendix D FGD (Group B: On TBAs)

\section{FGD Guide}

Investigating how useful are TBAs in improving the maternal health of HIV positive pregnant women and new mothers in resource poor Zambia?

\section{Introduction}

Welcome remarks and thank participants.

Introduce the study and allow them to sign the consent form

\section{Background information}

- How old are you?

- What is your marital status?

- What is your level of education?

\section{Part B: Traditional Birth Attendants (TBAs)}

Objective: Investigating how useful are TBAs in improving the maternal health of HIV positive pregnant women and new mothers in resource poor Zambia?

Questions to be answered women accessing services of TBAs:

- What services have you accessed from TBAs?

- How useful have you found those services?

- Why did you choose to go for the services of a TBA?

- How do TBAs provide antenatal and postnatal care?

- How do TBAs deal with emergencies?

- Do TBAs support you in accessing and adhering to medication (ARVs), if so, how?

- Do TBAs help you with Prevention of Mother To Child Transmission (PMTCT), if so, how?

- Do TBAs ever refer you to health centers for specialized treatment, if yes, how do they do it?

- What are the challenges you faced by working getting help from TBAs?

- Any other issues you want to rise?

THANK THE PARTICIPANTS!! 
Appendix E FGD (Group C: On community involvement)

FGD Guide

Part C: Collaboration between communities and professionals.

\section{$\underline{\text { Introduction }}$}

Welcome remarks and thank participants.

Introduce the study and allow them to sign the consent form

\section{Background information}

- How old are you?

- What is your marital status?

- What is your level of education?

Part C: Collaboration between communities and professionals.

Object: Investigating how useful collaboration between the community and professional health workers is in designing and implementing maternal health initiatives for improving maternal health outcomes of HIV positive women and new mothers in resource poor Zambia?

\section{Questions}

- How do you collaborate in the design and implementation of the maternal health project?

- Why is collaboration important for you?

- How does collaboration enable you access maternal health services?

- How does collaboration help you deal with stigma and discrimination?

- How does collaboration through with problems of access to maternal health facilities?

- How does collaboration allow you to access resources necessary for your maternal health?

- How does collaboration help in challenging maternal health inhibiting norms?

- How does collaboration help deal with maternal health emergencies?

- How does collaboration deal with the problem of poor infrastructure and lack of resources?

- Are there any challenges hindering effective operationalization of the collaboration in some of the projects in the village?

\section{THANK THE PARTICIPANTS!!}


Appendix FFGD (For group A, HIV positive women using TBAs)

\section{FGD Guide}

\section{Role of TBAs in maternal health care of women living with HIV}

Objective: Investigating the usefulness of TBAs to HIV positive mothers who used TBAs

\section{$\underline{\text { Introduction }}$}

Welcome remarks and thank participants.

Introduce the study and allow them to sign the consent form

\section{Background information}

- How old are you?

- What is your marital status?

- What is your level of education?

- What is your occupation?

\section{Questions to be answered women accessing services of TBAs:}

- What services have you accessed from TBAs?

- Why did you choose to go for the services of a TBA?

- How often did you visit the TBA?

- How easy was it for you to visit the TBAs?

- What services exactly did TBAs provide you with?

- How do TBAs provide antenatal and postnatal care?

- Did you have any emergencies? If so, how did TBAs deal with emergencies?

- Did TBAs support you in accessing and adhering to medication (ARVs)

- Did TBAs help you with Prevention of Mother To Child Transmission (PMTCT), if so, how?

- Did TBAs ever refer you to health centers for specialized treatment, if yes, how do they do it?

- Do you think the services that TBAs offered were good for you?

- What are the limitations to the services that TBAs offered you? 
Appendix G FGD (For group B, HIV positive women NOT using TBAs)

\section{FGD Guide}

$\underline{\text { Role of TBAs in maternal health care of women living with HIV }}$

Objective: Investigating the usefulness of TBAs to HIV positive by mothers who never used TBAs

\section{$\underline{\text { Introduction }}$}

Welcome remarks and thank participants.

Introduce the study and allow them to sign the consent form

\section{Background information}

- How old are you?

- What is your marital status?

- What is your level of education?

- What is your occupation?

\section{Questions to be answered women accessing services of TBAs:}

- When you were pregnant where did you go for antenatal?

- What services exactly did you receive there?

- How often did you visit this services provider?

- How accessible were they?

- What do you think is the function of local TBAs?

- Why did you not go to the local TBA?

- Do you think the services of TBAs are good for you? If so how, if not, why not?

- What is your opinion on the ability of the TBAs to handle emergencies?

- What is your opinion on the quality of care from TBAs

- In your opinion, how good were the services you received (professional care) when compared to services offered by TBAs?

- Do you think TBAs have any role to play in PMTCT?

- What are the limitations to the services that TBAs offered you?

THANK THE PARTICIPANTS!! 
Appendix H: Group C-Interview guide for TBAs

\section{Interview Guide}

$\underline{\text { Role of TBAs in maternal health care of women living with HIV }}$

Objective: Investigating TBA's opinions on the usefulness of their services to HIV positive mothers

\section{$\underline{\text { Introduction }}$}

Welcome remarks and thank participants.

Introduce the study and allow them to sign the consent form

\section{Background information}

- How old are you?

- What is your level of education?

\section{Questions to be answered by TBAs:}

- What kind of services do you offer pregnant women who are HIV positive?

- Why do you offer those specific services?

- Why do people choose to access maternal service from you?

- How do you help women access antenatal and postnatal services?

- How do you deal with emergences such as sepsis, hemorrhage?

- How do you help in the Prevention of Mother to Child transmission (PMTCT)?

- How do you help with access and adherence to medication (ARVs)?

- How do you deal with the unique challenges that HIV positive mothers face?

- How do you engage other professional health workers?

- What challenges do you face in your work and how can they be solved?

THANK THE PARTICIPANTS!! 
Appendix I: Group D-Interview guide for health workers

\section{Interview Guide}

\section{$\underline{\text { Role of TBAs in maternal health care of women living with HIV }}$}

Objective: Investigating health workers' opinions on the usefulness of services offered by TBAs to HIV positive mothers

\section{Introduction}

Welcome remarks and thank participants.

Introduce the study and allow them to sign the consent form

\section{Background information}

- How old are you?

- What is your level of education?

\section{Questions to be answered by Health workers:}

- What kind of services do you offer pregnant women who are HIV positive?

- Why do people choose to access maternal service from you and not from TBAs?

- What is your opinion on TBAs ability to help HIV positive women access antenatal and postnatal services?

- What is your opinion on TBAs' ability to deal with emergences such as sepsis, hemorrhage?

- In what ways do you think TBAs are useful in the Prevention of Mother to Child transmission (PMTCT)?

- In what ways do you think TBAs are useful in access and adherence to medication (ARVs)?

- How accessible do you think TBAs are to HIV positive women? Do you think this is bad or good? In which ways?

- What are the main limitations faced by TBAs here?

- Are there any specific ways you think TBAs can be useful in care of HIV positive women? If yes, what are they?

- Why do you think people here still use TBAs?

THANK THE PARTICIPANTS!! 
Appendix J: Table 5.2 Probit results at antenatal, birth and postnatal for birth HIV + and HIV-

\begin{tabular}{|c|c|c|c|c|c|c|c|c|c|c|c|c|c|}
\hline \multicolumn{2}{|c|}{$\begin{array}{l}\text { Professional care }=1 \\
T B A=0\end{array}$} & \multicolumn{4}{|c|}{ Antenatal } & \multicolumn{4}{|c|}{ At Birth } & \multicolumn{4}{|c|}{ postnatal } \\
\hline & & \multicolumn{2}{|l|}{ HIV- } & \multicolumn{2}{|l|}{ HIV+ } & \multicolumn{2}{|l|}{ HIV- } & \multicolumn{2}{|l|}{ HIV+ } & \multicolumn{2}{|l|}{ HIV- } & \multicolumn{2}{|l|}{$\mathrm{HIV+}$} \\
\hline \multicolumn{2}{|c|}{ Model detail } & \multicolumn{2}{|c|}{$\begin{array}{l}\text { N. of obs }=10,112 \\
\text { Prob }>\text { chi2 }= \\
0.0000 \\
\text { Pseudo R2 = } \\
0.0407\end{array}$} & \multicolumn{2}{|c|}{$\begin{array}{l}\text { N. of obs }=2,113 \\
\text { Prob }>\text { chi2 = } \\
0.0000= \\
\text { Pseudo R2 = } \\
0.0351\end{array}$} & \multicolumn{2}{|c|}{$\begin{array}{l}\text { N. of obs }=10,112 \\
\text { Prob }>\text { chi2 }= \\
0.0000 \\
\text { Pseudo R2 = } \\
0.0398\end{array}$} & \multicolumn{2}{|c|}{$\begin{array}{l}\text { N. of obs }=2,113 \\
\text { Prob }>\text { chi2 }= \\
0.0000 \\
\text { Pseudo R2 = } \\
0.0411\end{array}$} & \multicolumn{2}{|c|}{$\begin{array}{l}\text { N. of obs }=10,112 \\
\text { Prob }>\text { chi2 = } \\
0.0000 \\
\text { Pseudo R2 = } \\
0.0291\end{array}$} & \multicolumn{2}{|c|}{$\begin{array}{l}\text { N. of obs }=2,113 \\
\text { Prob }>\text { chi2 }= \\
0.0000 \\
\text { Pseudo R2 = } \\
0.0215\end{array}$} \\
\hline \multirow{2}{*}{\multicolumn{2}{|c|}{ Independent variables }} & \multicolumn{2}{|l|}{ HIV- } & \multicolumn{2}{|l|}{ HIV+ } & \multicolumn{2}{|l|}{ HIV- } & \multicolumn{2}{|l|}{ HIV+ } & \multicolumn{2}{|l|}{ HIV- } & \multicolumn{2}{|l|}{$\mathrm{HIV+}$} \\
\hline & & Coef & SE & Coef & SE & Coef & SE & Coef & SE & Coef & SE & Coef & SE \\
\hline \multicolumn{2}{|l|}{ Age } & $0.02^{* * *}$ & 0.02 & $0.03^{*}$ & 0.01 & $0.09 *$ & 0.02 & $0.03^{*}$ & 0.06 & $0.09 * * *$ & 0.88 & $0.06^{*}$ & 0.12 \\
\hline \multicolumn{2}{|c|}{ number children } & $0.04^{* *}$ & 0.04 & $0.50^{* *}$ & 0.03 & $0.17^{* * *}$ & 0.08 & $0.54 * *$ & 0.24 & 0.04 & 0.23 & 0.66 & 0.43 \\
\hline \multicolumn{2}{|c|}{$\begin{array}{l}\text { Number of years in formal } \\
\text { education }\end{array}$} & $0.09 * *$ & 0.02 & $0.86^{* * *}$ & 0.09 & $0.14^{* * *}$ & 0.11 & $0.23^{*}$ & 0.11 & $0.04 * * *$ & 0.14 & $0.08^{* *}$ & 0.55 \\
\hline \multicolumn{2}{|c|}{$\begin{array}{l}\text { Type of residence }(1=\text { Urban, } \\
0=\text { Rural) }\end{array}$} & $0.08^{* * *}$ & 0.28 & $0.11 *$ & 0.65 & $0.13^{* * *}$ & 0.03 & $0.43^{* * *}$ & 0.31 & $0.20 * * *$ & 0.24 & $0.22^{* * *}$ & 0.72 \\
\hline \multirow[t]{4}{*}{ Wealtha } & Poorer & 0.14 & 0.04 & 0.01 & 0.07 & 0.91 & 0.01 & 0.88 & 0.14 & 0.54 & 0.22 & 0.11 & 0.84 \\
\hline & Middle & 0.04 & 0.06 & 0.06 & 0.06 & 0.11 & 0.03 & 0.03 & 0.05 & 0.86 & 0.01 & 0.13 & 0.41 \\
\hline & Richer & 0.01 & 0.32 & 0.01 & 0.01 & 0.88 & 0.19 & 0.15 & 0.11 & 0.34 & 0.23 & 0.24 & 0.11 \\
\hline & Richest & $0.09 * *$ & 0.09 & $0.18^{* *}$ & 0.08 & $0.01 *$ & 0.92 & $0.11^{* *}$ & 0.12 & $0.33^{* *}$ & 0.06 & $0.18^{* *}$ & 0.20 \\
\hline \multirow[t]{3}{*}{ Religion $^{\mathrm{b}}$} & Protestant & 0.07 & 0.21 & 0.07 & 0.04 & 0.33 & 0.82 & -0.22 & 0.21 & -0.01 & 0.88 & -0.23 & 0.01 \\
\hline & Muslim & 0.05 & 0.01 & 0.02 & 0.22 & -0.62 & 0.11 & 0.11 & 0.86 & 0.56 & 0.40 & -0.88 & 0.43 \\
\hline & Other & 0.04 & 0.08 & 0.09 & 0.75 & -0.32 & 0.43 & -0.03 & 0.12 & 0.41 & 0.07 & -0.11 & 0.23 \\
\hline \multicolumn{2}{|c|}{ Possession of insurance } & $0.54^{*}$ & 0.07 & 0.01 & 0.04 & 0.26 & 0.94 & 0.10 & 0.93 & 0.11 & 0.87 & 0.33 & 0.75 \\
\hline Birth by & & $0.15^{* *}$ & 0.04 & $0.23^{* *}$ & 0.07 & $0.44^{* * *}$ & 0.31 & $0.32^{* * *}$ & 0.43 & $0.77^{* * *}$ & 0.11 & $0.54 * * *$ & 0.06 \\
\hline $\begin{array}{l}\text { Availabilit } \\
\text { centers }\end{array}$ & in health & 0.01 & 0.09 & 0.23 & 0.11 & 0.21 & 0.08 & 0.01 & 0.02 & 0.11 & 0.21 & 0.01 & 0.11 \\
\hline $\begin{array}{l}\text { Attitude o } \\
\text { centers }\end{array}$ & n health & 0.09 & 0.12 & 0.11 & 0.93 & 0.78 & 0.66 & 0.02 & 0.97 & 0.46 & 0.98 & 0.43 & 0.03 \\
\hline Distance & & 0.33 & 0.03 & 0.32 & 0.98 & 0.81 & 0.32 & 0.22 & 0.13 & 0.23 & 0.09 & 0.21 & 0.08 \\
\hline Constant & & $0.87^{* * *}$ & 0.17 & $0.81 * *$ & 0.11 & $0.33^{* * *}$ & 0.52 & $0.66^{* * *}$ & 0.0 .1 & $0.88^{* * *}$ & 0.13 & $0.49 * * *$ & 0.07 \\
\hline
\end{tabular}

${ }^{* * *} \mathrm{p}<0.01,{ }^{* *} \mathrm{p}<0.05,{ }^{*} \mathrm{p}<0.10$.

a reference is poorest

${ }^{b}$ reference is catholic 
Appendix K. Quality of matching process

After estimating the propensity scores for HIV positive and HIV negative women, we check the common support conditions. We find that in all our 3 PSM there is considerable overlap in common support. This is shown in figures $5 \mathrm{a}$ to $5 \mathrm{c}$ which indicate that the common support condition is satisfied: there is substantial overlap in the distribution of the propensity scores of both groups

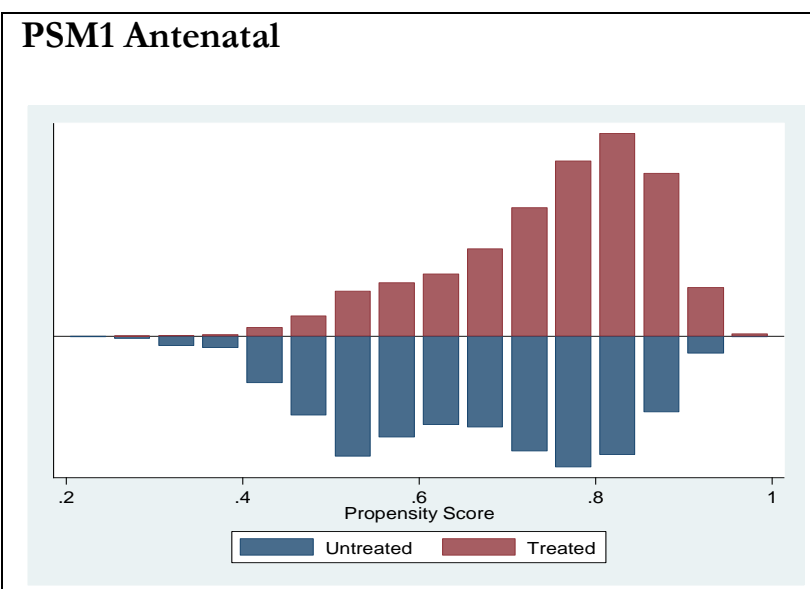

PMS2 At-birth

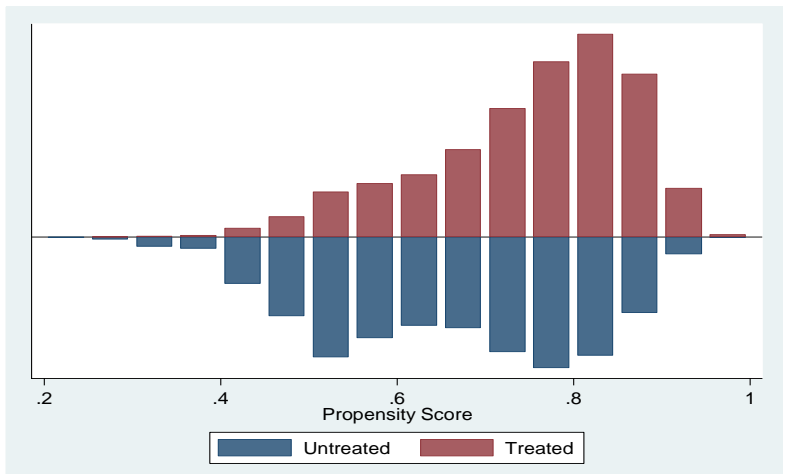

PSM3 postnatal

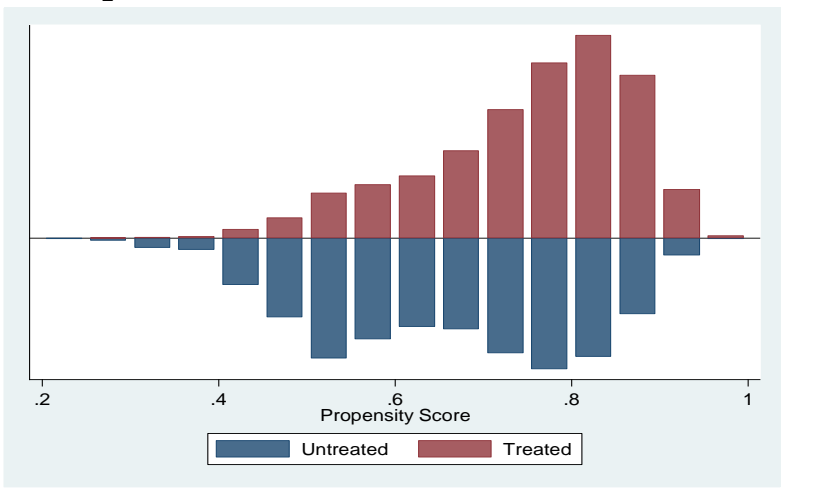


Appendix L. Checking for robustness (professional care or TBA)

ATT using Stratification method

\begin{tabular}{|c|c|c|c|}
\hline & $\begin{array}{l}\text { Professional-care } \\
\text { Usage rate for the } \\
\text { untreated }\end{array}$ & $\begin{array}{l}\text { Professional-care } \\
\text { Usage rate for the } \\
\text { untreated }\end{array}$ & ATT \\
\hline a) Antenatal & 0.777 & 0.766 & $0.011 * * *$ \\
\hline b) At Birth & 0.782 & 0.770 & $0.012 * * *$ \\
\hline c) Postnatal & 0.771 & 0.768 & $0.003 * *$ \\
\hline
\end{tabular}

Table 5.8: ATT using Kernel method

\begin{tabular}{|c|l|l|l|}
\hline & $\begin{array}{l}\text { Professional-care } \\
\text { Usage rate for the } \\
\text { untreated }\end{array}$ & $\begin{array}{l}\text { Professional-care } \\
\text { Usage rate for the } \\
\text { untreated }\end{array}$ & ATT \\
\hline a) Antenatal & 0.781 & 0.772 & $\mathbf{0 . 0 0 9 * *}$ \\
\hline b) At Birth & 0.783 & 0.771 & $\mathbf{0 . 0 1 2 * *}$ \\
\hline c) Postnatal & 0.777 & 0.773 & $\mathbf{0 . 0 0 4 *}$ \\
\hline
\end{tabular}


Appendix M: Atonji test (professional care or TBA)

Summary of P-Values from different r-levels

\begin{tabular}{|l|l|l|l|}
\hline \multirow{2}{*}{$\begin{array}{l}\text { correlation level } \\
\text { (r) }\end{array}$} & \multicolumn{3}{|c|}{} \\
\cline { 2 - 4 } & Antenatal & Birth & Postnatal \\
\cline { 2 - 4 } & P-Value & P-Value & P-Value \\
\hline 0.05 & 0.00 & 0.00 & 0.00 \\
\hline 0.10 & 0.00 & 0.01 & 0.00 \\
\hline 0.15 & 0.06 & 0.04 & 0.03 \\
\hline 0.20 & 0.08 & 0.07 & 0.07 \\
\hline 0.25 & 0.25 & 0.11 & 0.24 \\
\hline
\end{tabular}

Decision rule: significant results (seen by the P-V alue) despite increasing correlation indicate robust results.

To help us see the effect of unobservables on our outcome variable, we focus on the correlation between error terms which capture the extent to which unobservables affect the treatment and the outcome, in our case being HIV positive and eventually the probability of taking up professional care. The Altonji test works by assigning different values of correlation ( $r$ ) and estimating the probit model conditional on these r-values; this allows us to see if the parameter changes significantly given the different r-values. We allow our r-values to range from 0 to 0.25 (by using 0.05 intervals). If the ATT remains significant despite increasing $r$, then our results are robust.

By checking our p-values from table above, we can see that even assuming relatively high selection on unobservables $(\mathrm{r}=0.15)$, the effect of HIV positive status on utilizing professional care remains highly significant. This therefore means that sensitivity analysis shows that our results are robust and not affected by unobservables 


\section{Appendix N: Quality of matching process (Under-five mortality)}

After estimating the propensity scores for the Professional-care utilizers and TBA-utilizers we check the common support conditions. We find that in all our 6 PSM there is considerable overlap in common support. This is shown in figures $6 \mathrm{a}$ to $6 \mathrm{f}$ which indicate that the common support condition is satisfied: there is substantial overlap in the distribution of the propensity scores of both groups

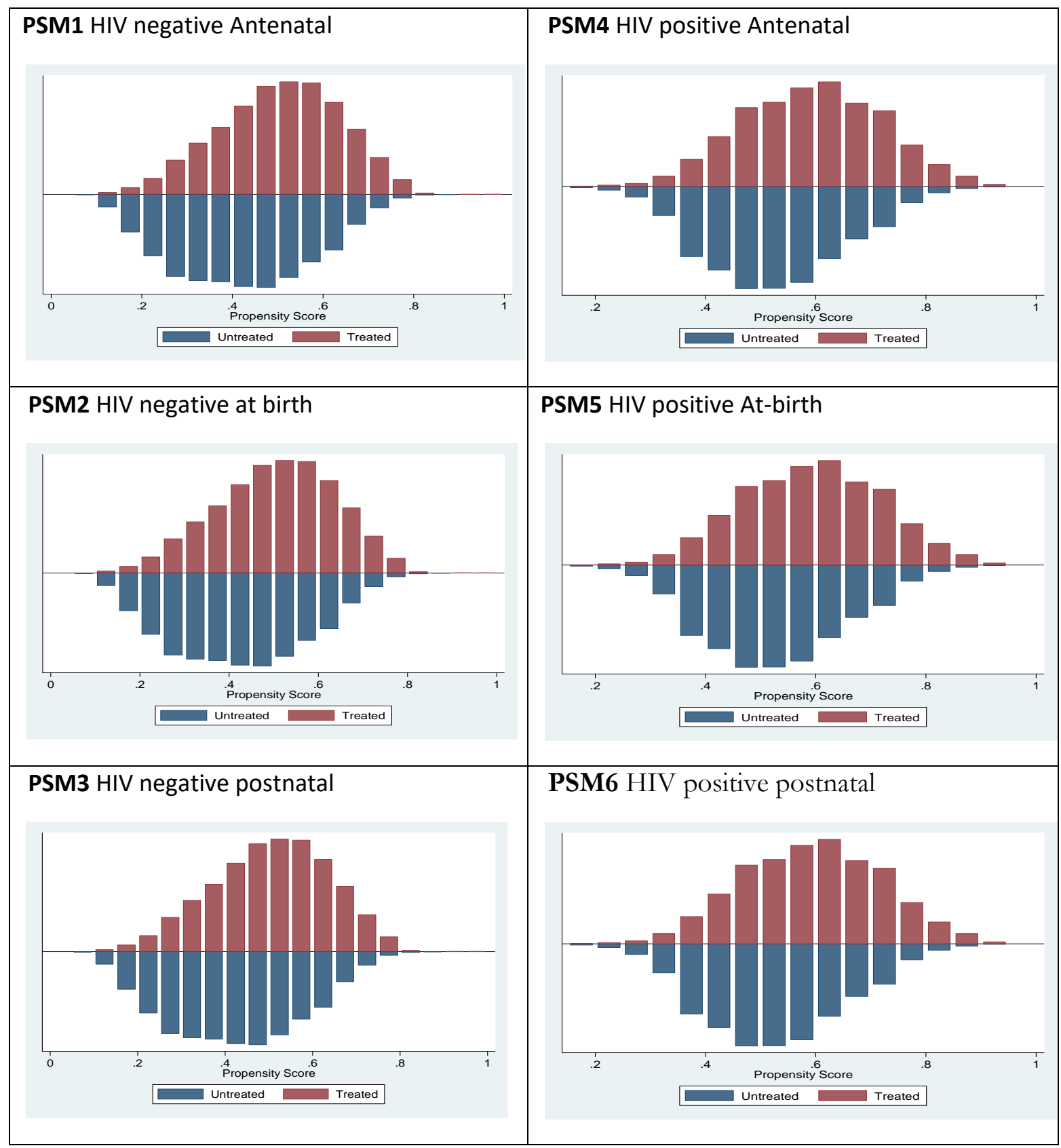




\section{Appendix O: Robustness checking (Under-five mortality)}

ATT using Stratification method

\begin{tabular}{|l|l|l|l|l|l|l|}
\hline $\begin{array}{l}\text { Maternal } \\
\text { Health Stage }\end{array}$ & \multicolumn{2}{l|}{$\begin{array}{l}\text { Survival rate } \\
\text { Treated }\end{array}$} & \multicolumn{2}{l|}{$\begin{array}{l}\text { Survival rate } \\
\text { Controls }\end{array}$} & $\begin{array}{l}\text { ATT } \\
\text { \% increase in the probability of a child surviving beyond } \\
5 \text { years })\end{array}$ \\
\hline & HIV+ & HIV- & HIV+ & HIV- & HIV+ & HIV- \\
\hline Antenatal & .970 & .972 & .966 & .971 & $\mathbf{0 . 0 0 4 1 * * *}$ & $\mathbf{0 . 0 0 1 2 * * *}$ \\
\hline At birth & .977 & .986 & .965 & .972 & $\mathbf{0 . 0 0 8 3} * * *$ & $\mathbf{0 . 0 1 4 0 * * *}$ \\
\hline Postnatal & .972 & .971 & .968 & .969 & $\mathbf{0 . 0 0 4 2} * * *$ & $\mathbf{0 . 0 0 2 2 * * *}$ \\
\hline
\end{tabular}

AT'T using Kernel method

\begin{tabular}{|l|l|l|l|l|l|l|}
\hline $\begin{array}{l}\text { Maternal } \\
\text { Health Stage }\end{array}$ & \multicolumn{2}{l|}{$\begin{array}{l}\text { Survival rate } \\
\text { Treated }\end{array}$} & \multicolumn{2}{l|}{$\begin{array}{l}\text { Survival rate } \\
\text { Controls }\end{array}$} & $\begin{array}{l}\text { ATT } \\
\text { \% increase in the probability of a child surviving beyond } \\
5 \text { years })\end{array}$ \\
\hline & HIV+ & HIV- & HIV+ & HIV- & HIV+ & HIV- \\
\hline Antenatal & .971 & .971 & .970 & .961 & $\mathbf{0 . 0 0 1 3} * * *$ & $\mathbf{0 . 0 1 0 3 * * *}$ \\
\hline At birth & .975 & .979 & .966 & .970 & $\mathbf{0 . 0 0 9 1} * * *$ & $\mathbf{0 . 0 0 9 0 * * *}$ \\
\hline Postnatal & .973 & .974 & .968 & .972 & $\mathbf{0 . 0 0 5 2}$ *** & $\mathbf{0 . 0 0 2 3 * * *}$ \\
\hline
\end{tabular}


Appendix P: Atonji test (Under-five mortality)

Summary of P-Values from different r-levels

\begin{tabular}{|l|l|l|l|l|l|l|}
\hline \multirow{2}{*}{$\begin{array}{c}\text { correlation level } \\
(\mathbf{r})\end{array}$} & \multicolumn{4}{|l|}{ HIV+ } & HIV- & \multicolumn{2}{l|}{} \\
\cline { 2 - 7 } & Antenatal & Birth & Postnatal & Antenatal & Birth & Postnatal \\
\cline { 2 - 7 } & P-Value & P-Value & P-Value & P-Value & P-Value & P-Value \\
\hline 0.05 & 0.00 & 0.00 & 0.00 & 0.00 & 0.00 & 0.00 \\
\hline 0.10 & 0.00 & 0.00 & 0.00 & 0.00 & 0.00 & 0.00 \\
\hline 0.15 & 0.04 & 0.02 & 0.06 & 0.04 & 0.07 & 0.06 \\
\hline 0.20 & 0.08 & 0.07 & 0.09 & 0.07 & 0.31 & 0.10 \\
\hline 0.25 & 0.31 & 0.41 & 0.27 & 0.29 & 0.63 & 0.55 \\
\hline
\end{tabular}

Decision rule: significant results (seen by the P-V alue) despite increasing correlation indicate robust results.

To help us see the effect of unobservables on our outcome variable, we focus on the correlation between error terms which capture the extent to which unobservables affect the treatment and the outcome, in our case taking up professional care and eventually the probability of kids surviving beyond age 5. The Altonji test works by assigning different values of correlation ( $r$ ) and estimating the probit model conditional on these r-values; this allows us to see if the parameter changes significantly given the different r-values. We allow our r-values to range from 0 to 0.25 (by using 0.05 intervals). If the ATT remains significant despite increasing $r$, then our results are robust.

By checking our $\mathrm{p}$-values from table above, we can see that even assuming relatively high selection on unobservables $(\mathrm{r}=0.15)$, the effect of professional care on under-five mortality remains highly significant. This therefore means that sensitivity analysis shows that our results are robust and not affected by unobservables. 
Dissertation Summary 
The role of community mobilization in the promotion of maternal health of women living with HIV in Zambia - Summary

The main aim of this dissertation is to investigate the role of community mobilization in the promotion of maternal health in women with HIV in Zambia. Community mobilization in maternal health is defined as any maternal health promotion strategy which makes use of a) indigenous resources (such as Traditional Birth Attendants-TBAs), b) peer support, and c) community involvement in designing and implementation of maternal health initiatives. Maternal health remains a challenge in low income countries. Studies show that on average, in Sub-Saharan African (SSA) countries, 720 women die each day during pregnancy and childbirth from causes which are largely preventable. The situation is even worse for women living with HIV. It is estimated that women living with HIV are four times more likely to die during pregnancy and childbirth than HIV negative women. HIV positive women suffer intersecting vulnerabilities. This is through a combined burden of pregnancyrelated complications and HIV status (which predisposes them to optimistic infections including stigma and discrimination). The traditional response to this predicament has been to recommend the evidence-based biomedical response which normally focuses on modernizing and improving quality of care through the provision of drugs, advanced equipment and skilled personnel, improved infrastructure etc. However, although these recommendations are useful, evidence has consistently pointed out that these recommendations are costly and as such they are never sustainably implemented in poor settings. It is for this reason why community mobilization is being suggested as a useful approach in such contexts. Gaps in knowledge still remain regarding how useful community mobilization is to women living with HIV.

Therefore, the main aim of this dissertation is to provide insights on the role of community mobilization in the promotion of maternal health in women with HIV in Zambia.

\section{Chapter 1}

In this chapter we provide an exploration of the concept of community mobilization. The chapter further shades light on the maternal health outlook of Zambia including the health system in Zambia in general and Mfuwe (our study area for the qualitative part of the dissertation) in particular. Further, we explain the objectives and methods used in subsequent chapters of the dissertation. The following are the objectives of the dissertation highlighted in chapter 1: 
- Objective 1: To outline the role of community mobilization in SSA countries:

Given the fact that, currently, there is a lack of synthesized empirical evidence of the role of community mobilization on maternal health outcomes of women living with HIV in SSA, a thorough search, analysis and documentation of this evidence was necessary. This was an important basis for demonstrating what has been studied and not studied, and where exactly the main gaps lay vis-à-vis community mobilization and maternal health in SSA. Thus by relying on systematic review technique, the first objective was to map-out the evidence available in the extant literature, and to also gain insists into the general operationalization of the concept of community mobilization.

- Objective 2: .To investigate the role of community mobilization in women living with HIV in rural areas in Zambia:

While the evidence on the role of community mobilization was more conclusive in HIV-negative women, similar evidence for women living with HIV was missing. Therefore, we use a qualitative study design to investigate the role of community mobilization in women living with HIV in resource-poor settings by using Mfuwe, Zambia, as a case study. Mfuwe is a rural settlement located in the South Luangwa national park in the Eastern province of Zambia. There exits only one hospital in Mfuwe (Kamoto hospital) catering for a population of over 207,000 people spread roughly around an arear of $370 \mathrm{~km}^{2}$. The settlement retains some of the highest HIV rates, including very high maternal and under five mortality rates in the country. It is for this reason that Mfuwe was selected as a case study. This specific objective was expected to yield useful insights by detailing specific ways community mobilization is useful for women with HIV in Zambia.

- Objective 3: To investigate the usefulness of TBAs on maternal health care of women living with HIV in rural areas in Zambia:

Out of the three components of community mobilization, indigenous resources, and in particular TBAs, play a dominant and controversial role in maternal care of women with HIV in Zambia. Thus it becomes important to provide more insights on the role of TBAs on the maternal care of women living with HIV. This objective is achieved through the use of a qualitative research design to investigate the relevance of TBAs to women living with HIV in resource poor settings by using Mfuwe, Zambia, as a case study. 
- Objective 4: To investigate and compare factors affecting choice of care (TBAs or professional care service) between HIV negative women and women living with HIV:

There is growing evidence which suggests that HIV positive women are more vulnerable than those who are not. However, the relationship between HIV status and maternal-care-utilization is not very well understood. It is not clear whether factors associated with professional maternal care utilization are similar for HIV positive and HIV negative women. Thus it becomes important to investigate the differences in factors affecting choice of maternal care (TBAs or professional care service) between HIV positive and HIV negative women. Other than that, it is also necessary to investigate the effect of HIV positive status on the utilization of professional maternal care. For this reason, we make use of the 2013-2014 ZDHS and quantitative methods to investigate factors which affect the choice of maternal care service between women with HIV and those who are HIV negative.

- Objective 5: To investigate and compare the effect of choice of care (TBAs or professional care service) between HIV negative women and women living with HIV on under-five mortality:

After establishing factors affecting choice of care between HIV negative and women living with HIV, it becomes necessary to assess the effect of this choice on biomedical outcomes such as underfive mortality. For this purpose, we take the discussion further by investigating the impact of choice of care on under-five mortality by comparing outcomes between women with HIV and those who are negative. Here we also make use of the 2013-2014 ZDHS and quantitative methods.

\section{Chapter 2}

Chapter 2 provides a systematic review of the literature on the existing empirical evidence on the role of community mobilization in maternal care provision of women living with HIV in SSA. The evidence on the role of community mobilization in maternal care provision in general (both HIV positive and HIV negative women) is also reviewed. This was done through a systematic search of existing literature on the role of community mobilization in PuBMed, Scopus, Web of Science, MEDLINE, COCHRANE, Allied Health Literature, and Cumulative Index to Nursing. We only include studies with an experimental design in order to identify causal effects. Strong evidence for causal inference is a useful basis for establishing definitive conclusions. Our review identified 14 publications for analysis. These papers were divided into two categories: those that involved HIV negative women (category 1) and those that involved women living with HIV (category 2). For 
category 1 (HIV negative) we had nine articles, and for category 2 (women living with HIV) we had five articles. Results from this chapter show that regarding HIV negative women, community mobilization is a useful strategy for promoting both positive maternal process results and maternal health outcomes. However, most of the literature on women with HIV has focused only on demonstrating the causal link between community mobilization and process results. There has been very little focus on demonstrating the causal link between community mobilization and maternal outcomes for women living with HIV. Overall, the results from this chapter show that while there is strong causal link between community mobilization and maternal health outcomes for HIV negative women, this kind of evidence is still missing for HIV positive women. Moreover, as shown by the studies, community mobilization as a maternal health strategy is still in its infancy. The chapter therefore concludes that given the gaps identified in our review, there is a need for further research which should aim at providing sound evidence on the role of community mobilization on maternal health outcomes of women with HIV in SSA.

\section{Chapter 3}

On the basis of recommendations from chapter 2, chapter 3 provides a qualitative study exploring the relevance of community mobilization in the promotion of maternal health care among women living with HIV in resource-poor settings by using Mfuwe, a rural district in Zambia as a case study. For this purpose, we collected data through Focus Group Discussions (FGDs). Our participants included 37 women living with HIV. Our results showed that within their social fabrics, resourcepoor communities often contain unrecognized and sometimes ignored strategies which are contextually-feasible and have been used for generations to promote maternal care of HIV positive women. Further, it was evident that although the three forms of community mobilization were largely useful in promoting maternal health care of women living with HIV, they also presented unique and various shortcomings. This chapter therefore shows that women living HIV characterize community mobilization as a force for good (e.g. providing support, improving access to maternal care etc.) and sometimes for bad (e.g. reinforced harmful misconceptions, superstition and clichés ). Thus we recommend that community mobilization needs to be factored into maternal health care policies for HIV positive women in resource poor settings either to optimize its potential benefits or to minimize its potential harm. This chapter also highlighted the unfinished debate on one of the three components of community mobilization; namely, use of indigenous resources and in particular, TBAs. The debate is on whether it is beneficial to HIV positive women for the 
government of Zambia to ban TBAs from the line of care. This debate informs the aims of the next chapters.

\section{Chapter 4}

In this chapter, we take the discussion on TBAs further by assessing the relevance of TBAs to women living with HIV in resource poor settings by using Mfuwe, Zambia as a case study. For this purpose, we undertake a qualitative study in Mfuwe consisting of two FGDs, one involving HIV positive women utilizing TBAs and the other with HIV positive women not utilizing TBAs. Additionally, in-depth interviews were conducted with TBAs and health workers. Our findings from this chapter suggest that in the face of an inefficient health system, TBAs were seen to be useful in providing efficient, cheap and quality care. This was exemplified through counselling, referral and logistical support to HIV positive women, including treatment-adherence support which are collectively known as 'soft-services'. This chapter also establishes that HIV positive women do indeed need professionals to handle complications and access antiretroviral treatment to ensure Prevention of Mother to Child Transmission (PMTCT). However, additional "soft" services offered by TBAs are equally important in the promotion of maternal health care for HIV positive women. Thus, it seems there is more to gain by systematically allowing TBAs work alongside professionals in a well-coordinated and complementary manner.

\section{Chapter 5}

Chapter 5 focuses on investigating the differences in use of antenatal, delivery and postnatal health service between HIV positive and HIV negative women. We also investigate the effect of HIV positive status on the utilization of professional maternal care during antenatal, delivery and postnatal periods. To do this, we use the 2013-2014 ZDHS to perform two different quantitative analyses: a) Regression analysis: to identify and compare factors associated with the likelihood of utilizing professional care during antenatal, at birth and postnatal periods between HIV positive and negative women. b) Propensity score matching: to investigate the effect of being HIV positive on the choice of care (Professional care or TBAs). Our findings in this chapter show that there are no differences between HIV positive and HIV negative women in factors that are associated with choice of care during antenatal, at birth and postnatal periods. More wealth, high level of education and urban-residence seem to increase probability of utilizing professional care in both HIV positive and HIV negative women. Further, we showed that although the probability of utilizing professional 
care for HIV positive appears to be slightly higher than those who are HIV negative, the difference is small. We also show that although institutional care is desirable and an ideal solution for HIV positive women, insisting on exclusive institutional care (which is ideal) while ignoring the many challenges and barriers that exist within professional care in Zambia is counterproductive. The chapter ends by recommending further investigation on the effect of choice of care (skilled or TBAs) on maternal outcomes such as under-five mortality.

\section{Chapter 6}

This chapter concentrated on investigating the effect of using professional maternal care or TBA care (during antenatal, delivery and postnatal) on under-five mortality. We also compare these outcomes between HIV positive and HIV negative women. By relying on the 2013-2014 ZDHS, we use Propensity Score Matching to investigate the effect of utilization of professional care or TBA during antenatal, childbirth and postnatal periods on under-five mortality. Our results show that the use of professional care (as opposed to TBAs) in all three stages of maternal care increases the probability of children surviving beyond five years old. However, although there is a positive impact when mothers choose professional care over TBAs, the difference at all three points of maternal care is small. We therefore conclude that indeed, professional care is desirable and appears to be an ideal solution for reducing under-five mortality of children, but completely excluding TBAs and insisting only on professional care when the health facilities in Zambia, especially in rural areas, continue to lack adequate trained personnel, drugs, and equipment seems counterproductive. Our results in this chapter highlight an opportunity for improving maternal care by incorporating, regulating and making use of TBAs in a complementary manner. From this end, it seems plausible that integrating TBAs in the response unit rather than excluding them may make it easier to mitigate their shortcomings, amplify their potential benefits, regulate, and monitor them in a manner that complements institutional care.

\section{Chapter 7}

This chapter focuses on discussing the main findings of the dissertation (Chapter 1-6). We also highlight some policy implications and recommendations for future research. Firstly, overall findings from chapter 1-6 indicate that in the face of a poorly-resourced government and inefficient health system, women living with HIV in Zambia rely on community mobilization (support from peers, TBAs, and community-led and collaborative initiatives) to improve maternal health outcomes. In 
this regard, we show that that even though local communities in Zambia lack proper health centers, their survival over generations has been dependent on social networks, reliance on locally-available resources and collective action. Relying on these resources in the face of weak health institutions made access to the much-need care possible. This argument is presented not as a critique to highlyfunctional and accessible professional care, but rather as a confirmation that local people are not passive victims of failed health systems. Communities are aware of the importance of professional care, but their attachment to community resources (in the absence of professional care) reflects the need to develop useful local alternative strategies nonetheless.

We further demonstrate that community-strategies are characterized as "useful and effective" by local people and in some cases they produce under-five mortality results that are not all that different from those of professional care. Locals remain loyal to practically feasible and locallyavailable solutions (albeit their limitations) rather than putting their faith in attractive yet unavailable solutions (in the form of efficiently operational facilities). We further highlight that TBAs and skilled care givers have comparable effects in so far as under-five mortality is concerned in both HIV positive and negative women. It is for this reason that we demonstrate that the policy to exclude TBAs on grounds that they produce significantly worse outcomes is misplaced in the absence of good quality professional care. This finding reflects the fact that taking into account local worldviews and context-specific realities is crucial in handling maternal health challenges especially in women with HIV in resource poor settings.

We also show in chapter 7 that ignoring or excluding components of community mobilization in maternal health care of women with HIV obliterates the opportunity to maximize their benefits and minimize their costs. It is effectively a 'lose-lose' situation. The dominance and subsequent universalization of the evidence-based biomedical approach in maternal health has become pervasive in resource-poor settings. 'Wholesale' transposition of global initiatives in local settings in SSA in maternal health policy should be looked at critically. In this sense, future policies need to depart from top-down global prescriptions which do not take into account localized-realties. The idea that 'because it worked there it must therefore work here' is pervasive in the fight for better maternal health outcomes for women with HIV in SSA. Policies on maternal health should take into account the contrasting outcomes and characterization of popular global maternal health initiatives between wealthier and resource poor settings. Rather than establishing the biomedical approach as an 
incontestable good for all contexts, it is important to interrogate its suitability for different contexts especially in resource poor settings.

We end by demonstrating that community mobilization offers space for engagement between externally-imposed interventions and local people in a manner that allows for improved maternal care and outcomes in women with HIV in resource-poor settings. It was clear from the dissertation that both local and global strategies have useful elements and shortcomings; the two are also not mutually exclusive, meaning that they can complement rather than replace each other. As such, responding to maternal health needs in Zambia requires cooperation between professional care and the community. Community mobilization offers an opportunity for open recognition and dialogue between local and global strategies in an effort to build partnerships. This leads to strengthening of maternal health response in a manner that is regulated, feasible, contextually-suitable and beneficial. It was clear that maternal health policy would benefit from community mobilization which offers space for engagement between local and global in a context-specific way. There is more to benefit from sustained and careful engagement of local and global initiatives via community mobilization. 


\section{Valorization Addendum}

The Alma Ata declaration of 1978 stressed the importance of involving beneficiaries in designing and implementing health programs thereby invoking an interest in community mobilization within public health efforts. This dissertation builds on this by providing insights on the role of community mobilization on maternal health care of women living with HIV in resource poor settings.

The dissertation suggests that through its three components (peer support, TBAs and community involvement), community mobilization provides opportunities for survival in various and contextspecific ways. For example, in the face of weak health systems, peer support (e.g. economic, nutritional, logistical support etc.) provides health-enhancing opportunities to women with HIV. Further, given the various health-system challenges prevalent in resource-poor countries, TBAs also occupy a substantial role in maternal health response for women with HIV. It was also clear that through collaboration with professionals, communities construct local initiatives that help to counter the structural limitations that may exist. Community mobilization thus provides opportunities to navigate various structural limitations in poor-settings. That notwithstanding, while providing opportunities for survival, it is also worth-noting that local initiatives are not unquestionably always good for health. Local practices have limitations which may be harmful for maternal health of women with HIV. Certain harmful practices and norms can easily be reinforced through local strategies such as peer-support and TBAs. Thus the dissertation (in chapter 2,3 and 4) suggests that in each context, effort needs to go into understanding the different ways in which community mobilization creates or inhibits opportunities for care and at the same time, work towards reducing its harm and improve its potential benefits.

The dissertation further suggests that the success of maternal health interventions depends on their compatibility, accessibility and availability to the local people. The act of promoting only 'attractive' but unattainable solutions (mostly from a biomedical approach) while ignoring local strategies might be counterproductive. There is more to benefit from taking into account the contrasting outcomes and characterization of popular global maternal health initiatives between wealthier and resource poor settings. Rather than establishing the biomedical approach as an incontestable good for all contexts, it is important to interrogate its suitability for different contexts especially in resource poor settings. Maternal health policy at an international level needs to be detached from a decontextualized one size-fits-all approach by focusing on ways global efforts can be appropriated into local contexts much to the benefit of HIV positive women. Uncritical adherence and mechanical-rule-following of established global standards may sometimes deny the women it is meant to serve the much-needed care. The dissertation ends by showing that community mobilization offers space for engagement between externally imposed interventions and local people in a manner that allows for improved maternal care and outcomes in women with HIV in resourcepoor settings. 


\section{Acknowledgements}

As my PhD journey comes to an end, I am humbled and overwhelmed by the number of people who have made this journey exciting, worthwhile and timely. Top on my list is my supervisory team; Wim, Milena and Sonila who have walked me through this process smoothly. To Sonila, Milena and Wim, I want to sincerely thank you for your guidance, support and patience throughout this process. In this journey, there were times when my personal situations would stress and overwhelm me immensely, but your ability to calm my nerves and bring me back to focus was well-spirited. I am forever grateful for your positive support and guidance throughout my research. Your easy-toapproach personas is highly appreciated. I also sincerely thank you for always taking the time to guide and respond to my emails very timely even on weekends sometimes late at night. Your very detailed guidance (in track changes) is what made this journey exciting and manageable for me. I consider myself extremely lucky to have worked with you. In times of uncertainty your guidance and suggestions cleared up the way for me. I always looked forward to our meetings; they always left me challenged, enthusiastic and at the same time gave me direction. Also, thanks to Suus for always organizing meetings. Thank you to Iryna Rudd for your input in my work and for co-authoring with us.

I would also like to thank the reading committee, namely; Prof.dr. J.S.M Kruimeich (Maastricht University), Prof.dr. F. Gassmann (Maastricht University), Prof.dr. S. Ramani (Maastricht University) and Prof.dr. R. Reis (University of Amsterdam). I really appreciate the time and effort you took to review our work.

I am so very grateful to my two very dedicated paranymphs; Hugo and Mario GS. Really appreciate your support.

Further, there are several people at UNU-MERIT/MGSoG who have been critical in my journey; key among them is Eveline. To Eveline, thank you for making my stay at the institute and in the Netherlands smooth; from organizing my permits to helping me with all my requests, taxes, subsidies etc. Your open-door policy and comforting words and advice are greatly appreciated. Without your help, this journey would have been extremely difficult.

Several other people helped me in my proposal development. In particular, I am very grateful to Eddy Szirmai, Neil Foster-McGregor, Gintare, Nyasha, Maty Konte, Zina and Theo. I am also very grateful to Dorcas for your support and friendship throughout the journey; thanks for opening your doors to me and also for your support during my applications for jobs.

This journey wouldn't have been more exciting, enlightening and exhilarating had it not been for the wonderful friends and colleagues from my batch, Particularly, Hugo, Jemal, Mario, Francesca, Maria, Nga, Davia, Arip, Bruhan, Nora-Jasmine, Eli, Wondie, Clotildeh, Janyl and Fernando. Thanks for all the fiery debates, inputs in my proposal, the random beers, parties, dinners etc. And cheers to Hugo for the football trips to France (although I secretly supported Croatia that day, it was nice to see 
Portugal win) and watching the Netherlands failing to simply beat Sweden 7-0, Music festival in Sines, Utrecht, Amsterdam etc. and the wonderful experiences in Portugal, music concerts here and there etc. My office mates Jemal, Francesca, Eli and Tatenda. Thanks for a wonderful atmosphere in the office and the never-ending philosophical debates; always made the journey exciting. To my Econometrics gurus, the Ethiopian trio; Wondie, Tigist and Jemal, I sincerely thank you brothers and sister. Your ability to respond to my questions and helping me through all my confusion was well-spirited. I forever remain grateful to you. It is perhaps the first step towards achieving Jemal's dream of a United States of Africa, congrats on a new president; I hope he will be better than ours. I also had wonderful times with many UNU-MERIT colleagues, it was always a pleasure to spend awesome times with you: Jenny, Elvis, Racky, Irina, Stephan (and Fabiola), Mary, Elisa, Bea, Alison, Ibrahima, Juan Carlos, Juan Carlos, Tobias, Solomon, Emma (super-star), Victor, one Chuxs, Halefon, Hassen, Gideon, Shivani, Mueid, Gintare, Danilo, Caio, Godsway, Lika, Michelle and many others!!!

Also very grateful to the many wonderful friends and colleagues in Maastricht for a wonderful atmosphere particularly Afonso, thanks for the awesome parties, BBQs events and overall great times in Maas. Also grateful for great times to many others e.g. Nello Aygul, Daniella, Daniele, Katharina, Zarina, Boye, Charli, Seg, Tadala, Aisa, Jasia, Rita, Andrea, Nasser, Sergio, Amber, Stacy, Kristina Yang, Tari, Claudia, Lydia, Jeraldine, Einav, Petra-Innbetween, Kesa, Stella and many many many others!!

And to my family here in Maastricht who made the journey extra exciting, worthwhile and with a family feel. I thank you. The likes of Themba, thanks Baba for all the great time times in Maas. I am still under your leadership hehe. Cde leader Whitlaw, Jimmy the ordinary observer, Tendai, Zemar, Chamba, Jko, Gumbie, Ras Kuda, Shaun, Courage, Elvis, Mpande, Purity, Roya, Ildo, the entire Ghanaian and Nigerian crew (too many to mention; these west Africans! Yo!).

Most importantly, I am grateful to my family. My mum and dad (posthumously) who sacrificed so much to see me reach were I am today. Your support and dedication to my studies was exemplary. Amai you waited for this day, to see your son reach this far, well, here we are today. To my Ambuye, thanks for your lessons; your dream to have at least one of your grandchildren reach this far in education has been realized. I will send you my book and extra reading glasses. My uncle Ephraim and Lufunda, thanks for your financial support throughout my education. NB. I have no intention of paying you back your money so that I can remain forever indebted to you. I thank you uncles. I am also grateful to my siblings who have always offered me support throughout my journey.

I also extend my gratitude to all members of the corona and all the attendees at my defense. 


\section{Choolwe Muzyamba's Bio}

Choolwe Muzyamba originates from Zambia. He holds a Master of Science degree in Health, Community and Development from the London School of Economics and Political Science (LSE). He also did a Masters in Economics at Istanbul University and a Bachelor of Arts degree in Economics at the University of Zambia. Previously, he worked for the World Bank, the Common Market for Eastern and Southern Africa (COMESA), Global Health Corp Fellowship and Africa Action Help International. He has also been a tutor in the Master of Global Health programme at the Faculty of Health and Life science (FHML) Maastricht University; and the Master of Public Policy (MPP) programme at the Maastricht Graduate School of Governance (MGSoG). Choolwe also worked for the Royal Tropical Institute (KIT)/Vrije Universiteit Amsterdam (VU).

\section{Publications:}

\section{Articles (journal, professional, popular)}

Muzyamba, Choolwe; Groot, Wim; Tomini, Sonila; Pavlova, Milena \& Rud, Iryna 2018, Professional care delivery or traditional birth attendants? The impact of the type of care utilized by mothers on under-five mortality of their children BMC Tropical medicine and health, 46 (8).

Muzyamba, Choolwe; Groot, Wim; Tomini, Sonila \& Pavlova, Milena 2018, Community mobilization and maternal Care of Women Living with HIV in poor settings: the case of Mfuwe, Zambia, BMC Health Services Research, 18(155).

Muzyamba, Choolwe; Groot, Wim; Tomini, Sonila \& Pavlova, Milena: 2017, The role of Community Mobilization in maternal care provision for women in sub-Saharan Africa- A systematic review of studies using an experimental design, BMC Pregnancy and Childbirth , 17(274).

Muzyamba, Choolwe; Groot, Wim; Tomini, Sonila \& Pavlova, Milena: 2017, The relevance of TBAs to women living with HIV in resource poor settings: The case of Mfuwe, Zambia; BMC Tropical medicine and health; 45(37).

Muzyamba, Choolwe: Broaddus, Elena \& Campbell, Catherine: 2015, You cannot eat rights: a qualitative study of views by Zambian HIV-vulnerable women, youth and MSM on human rights as public health tools, BMC International Health and Human Rights, 15 (26).

\section{UNU-MERIT Working Papers}

Moldalieva, Janyl, Arip Muttaqien, Choolwe Muzyamba, Davina Osei, Eli Stoykova \& Nga Le Thi Quynh, 2016, Millennium Development Goals (MDGs): Did they change social reality?, UNUMERIT Working Paper 2016-035.

\section{Conference contributions}

Muzyamba, Choolwe, Catherine Campbell \& Elena Broaddus, 2017, You cannot eat rights: a qualitative study of views by Zambian HIV-vulnerable women, youth and MSM on human rights as 
public health tools, Knowledge Platform on Sexual and Reproductive Health and Rights and HIV, University of Amsterdam.

Muzyamba, Choolwe, 2017, Evidence-based policy practice has become pervasive and counterproductive in the global HIV response, 7th European Conference on African Studies ECAS 2017 The Centre for African Studies Basel, University of Basel, Switzerland. 